\title{
BIOMASS ENERGY
}

\section{State of the Technology \\ Present Obstacles \& Future Potential}

\author{
Prepared for: \\ United States Department of Energy \\ Conservation and Renewable Energy \\ Office of Energy Related Inventions \\ Washington, DC 20585 \\ Prepared by: \\ Larry Dobson \\ Northern Light Research \& Development \\ 1385 33rd Ave. S. \\ Seattle, WA 98144 \\ Under Contact No. DE-FG01-89CE15425 \\ in Fulfillment of the Terms of \\ Energy Related Inventions Grant \\ Project Officer: Glenn Ellis
}

June 23, 1993 


\section{CONTENTS AT A GLANCE}

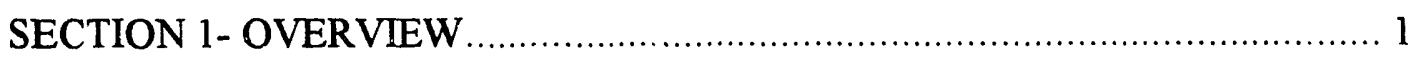

History of the Project ................................................................... 1

Northern Light Technology ............................................................ 3

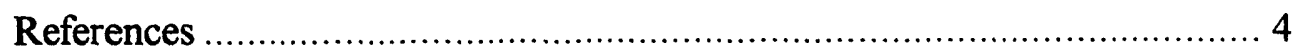

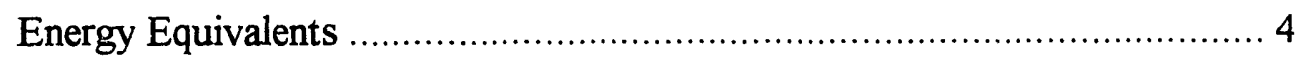

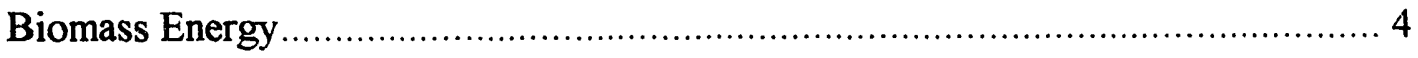

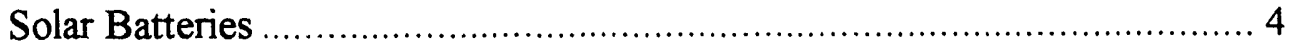

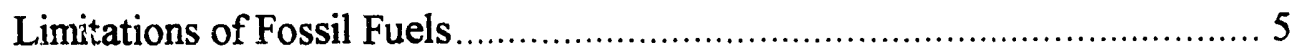

Reserves Running Out .......................................................... 5

Prices Rising for Fossil Fuels, Falling for Biomass.......................... 5

Delivered Fuel Costs - Chart....................................................... 6

Fossil Fuels Cause Global Warming ............................................. 6

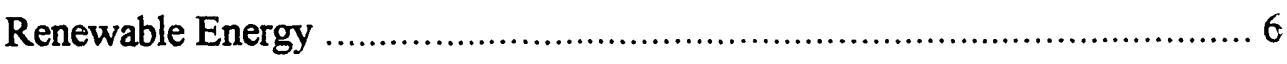

Biomass Can Replace Fossil Fuels ............................................ 6

CO2 Emissions - Chart .................................................................. 7

Biomass Fuels Prevent Global Warming ....................................... 8

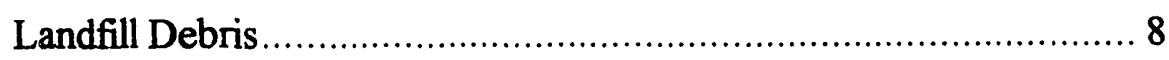

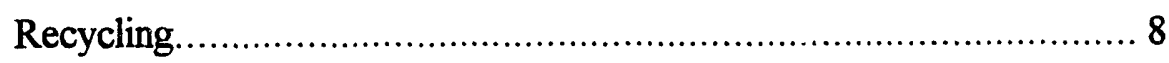

Logging and Agricultural Residue........................................... 9

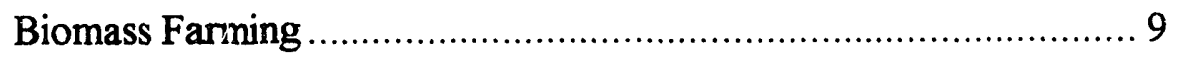

Biomass Energy Saves Dollars, Creates Local Jobs....................... 10

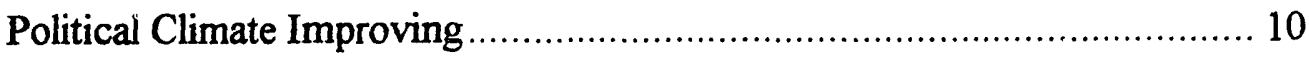

Environmental Regulations Demand Better Technology .................. 11

Permits Need to be Streamlined ................................................. 11

Biomass Energy - The Problems........................................................... 12

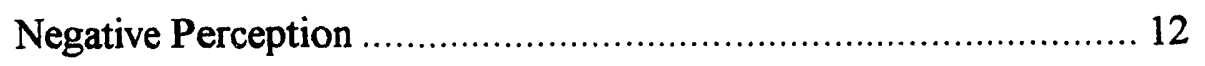

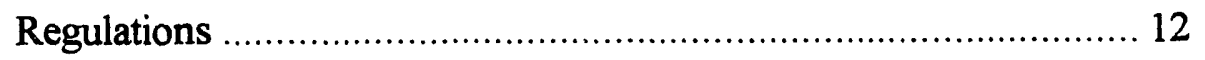

Fuel Nature \& Availability .................................................... 13

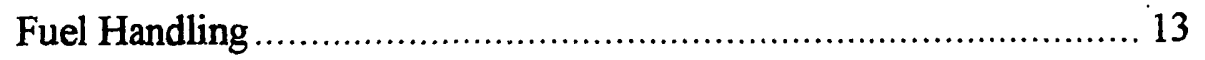

Defects of Available Technology ................................................ 14

Defining the Market.............................................................. 14

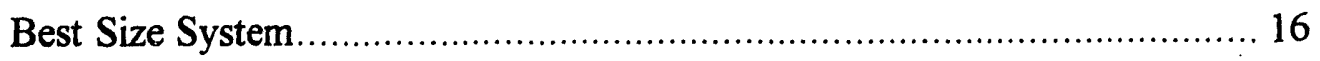

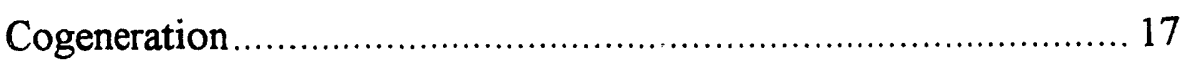

Biomass Energy Potential - Chart .................................................. 18

Municipal Solid Waste .............................................................. 19 


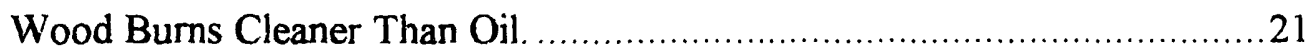

Heat Transfer \& Furnace Design - Graph.........................................23

Emissions from "Helen" Prototype - Chart.........................................24

Woodstove Emissions - Graph........................................................25

Carbon Monoxide Emissions \& Standards - Chart ...........................26

PSAPCA Emission Standards - Chart ...........................................26

Industrial Boilers Emission Levels - Chart........................................27

Excess Air Requirements - Chart....................................................27

Fuel Cost Comparisons - Chart.........................................................28

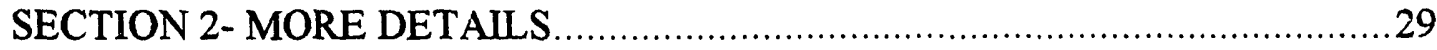

Grendle Family Lineage

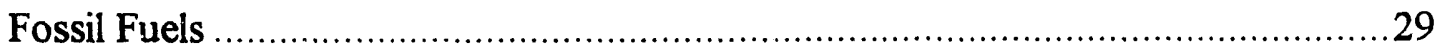

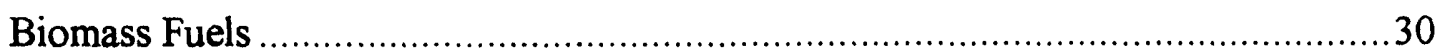

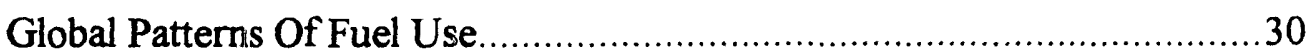

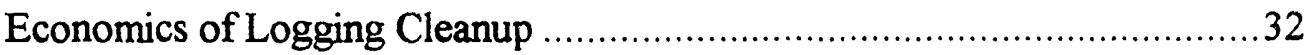

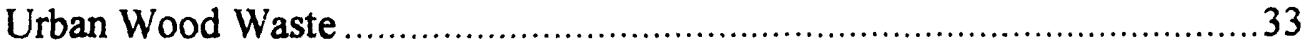

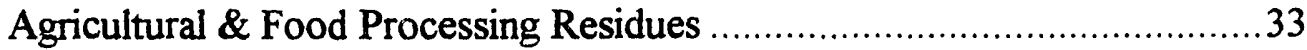

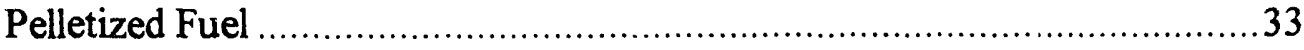

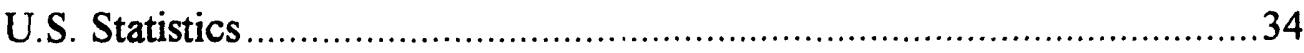

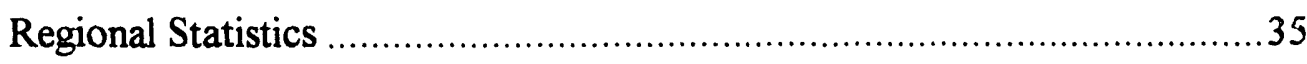

Pacific Northwest \& Alaska Region.................................................. 35

Agricultural Field Residues ..................................................

Typical Installations In Washington.......................................

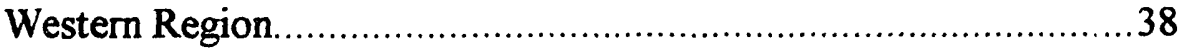

Southeastern Region .............................................................

Nonforestry Related Biomass Fuel ...................................39

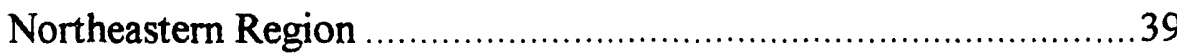

Great Lakes Region................................................................... 41

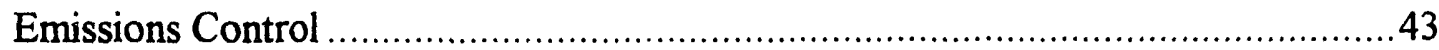

Effect Of Wood Combustion On Climate Change ......................................43

Cause of Emissions In Biomass Combustion ............................................4

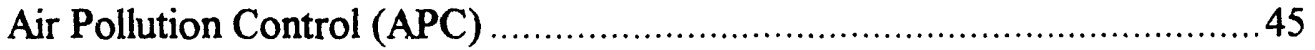

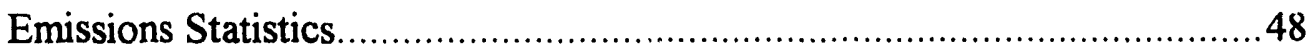

RELATIVE EMISSIONS COMPARISONS ................................48

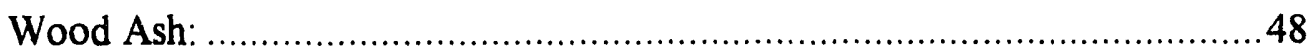

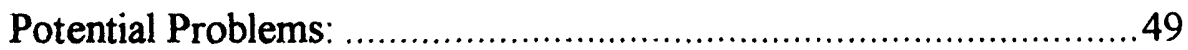

Ash Disposal \& Utilization: ......................................................... 49 
Condensate: 50

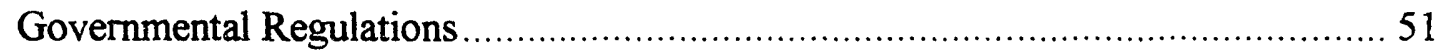

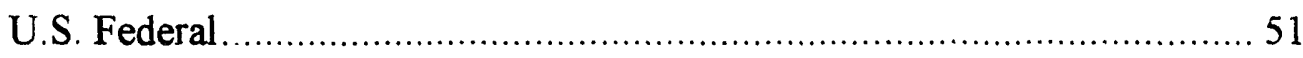

EPA's Woodstove Regulations........................................ 52

New Source Performance Standards (NSPS) ......................... 52

Prevention of Significant Deterioration Requirements (PSD).......... 53

Emissions from MSW Combustion Facilities - Chart ..................... 53

The 1990 Clean Air Act Amendments....................................... 53

Financial Assistance ....................................................... 54

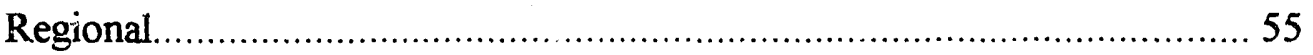

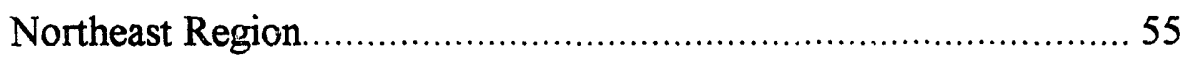

Southeast Region.......................................................... 55

MSW Combustion in SERBEP ................................. 56

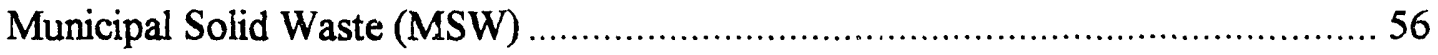

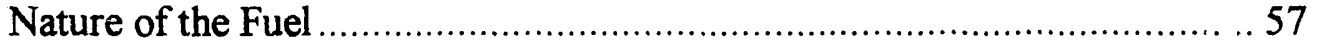

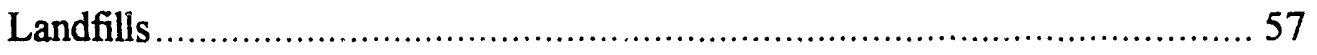

Projected Growth Of MSW Combustion .......................................... 57

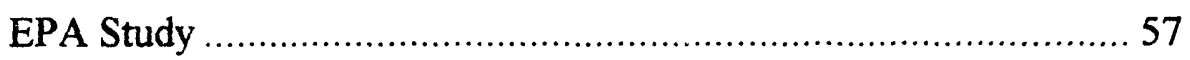

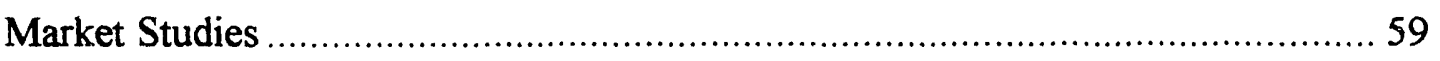

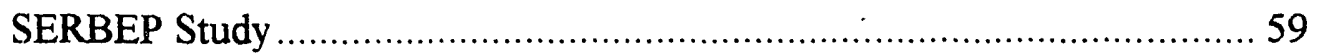

Great Lakes Study ................................................................. 62

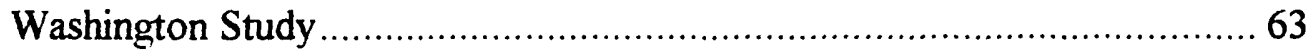

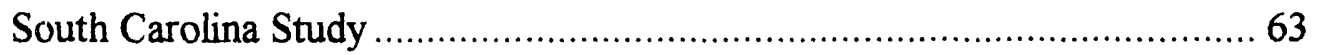

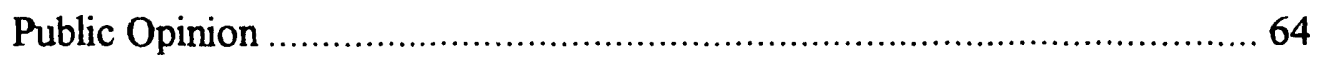

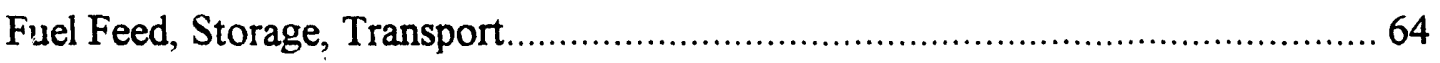

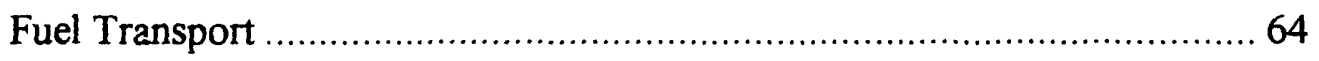

Weather Considerations ............................................................. 64

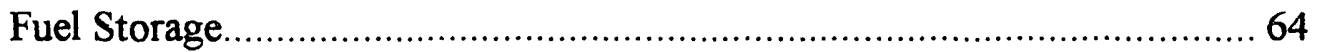

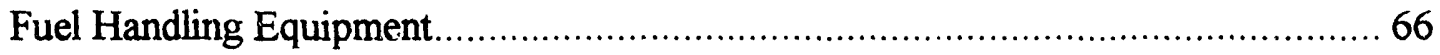

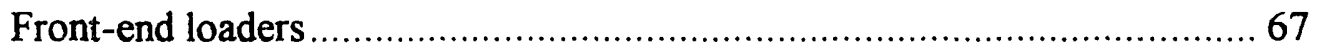

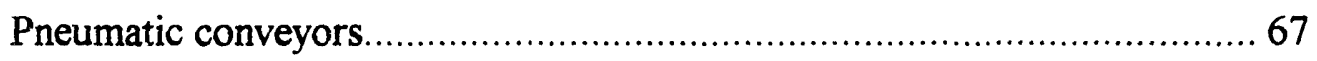

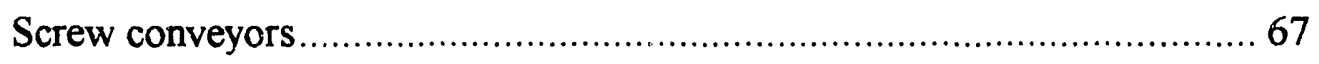

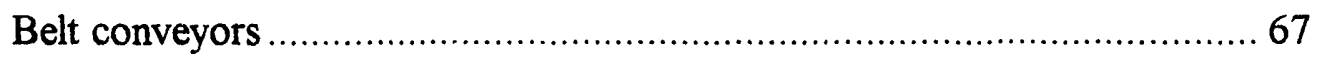

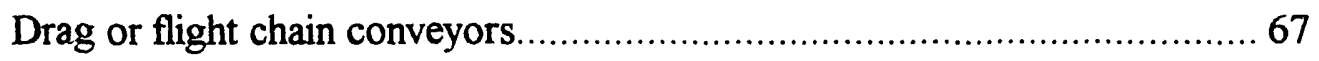

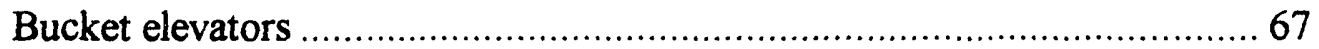

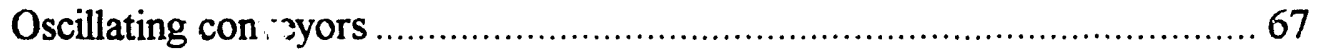

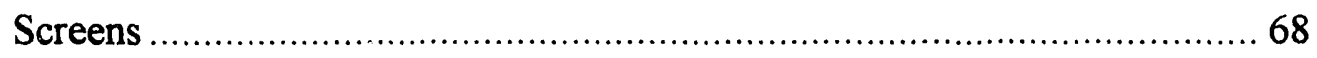


Canadian Fuel Feed Research.....................................................6 68

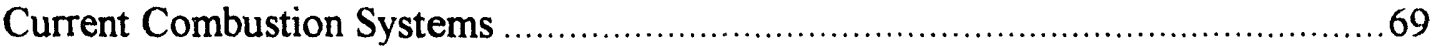

Pile Burning Equipment- Dutch Oven .............................................69

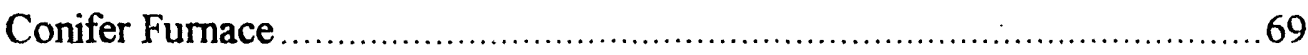

Horizontal Return Tubular (HRT) Industrial Boiler .......................... 70

Modified Firebox Industrial Boiler ............................................... 70

Watertube Industrial Boiler ................................................... 70

Suspension Burning Equipment............................................. 70

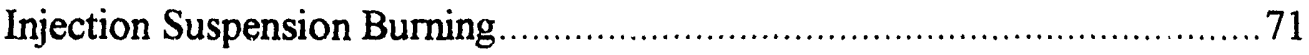

External Direct-Fired Suspension Burning......................................... 71

Fluidized Bed Combustion Equipment ........................................... 71

Hot Air Furnace.................................................................. 72

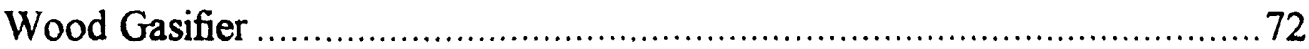

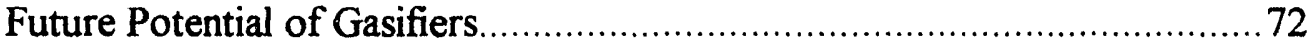

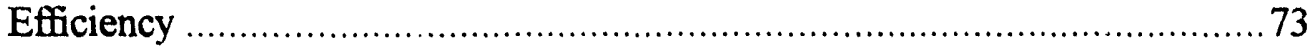

Turn-Down Ratio .......................................................... 74

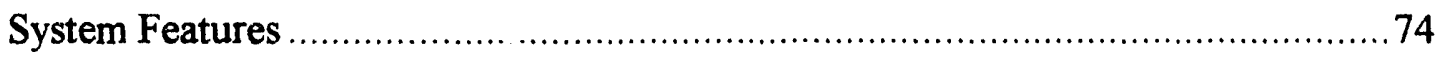

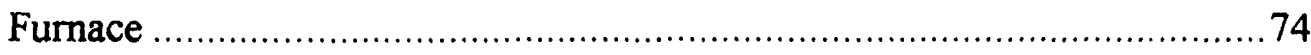

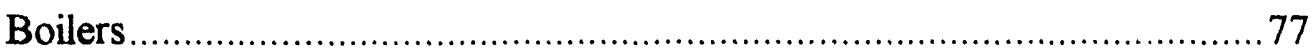

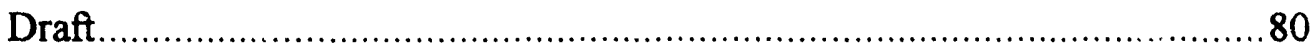

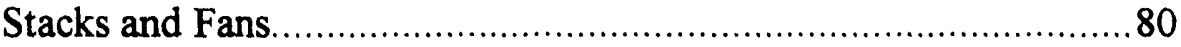

Boiler and Combustion Controls ..................................................... 81

Small-Scale Cogeneration .................................................. 82

Costs Of Complete Systems ...........................................................8 83

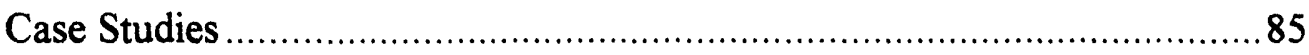

- Typical Problems - Case Studies .........................................88

The Agni Boiler System ..................................................................... 90

Agni Fuel Handling .................................................................. 91

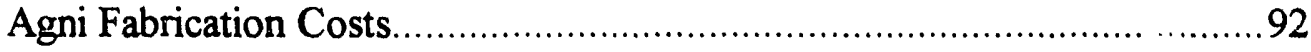

Total Package Cost.................................................................. 92

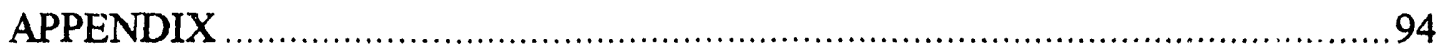

UNITS AND CONVERSION .............................................. 94

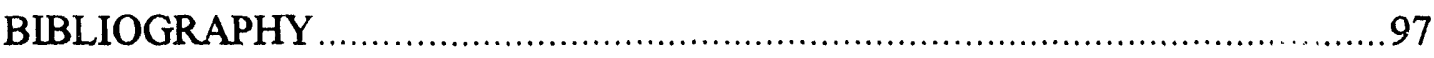

SUPPLEMENTAL BIBLIOGRAPHY ................................................. 105 


\section{SECTION 1 \\ - OVERVIEW}

The prevailing image of wood and waste burning as dirty and environmentally harmful is no longer valid. The use of biomass combustion for energy can solve many of our nation's problems: waste cleanup, cheap energy as heat and electricity, conservation of fossil fuel reserves, reduction of our foreign debt, increased local employment, retention of energy dollars in the local economy, improved air quality, land reclamation, and retarding of global warming. Numerous factors combine to produce unprecedented opportunities in the field of biomass energy:

- Wood and other biomass residues that are now causing expensive disposal problems can be burned as cleanly and efficiently as natural gas, and at a fraction of the cost.

- New breakthroughs in integrated wasteto-energy systems, from fuel handling, combustion technology and control systems to heat transfer and power generation, have dramatically improved system costs, efficiencies, cleanliness of emissions, maintenance-free operation, and end-use applications.

- Increasing costs for fossil fuels and for waste disposal, strict environmental regulations and changing political priorities have changed the economics and rules of the energy game.

This report will describe the new rules, new playing field and key players, in the hopes that those who make our nation's energy policy and those who play in the energy field will take biomass seriously and promote its use.

\section{History of the Project}

The subject and content of this report has been dictated not by the originally projected scope of the project but by the realities of the economic and political climate of this country. This DOE Energy-Related Inventions Grant was applied for six years ago, and much has hap- pened since then. The original task was to build a pre-production prototype 1.5 Million Btu/hr wood-fueled boiler (named Agni) based on the clean combustion and efficient heat-transfer technology developed through ten previous prototypes.

During the initial two years before the grant was awarded to Northern Light R\&D, we developed a 150,000 Btu/hr hot air furnace (named "Vaagner") for Vaagen Timber Products Company, the new manufacturing wing of Vaagen Brothers Lumber Company. This residential size system complimented the large industrial wood-waste burner (the .Johnson burner) they were manufacturing.

Vaagner evolved from the revolutionary design of "Helen", a sawdust-burning cookstove that officially proved for the U.S. DOE that green wood can be burned as clean as gas. Design, fabrication, and controls were further refined, but the company was loosing its shirt on the Johnson burner and soon dropped out of manufacturing entirely. Vaagner was never commercialized by them, but it proved the soundness of many new design features, indicated new improvements, and allowed extensive development of the microprocessor controls. Vaagner was put through lengthy and rigorous testing, and plans for the larger $A g n i$ system were further refined.

Meanwhile, the 40,000 sq. $\mathrm{ft}$. greenhouse which was to be heated by the Agni boiler decided to go out of business, so it became necessary to seek a new site to install the prototype. (This proved to be an elusive $2 \frac{1}{2}$ year challenge.) A number of sites expressed interest in heating their facilities with wood waste, but the great expense of installing an automated fuel feed system (which the original greenhouse already had), along with the depressed economic times and concern about future dependability, serviceability and spare parts for an untested prototype, combined to eliminate many of the potential users. Concern about obtaining permits in a political climate hostile to wood burning, and uncertainty about future regulations and dependable fuel 
supplies in the rapidly changing logging/waste biomass industries also made the sales job tough. We were slowly learning the many obstacles and pitfalls to commercialization.

Pyro industries, the major pellet stove manufacturer in the industry, became enthusiastic about the project and decided to seriously explore the manufacturing and sales potential of the Agni size commercial boiler. They revised the plans for their new 100,000 square foot manufacturing facilities in Burlington, WA to include a hot water heating system and gas-fired boiler, with provisions for the Agni boiler and feed system to be installed within a year. The burner/boiler plans were redrawn to incorporate their manufacturing expertise, and the ceramic heat exchanger castings were redesigned to reflect test data from Vaagner and the new boiler configuration.

Existing fuel feed systems can be $2 / 3$ the cost of an installed burner/boiler/ feed system for the commercial/small industrial market. Because they are too complex and over built for our use, Northern Light designed an automated feed system that can be fabricated and installed for $1 / 3$ to $1 / 4$ the cost of the ones presently available.

The design allows a delivery truck to dump its load straight into a storage area, where it is slowly fed to the fuel hopper by a low-powered "pile feeder" and low-cost conveyor belts. It is designed to handle a large variety of fuel types, including stringy bark and branches, major problems for conventional feed systems.

Still, the board of directors was not convinced that they should launch so quickly into this major new product line, so they commissioned an exhaustive six month marketing/feasibility study. They also requested thorough testing of the Vaagner prototype at the Pyro R\&D facilities.
We tested a wide variety of fuels, including refuse-derived-fuel (RDF) pellets and agricultural waste pellets. This yielded more exciting evidence that our technology could handle the least desirable biomass fuels without the problems usually associated with their combustion and with unequaled efficiencies. We also discovered that we could burn wetter fuels than ever thought possible in the industry.

After two years of deliberation and several unforeseen challenges to their corporate health, Pyro decided not to make the required multimillion dollar investment at this time and not to build the Agni prototype. We were greatly disappointed, but all the more convinced by the findings of the marketing study that we had a winner.

Since time was running out on the grant, we decided to pursue the prospect of installing the prototype at a remote penal institute on the Olympic Peninsula. The Clearwater Correction Center was enthusiastic about utilizing locallyavailable logging waste to save them $\$ 30,000$ in annual fuel bills, but the state procurement officials were in no hurry to rush the slow steps of bureaucracy. They are still studying the case.

Next, Clean Fuels, Inc., a waste-stream-technology marketing firm in Washington state, became enthusiastic about Northern Light's technology and wanted to fund the production prototype, but their expected financing fell through and they are struggling to maintain their present commitments. Two other very promising options were pursued to no avail within the time constraints of the DOE grant.

Eventually, Northern Light R\&D developed a business plan to seek private funding for a limited production run of Agni size commercial combustors and boilers. The figures are very encouraging and we are eager to get on with the project.

We will first build the production-prototype low-pressure hot-water/steam boiler fueled with waste biomass. It will incorporate all of the advanced features described below. We will test 
emissions from notorious "problem" fuels, such as wet, stringy hogged fuel, sawdust that has been stored out in the rain for years, agricultural wastes, hospital waste, chicken manure, and municipal solid waste (MSW).

Emissions are expected to be well below the most stringent regulations in the nation without expensive stack cleanup equipment. Efficiencies are expected to be above $90 \%$ within a very broad power range. Our market study showed this commercial-size to meet the needs of the largest potential market and its production costs to be highly competitive.

Meanwhile, Sunpower, Inc., a major R\&D firm specializing in the development of freepiston Stirling engines with linear alternators, approached Northern Light concerning a joint development effort to produce a biomass-fueled residential cogeneration system incorporating their grid-coupling linear alternator and duplex cooler technologies. These engines and coolers use hermetically-sealed helium to transfer externally-produced heat, in this case from biomass combustion, to apply power to the piston.

We are currently assessing the technical merits of Sunpower providing the Stirling alternator, to generate household energy, and their cooler technology, for CFC-free refrigeration and airconditioning. Northern Light R\&D would develop a biomass-fueled combustion/heat-transfer system to power the engines and transfer the remaining heat to the dwelling and its hot water. We are excited about its potential impact on the alternative energy market throughout the world.
Ultimately, a central energy system is envisioned, providing the power, cooking, baking, clothes drying, refrigeration, air conditioning and waste disposal needs of a household. The integrated components of the system would be fully automated to provide efficiencies several times that of separate stand-alone units. Because of superior combustion and heat-exchanger design, a Northern Light Energy System can also hurn fuel pellets, oil, natural gas, propane or alcohol more efficiently and cleaner than in commercially available heating systems. The auxiliary fuel can be used for startup and as an automatically switched-on backup fuel.

\section{Northern Light Technology}

Cheap biomass fuel is not being utilized primarily because no combustion system is available on the market that is clean-burning enough to pass strict new emission regulations and is also affordable, fully automated, reliable and able to feed and burn the great variety of biomass fuels available, in diverse sizes, composition and moisture content. Northern Light R\&D has been working on these problems for twenty years now, and we think we have most of the answers. This unique technology evolved through 10 prototypes which were designed, built, extensively tested, modified and redesigned in a long lineage beginning 20 years ago. Three of the prototypes are still in operation, in service for as long as 10 years.

Throughout this development we have tried to solve the problems of existing technology in the context of real world needs and constraints to optimize efficiency, compactness, cost-effectiveness, durability, and maintenance-free operation. These factors are quite complex, which is why the tremendous opportunity for biomass energy has not been capitalized on sooner, and why this report summarizes all these factors in such detail. 
The information used to compile this report comes from over 150 different document sources, as well as a large variety of other sources, including first-hand interviews and Dialog database searches. Much valuable research work has been done in recent years by universities, state energy offices, and mosi commendably, the U.S. Department of Energy Bioregional Offices. If you find some of the figures quoted conflict, don't be surprised. Considering the fact that we have been in the habit of discarding what we don't use and forgetting about it, it is laudable that so many people are beginning to catalog our wasted resources.

Bibliographical reference numbers are cited at the end of a particular source in brackets. [43] I have sometimes quoted verbatim from the original document. I have taken the liberty to set off in bold type what I consider to be some of the more important points. I have also injected comments freely after quotes fin bold italic brackets.\}

The Bibliography was originally compiled alphabetically with 98 references. New sources were continually added, inserted in alphabetical order, with addresses like 45A, 45B, etc.

I apologize for the occasional reference number omitted in shuffling information around. Give me a call if you can't ascertain the source from the bibliography, if you find any erroneous or outdated fact, if you are aware of new and exciting breakthroughs happening in the industry, or you just want to help out the cause, give me a ring at (206)-325-6472, or write:

$$
\begin{gathered}
\text { Laurence Dobson } \\
\text { Northern Light Pesearch \& Development } \\
138533 \text { d Ave \& } \\
\text { Seattle, WA } 98144
\end{gathered}
$$

\section{Energy Equivalents}

Throughout this report many figures will be given on volumes, weights and energy equivalents of biomass fuels. To give some feel for the size of these numbers, I will sometimes give an "AGNI" equivalent. This means roughly the amount of biomass fuel that the AGNI boiler would consume over a year operating at $50 \%$ capacity day \& night, or the amount of fuel that will heat a typical 100,000 sq. $\mathrm{ft}$. uninsulated industrial facility or a 200,000 sq. ft. insulated building using an AGNI Boiler in the Pacific Northwest.

One "AGNI" is roughly equivalent to 7.3 Billion Btu high heat content, 777 tons of green wood/year, 420 Bone Dry Tons (BDT) of most biomass (forest and agricultural), or 2,400 cu. yd. wood chips/yr.

\section{CONVERSION FACTORS}

1 Million Btu (1 MBtu) $=293 \mathrm{~kW}$

$=29.9$ Boiler $\mathrm{Hp}=1,000 \mathrm{lb}$ Steam

$=120 \mathrm{lb}$ dry wood $=7 \mathrm{gal}$. Diesel Oil

$=1000$ cu.ft. (10 Therms) Natural Gas

\section{Biomass Energy}

\section{Solar Batteries}

It is obvious that the sun keeps our earth warm with its radiant energy. It is perhaps not so obvious that all living and once living matter on this planet is a form of solar battery, storing the suns energy in chemical bonds of air, earth and water, to be later released in a profusion of life processes...or as fire.

When we burn a plant we release the stored water, carbon dioxide and ash along with heat. If we do it right, that's all we get - no pollution. This has been our obsession for twenty years, discovering how to do it right. 
Biomass fuel consists of any organic matter available on a renewable basis including forest residues, agricultural crops and wastes, wood and wood wastes, animal wastes, livestock operation residue, aquatic plants, and municipal wastes. Such fuels can provide cheap, clean, efficient and environmentally friendly contributions to the world's energy and waste problems.

A complex interplay of forces have prevented the realization of this potential, and more importantly, continue to retard its development. The U.S. is facing an unprecedented energy/environmental crisis which demands long-range solutions based on detailed knowledge of what is happening in many diverse areas of commerce, government, agriculture, forestry, waste disposal, combustion technology, pollution prevention, and ecology. This report is the culmination of six years of effort pursuing the original mandate of the DOE Energy-Related-Inventions Grant, to commercialize this technology and help meet the nation's energy needs.

I will attempt to show the big picture: the potentials and problems of biomass energy, the solutions that Northern Light and others have developed to solve the problems, and the governmental, attitudinal and marketing constraints to its successful commercialization.

SECTION 1 - an overview. If you want more detail in any area, go to

SECTION 2 - lots of facts, case studies and comments. If you want still more facts, read the appropriate bibliographical references.

\section{Limitations of Fossil Fuels}

\section{Reserves Running Out}

Natural gas is the preferred fossil fuel of the "clean" 90's, but prices are predicted to steadily rise. Imports from Canada \& Mexico will also increase, along with greenhouse gas emissicns from burning this fossil fuel. In the U.S., gas is found in only 9 out of 100 natural gas wells drilled, and only 2 of these are of commercial value. The surplus of natural gas that has existed in North America in recent years has driven wellhead prices down to less than the long-term replacement cost in many cases. In the last 2 years, only $65 \%$ of U.S. gas production was replaced. As a result, we are close to a balance of supply $\&$ demand for the first time in 9 years, and prices should increase.

Extraction costs of oil \& coal have also increased, along with the costs of complying with environmental regulations. Major oil companies are finding it much more profitable to invest their resources abroad. The ratio of energy in coal to the energy required to mine the coal has dropped to $59 \%$ of what it was 24 years ago. The price of commercial coal in Washington State has increased $238 \%$ in 10 years. In contrast, wood chippers use less than $1 \%$ of the energy produced, compared to the high extraction and refining costs of coal and oil, often well over $30 \%$ of the energy in the final product. Where steam is used to extract heavy offshore crude oils, well over half of the extracted oil is burned to produce the steam. Such wasteful behavior will impoverish our grandchildren. Our valuable fossil reserves are better invested in recyclable plastic and other refinements for future abundance.

\section{Prices Rising for Fossil Fuels, Falling for Biomass}

All fossil fuel prices are predicted to escalate at an increasing rate, while costs for biomass fuels such as logging and wood-processing waste, tree trimmings, sawdust, bark, demolition and land-clearing debris, chicken and stockyard manure, orchard prunings, corn cobs and other agricultural field and processing wastes are dropping, as disposal costs rise.

Energy costs for wood residues burned in an efficient Northern Light system are presently only one-eighth of the cost of energy from natural gas in most areas of the U.S., and energy savings are greater yet for biomass residues tha: would otherwise be disposed of in costly landfills.

Twenty-five billion dollars worth of imported oil could be replaced yearly with the biomass in our nation's municipal waste. The 
DELIVERED FUEL COSTS @ 1 MILLION BTU/hr

At Typical Efficiencies

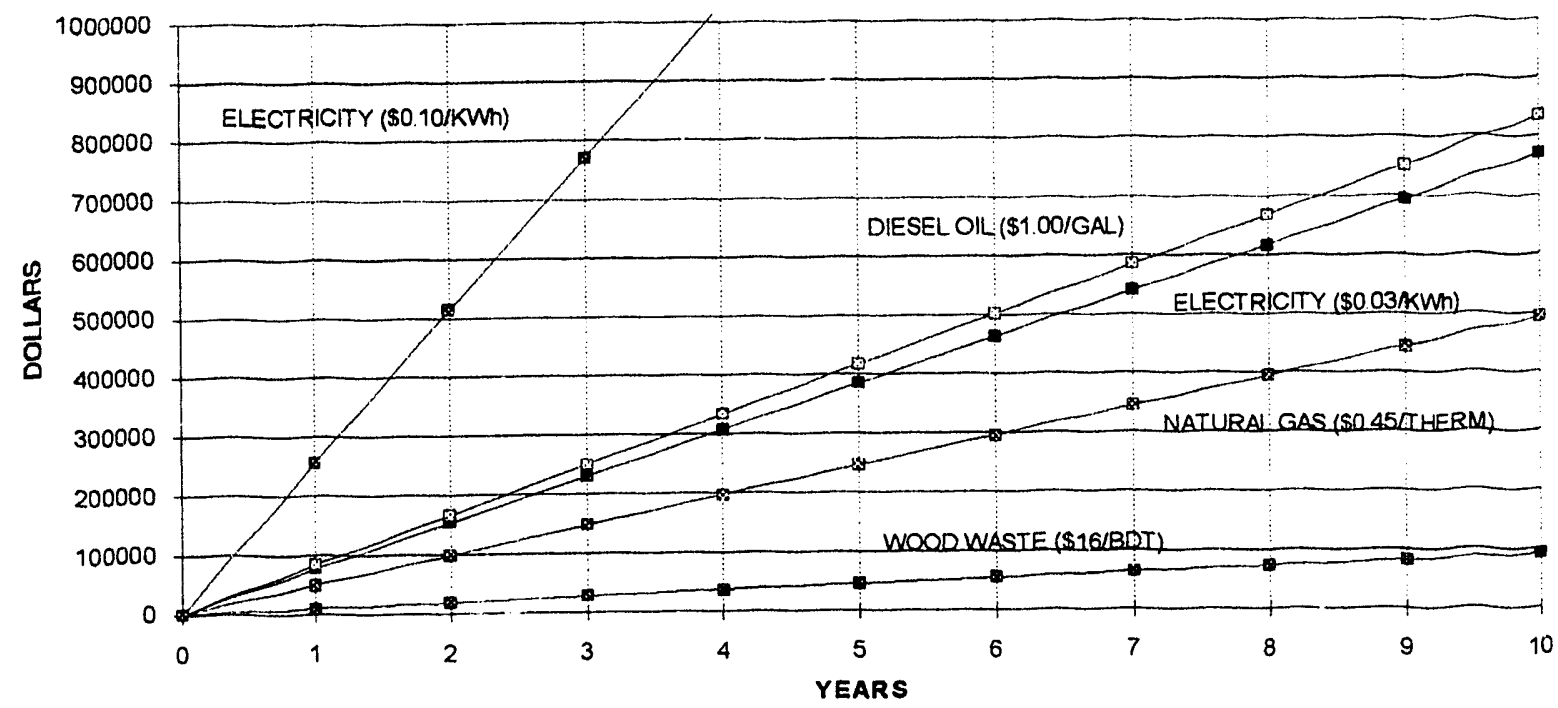

potential exists to supply fifty times this amount of energy from other biomass fuels .

\section{Fossil Fuels Cause Global Warming}

Scientists now broadly agree that the greenhouse effect is bringing about the greatest and most rapid climatic change in the history of civilization, with enormous consequences for all life on earth. Its primarily cause is the burning of fossil fuels (oil, coal and gas), which dump some 24 billion metric tons of $\mathrm{CO}_{2}$, the primary greenhouse gas, into our atmosphere annually. 750 million metric tons more are added each year.

Each American sends 15,000 pounds of carbon into the air every year, adding up to $22 \%$ of the total world-wide carbon release from a country containing less than $5 \%$ of the world's population. [World Watch, 6/93]

When biomass decays in a landfill, it generates methane gas, a more potent greenhouse gas than carbon dioxide; it is better all around to burn it rather than bury it. Scientists predict that until we stop burning fossil fuels and begin reversing this trend by increasing the vegetation upon the earth many dire consequences will follow, including inundation of land by a rising sea level, water shortages and crop failures worldwide. Biomass fuels have the potential to reverse this trend when planting levels exceed harvesting. [5B]

\section{Renewable Energy}

\section{Biomass Can Replace Fossil Fuels}

According to the International Energy Agency, even though biomass conversion provides 15 percent of the world's energy, only one percent of the available biomass is used. Yet biomass meets the direct fuel requirements of a majority of the world's population. Despite the fact that we are now destroying our natural ecosystems faster than we are replanting, there exists a vast untapped global energy resource in annually renewable biomass.

About $3.7 \%$, or 2.7 quads, of all energy consumed in the U.S. today comes from woody biomass, comparable to our use of hydropower and nuclear power.[83A] Various authorities predict that biomass energy from our forest, agricultural, industrial and municipal waste streams can replace from $10 \%$ to $90 \%$ of our current energy needs. Even in urban areas the biomass produced from land clearing, tree trimming and demolition alone can provide much of the residential heating requirements of the area, rather than disposing of it in ever more costly dumps. According to a 1989 U.S. Department of Energy study, solar and biofuels account for $\mathbf{8 7 . 8 \%}$ of the economically accessible fuels of the future. 


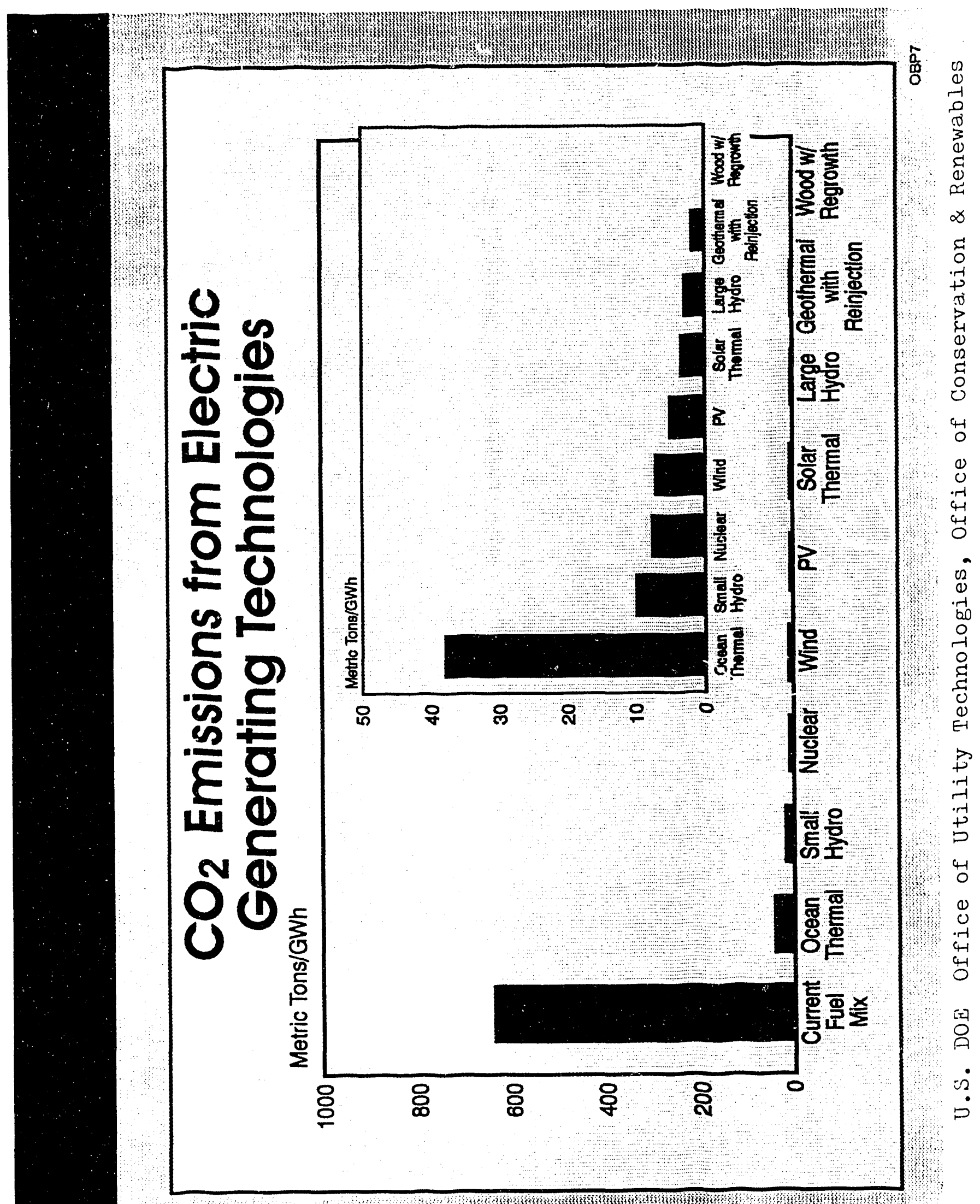




\section{Biomass Fuels Prevent Global Warming}

Fast-growing biomass takes up more carbon than any other process and yieids oxygen. In taking into account the total fuel cycle, several studies show that biomass energy is the only option that has a net gain over the carbon/oxygen cycle. Planting trees can reverse the $\mathrm{CO}_{2}$ buildup faster than any other means, and young forests fix more carbon than mature forests. Woody plants capture more sun and are more efficient than annual crops in temperate climates.

\section{Woody crops actually fix over three times more carbon per field per year than a single crop of corn.}

Annual crops require annual tilling, which harms the soil by killing not only macroorganisms, but by impoverishing the soil microbiota. During peak sun annual crops have at best only half their photosynthetic surface deployed. Woody plants with rapid early leaf deployment, multiple leaf layers and longer growing season can capture significantly more solar energy than traditional annual crops. Deep roots allow them to continue this even during moderate dry spells. This means more -- potentially much more -$\mathrm{CO}_{2}$ fixed. The significance for global climate change is profound.

\section{Landfill Debris}

In our throwaway society, biomass waste is generally becoming an increasingly costly disposal problem. Landfills are filling faster and faster, and EPA's strict new regulations are expected to cost taxpayers \$1 Million per acre to open new ones and force the closing of half of the nation's 5,499 dumps by 1996 . From $1 / 3$ to $3 / 4$ of our MSW is biomass suitable for fuel which could replace nationwide 824 Million barrels of imported oil a year.

Urban wood waste processing and delivery services are springing up across the country, charging a tipping fee less than the local landfill for yard waste, tree trimmings, land clearing and demolition debris and reselling chips and compost for a tidy profit. Secondary wood product industries, tree services and agricultural processing industries are looking for alternatives to costly dumping of their residues.

\section{Recycling}

"Recycle" is the buzzword of the '90s because it is generally cheaper and more environmentally sound to do so. Premium grade wood residue can be sold as fiber crips, paper recycled, and yard waste composted. But there is always a large part of our biomass waste stream that is too poor quality to recycle into products. Household garbage and low grade mixed waste paper are better recycled into energy, as long as there is no mercury present to contaminate the exhaust. In the Puget Sound region, 270,000 tons of mixed waste-paper are generated daily from recycling, and much of it landfilled because no one wants it. This would heat 75,000 homes for one fifth the cost of natural gas, and just as cleanly. Even premium grade fiber chips are a quarter to a third the price of gas. Tree trimmings and other wondy residues compost slowly and would be much more economically used as fuel.

"Since 1986, 40 states have enacted legislation requiring communities to recycle parts of their waste. The effect has been dramatic. In 1980 the nation recycled only 14 million tons of its MSW and burned virtually none to produce energy. In 1988, 24 million tons were recycled, and 26 million more were incinerated to produce electricity." [62A, 1/92]

Recycling of certain materials continues to increase steadily. The country now recycles $55 \%$ of all aluminum cans. While Americans recycle one quarter of the 67 million tons of paper consumed annually, the recycling industry probably couldn't handle the remaining three quarters even if people brought it in. Because demand for recycled paper now roughly equals supply, few recycling mills are being built. [62A]

"The paper recycling process has been refined so that it's inexpensive and efficient. But recycling plastic is expensive, requires a lot of energy, and generates pollution. The furor over juice boxes epitomizes the plastic-recycling 
predicament: Americans purchase more than four billion of the convenient little boxes each year and recycle almost none. Made of laminated layers of paper, foil, and plastic, these so-called aseptic packages produce pulp of such a low grade that no one wants to buy it." [62A] This material would make excellent fuel in a Northern Light burner.

Communities throughout the U.S. are now accumulating mountains of recycled glass and low grade waste paper with little or no demand for these raw materials. The waste paper, along with other combustibles from municipal waste, is an excellent fuel in our Northern Light combustors to melt waste glass and turn it into useful commercial products.

Northern Light is also developing new technology to recycle glass into durable, lightweight, strong and insulating foamed building products. Currently foamed glass insulation is the monopoly of Pittsburgh Corning, does not utilize recycled glass, and is about three times the price of foamed plastic. Studies show very promising economic viability for such products.

\section{Logging and Agricultural Residue}

The amount of unused biomass residue produced in this country is monumental. Most of it doesn't end up in municipal landfills.

MSW is less than $2 \%$ of the total available biomass fuel from logging, agricultural harvesting and processing, industrial and municipal waste streams.

In the Pacific Northwest alone, about one quad (1,000 trillion BTUs) of biomass residues are physically generated each year. This is equivalent to 160 million barrels of oil, or $\mathbf{\$ 1 0}$ billion per year in residential fuel oil. It represents the heat equivalent of $1 \frac{1}{2}$ times the annual electric power consumption of the Pacific Northwest. This scenario is repeated across the nation and around the world.
While fossil fuel costs are steadily increasing, the cost of wood fuels is generally declining, with increasing disposal costs for land clearing, logging cleanup, yard trimmings, and mill waste. A BPA study, Regional Logging Residue Supply Curve Project, states,

"Current indications are that recovery and transportation costs for any given piece size will decline...In no case can it be shown that there will be a significant rise in wood fuel prices for the remainder of this century."

"American demand for wood continues to rise, yet the nation's forests are growing faster than they're being harvested. In 1990, logging companies planted some 41.9 billion seedlings, according to the American Forest Council (AFC)." [22]

Dr. Harold E. Young calculated Maine's wood resources, based on utilizing the whole tree, and compared them with the U.S. Forest Service's figures, which are based only on the merchantable bole (excluding tops, needles \& leaves, branches \& roots). The annual production of the complete forest is 8.75 times as great as the merchantable bole harvest! This impressive number gives some indication of the increased potential for energy from logging waste.[22]

\section{Biomass Farming}

Energy crops are seriously being considered as an alternative to fossil fuels, sparked by environmental concerns about conventional forestry practices, the Clean Air Act, global climate change, soil conservation and energy needs. While only 15,000 to 20,000 acres of short-rotation woody crops are planted in the U.S. today, the feedstock potential could easily lead to more than 20 gigawatts of new capacity by 2010.

Jerry R. Allsup, director of DOE's Office of Alternative Fuels, Transportation Technologies, Conservation \& Renewable Energy, says the agency "believe(s) that (wood's) role in energy is likely to grow in the future because of an in- 
creased research effort to produce faster growing trees, better utilization of the existing stands of energy and a renewed effort to utilize wood waste for energy as a part of better integrated resource planning." [Alternative Energy Retailer]

In Minnesota, short rotation intensive culture (SRIC) of trees can produce 3 to 6 dry tons/acre/year, as compared to yields of 1 dry ton/acre/year in native forest stands.[Pamphlet published by University of Minnesota, Office of Biomass Research, 10/91]

Hemp cultivation can produce 8 to 24 BDT/acre/year. Sugar cane and some tropical crops yield 40 or 50 tons per acre. [45]

Crop set-aside programs, conservation programs, emission taxes \& air quality non-attainment areas have helped energy crops to become marginally competitive in some areas. Delivered energy crop production costs are now estimated at about $\$ 39$ to $\$ 63 / \mathrm{dry}$ ton.

Energy crops could be planted on the 200 million acres of underutilized and marginal agricultural land in the United States. [62B] Much of this land could be improved with the proper balance of biomass plantations, while at the same time generating a large renewable fuel suppiy. BACH (Business Alliance for Commerce in Hemp) claims that if only $5 \%$ of the nation's land were devoted to hemp, it would supply all the energy, and that land doesn't even have to be arable."

Sweden demonstrates the economic viability of biomass energy. The country plans to double its present reliance on wood energy in the next decade, providing $28 \%$ of its energy needs largely from fuelwood plantations surrounding decentralized power plants located in each community.

\section{Biomass Energy Saves Dollars, Creates Local Jobs}

The most expensive biomass fuel, premium grade fiber chips for paper making and chipboard, costs only one third as much as Texas intermediate crude oil at the pump and one fourth the price of commercial natural gas for the same energy content. Typical fuelgrade biomass is often one eighth the cost of fossil fuels, delivered. Additionally, Northern Light biomass energy systems extract more heat from the fuel than most fossil fuel fired systems.

By substituting Municipal Solid Waste (MSW) for imported oil, we could save an estiruated \$25 billion a year in foreign exchange, while at the same time creating thousands of new jobs locally and saving $\$ 10$ Billion on landfill costs.

The economic benefits in other areas of biomass energy are much greater. Energy investments stay in local communities; workers of varied skill levels can be employed. Industrial wood energy utilization in the Southeastern Region of the U.S. is projected to generate approximately 97,000 jobs and $\$ 1.4$ billion annually by the year 2000 .

\section{Political Climate Improving}

State and regional governments are waking up to the manifold possibilities of a local wasteto-energy infrastructure to provide jobs, keep energy investments from leaving the state, solve waste disposal problems and eliminate air pollution from slash and field burning. Programs to inform businesses of the advantages of biomass energy and to fund demonstration and research projects are being developed nationally and locally. The vast potential for biomass farming is receiving more and more serious consideration and funding. The net gain in the greenhouse cycle has the capacity to preserve our planet, and a growing wave of environmental concern may push biomass energy into the forefront of future energy options.

"I'm hearing from the marketplace, " says Stan Sorrell president and C.E.O. of the Calvert Group of mutual funds, "and what I am hearing is that environment is and will be the main issue of the nineties." [The Nation, 3/26/93] 


\section{Environmental Regulations Demand Better Technology}

Recently, tough environmental laws passed by the EPA, notably the Clean Air Act, Clean Water Act, new landfill regulations, and Woodstove Performance Standards, have dramatically changed the playing field in the biomass energy game. State and local regulations have compounded the effect in many areas.

"Changing landfill regulations have a decided impact on the availability of mill residues. More stringent disposal standards increase the cost of disposal forcing mill operators to explore additional options including potential fuel applications. Currently, some sawmills are finding disposal costs so expensive that they may be forced to close down. This situation is partially responsibie for the low current (1990) price of mill residues. In fact, some mills are paying a fee to energy users to dispose of their residues. They do so because the landfill disposal costs are even higher. This is another case where environmental policy can make more material available for energy uses. "[6]

The new Clean Water Act will indirectly provide significantly more biomass feedstock and need for incineration of wastes that are now polluting ground water in landfills and storage dumps. Candidates include poultry and chicken litter, manure from dairies and feedlots, onion culls, chicken carcasses, etc.[77] Because Northern Light's burners can handle such diverse wet fuels, they should serve this market well.

Title XIX of the Energy Policy Act of 1992 included tax provisions to encourage investment in renewable energy sources, including biomass. The Energy Act also provides a 1.5 cent tax credit for every kilowatt-hour of electricity produced from "closed-loop biomass" (crops grown exclusively to produce electricity).

The U.S. Department of Energy, Office of Utility Technologies, is enthusiastic about biomass energy. [62B]

"The future for biomass power looks particularly attractive given the potential for substan- tially expanding biomass supplies by growing new energy crops on millions of acres of underutilized land; the potential for significantly improving the performance of biomass power technologies through R\&D; important environmental benefits offered by biomass power such as recycling of atmospheric carbon and its low sulfur content; as well as the potential for biomass power to provide substantial rural economic development benefits.

The growing demand for electricity, in conjunction with a new regulatorycompetitive environment and environmental pressures such as those created by the clean air act, has created a substantial target of opportunity for biomass power over the next decade. The 1980's provided a decade of technological progress to build upon."

"The plan of the DOE Biomass Power Program is to make the 1990 's a decade of commercialization. The strategy is to develop advanced high-efficiency biomass power systems with competitive feed stocks and to capitalize on Clean Air Act requirements and state environmental actions."

Much more governmental support needs to be directed toward these ends than is now in the budget. Sweden has taken biomass energy seriously, and is now spending as much on R\&D in this area as is the entire United States. "At the heart of Sweden's program is public support. Enlightened, environmentally-conscious citizens and an elected body free from the domination of nuclear and fossil fuel lobbyists have been essential for the progress to date." [83A]

\section{Permits Need to be Streamlined}

Regional regulatory officials tend to be suspicious of poorly performing old-technology wood-fueled systems. This makes permitting difficult and time-consuming. In contrast, numerous officials in the Department of Energy, the Environmental Protection Agency, and State Energy Offices are anxious to see such clean, efficient technology as Northern Light has devel- 
oped commercially available. Government funding is available for extensive emissions testing, and with the support of the EPA and DOE, local permitting should become easier than at present.

\section{Biomass Energy - The Problems}

\section{Negative Perception}

Surprisingly, this increasingly favorable renewable energy alternative is not being capitalized on and few people are even aware of it. In fact, general public and governmental attitudes are often decidedly negative. Influential environmental groups, such as The Sierra Club and Friends of the Earth, equate wood burning with noxious emissions and environmental degradation. They maintain that garbage and processing waste should either not be generated in the first place or should be recycled. Energy conversion is not considered recycling, yet the facts show it to be a better option than burning of 40 million year-old fossilized biomass, at least for the next few decades until energy becomes cheaply available without using fuel. Even then, there will always be byproducts of human endeavors that can best be disposed of by burning, and where heat is needed, combustion is the most direct approach to getting it, outside of direct solar radiation.

The New York State Energy R\&D Authority gave up on trying to get any large wood-fueled installations permitted. Public sentiment is against "incineration" of any kind, and burning wood waste is seen in the same light as municipal waste.

The Northwest Power Planning Council has dismissed biomass as a potential future source of energy. In fact, in their 40 page draft plan (vol.I), only two sentences are devoted to biomass, and its projected contribution to the regional power pool is only $0.6 \%$ of the total! Cost and public sentiment seem to be keys to that decision.

Heat from waste wood in the area can directly replace electric heat - at one ninth the cost. This is not currently being factored into the Regional Power Plan, despite the fact that already one fifth of all Washington State households heat their homes with both wood and electricity, displacing up to $1,000 \mathrm{MWa}$ of electric power in the region. [41A, 6] In other parts of the country, the cost advantage of wood heat over electric heat is more like 30 to 1 and rising.

Instead, $76 \%$ of the new power sources under development in the region are generators that run on natural gas, a fuel imported primarily from Colorado and Alberta. Yet the quantities of biomass residues produced each year in the region are equivalent to $7,600 \mathrm{MW}$ of electric generating capacity, almost twice NPPC's projected new generator capacity requirements to the year 2010 !

\section{Regulations}

The standardization and coordination of regional and national regulations for biomassfueled boilers is complicated by several factors:[80]

* Each state may require different levels of emission control to satisfy their State Implementation Plan.

* Each state has a different level of industrialization.

* Each state may pursue promotion of energy resources most abundant in their area.

* The impact of emissions varies with terrain and climatic factors.

"While the potential for conversion to woodenergy is high, fossil fuel sources will remain prominent in some areas as long as the current state regulatory scenario is perceived to be detrimental." [80]

There has been major reduction in the number of new wood-waste combustion systems installed in the Puget Sound region in the last 7 years. Much of this is due to (1) state regulations to discourage residential woodstoves and (2) Puget Sound Air Pollution Control Authority's (PSAPCA) strict 1990 emissions regulations on new wood-fueled boiler installations. The latter regulations allow new sys- 
tems to emit only a tenth of the particulates that the older systems are permitted. This has prohibited small to medium sized installations of any waste-wood-fueled system now on the market because of the extremely costly cleanup equipment required to achieve compliance (cyclone separators, baghouse filters, electrostatic precipitators, etc.). Even the new state-of-the art 46 megawatt biomass power generating facilities in Kettle Falls, WA, just barely meets this standard.

Despite great improvements in residential woodstove design over the past 7 years, Most people assume that wood can never be burned cleanly. Wood smoke has become synonymous with pollution in official circles as well. A joint report by the State of Washington and the U.S. Environmental Protection Agency, "Toward 2010: An Environmental Action Agenda", recommends that Washington State "Phase out residential wood-burning stoves and inserts." The logic is that, "A decade or so ago, heating a home with wood was considered a clean alternative and an answer to the energy crisis. Today, residential wood burning is widely recognized as one of the most significant sources of air pollution--especially of small particulates--in our state."

There seems to be little interest in the results of a study commissioned by the local Bonneville Power Administration, Environmental Impacts of Advanced Combustion Systems, which proved that a residential cookstove designed by Northern Light R\&D burned wood 65 times cleaner than the average woodstove and cleaner than most oil and gas fueled residential furnaces, without contributing to the greenhouse effect. The disturbing destruction of our remaining virgin forests has totally overshadowed the fact that forests can be a renewable crop and that large quantities of biomass waste of all kinds are continuously being produced and need to be disposed of.

\section{Fuel Nature \& Availability}

Biomass fuels are produced wherever plant material is harvested, processed or used, generally in millions of decentralized locations throughout the country. They exists in such varied location and form as logging slash, agricultural crop residue, stockyard manure, food processing remains, demolition debris and cabinet maker scraps. No national distribution system is possible. Biomass fuels are locally generated and must be locally utilized to be cost-effective. While this has economic advantages, it does not lend itself to centralized coordination, and therefore is not so attractive to large corporations and governmental bodies.

Local processing and hauling operations are springing up wherever waste has become an expensive disposal problem, but a well-established and dependable fuel delivery service does not exist in many areas, simply because there has not been the customer base of biomass fuel users.

Without an existing fuel delivery infrastructure, potential customers are reluctant to invest in a biomass energy system. This situation also dissuades potential investors, manufacturers and marketing firms from getting involved in the biomass energy game. The prevailing attitude is, "Let the industry get further developed...Then I will get involved." Now is the time for government and industry to make major investments in the future of a decentralized biomass energy industry to get it established and over the initial hurdles.

\section{Fuel Handling}

Fully automated fuel feed systems are expensive. Currently available fuel feed systems are individually designed and fabricated for the logging industry. They are too complicated, over built, and expensive for such small-scale systems as we have determined to be the best market. This has been a major factor in preventing greater utilization of bioenergy on the commercial scale. A fully automated fuel storage/feed system of present design could make up two 
thirds of the total cost of an installed commercial wood-fueled boiler system of Agni size. Such an investment is not cost-effective in today's shortterm investment market. Northern Light R\&D has done considerable research in this area and has developed a simple system which should drop the cost by 50 to $75 \%$. Additional funding will be needed to perfect the most economical fuel feed system and open up the market to the widest customer base.

\section{Defects of Available Technology}

All indications point to a very promising future for bioenergy, but the industry is not yet prepared with answers to the many perplexing problems confronting the would-be customer. Equipment is complex, costly and too often plaguer' with aggravating problems and limitations. Variations in fuel type, size and moisture content are not easily accommodated in any one combustion/fuel-handling system. Much of the potential fuel is too wet, too stringy, not uniform enough in size and moisture content or too high in ash and dirt content for existing systems to handle at all. Most biomass combustion systems available at present have a very narrow range of clean combustion, with a turn-down ratio of only 2 or 3 to 1 . This makes them inappropriate for many applications that have seasonal variations in heat demand.

All wood-burning boilers on the market today have difficulty meeting increasingly strict emissions regulations without costly stack cleanup air pollution controls. Typical flue gas scrubbing and conditioning equipment costs average from 25 to $40 \%$ of the total capital costs of coal-fired plants and consume large amounts of power (approximately $3 \%$ of the total unit output). [Biologue, Dec'88/Jan'89]

Fuels with moisture content higher than $40 \%$ have unacceptable emissions problems, and nothing currently available can even burn fuel above $66 \%$ moisture content. Yet there are huge outdoor stockpiles of wood-waste throughout the country that are wetter than that. Because all of the moisture in the fuel is vaporized and sent up the stack, net system efficiencies drop to unacceptable levels with high moisture fuels.

Controls are generally very basic and incapable of analyzing changes in multiple variables to self-correct imbalanced conditions and optimize combustion conditions. None except the very largest industrial installations even monitor fuel/air ratios.

A boiler with fully-automated feed system is so expensive that it has not been cost-effective in sizes below 10 million $B t u / h r$, but this size represents the largest customer base. For a heating system the size of $A g n i(1.5 \mathrm{MBtu} / \mathrm{hr})$ a fullyautomated feed system could amount to $75 \%$ of the total installation cost.

If, in addition to a hassle-free fully automated feed system one requires a sophisticated microprocessor control system for feed, combustion, boiler monitoring and control, with multiple alarms; automated ash-removal; the capacity to automaticaily handle various low-grade fuels; a high turn-down ratio; very low emissions to meet strict governmental standards; and high efficiencies even with wet fuels; they will find nothing on the market at any price.

But most of these problems have been solved and extensively tested in the 10 prototypes Northern Light $R \&$ D has developed over the past 20 years. The remaining challenges have been addressed in the most recent improvements to the Agni design, and in new approaches to inexpensive fuel handling described at the beginning of this paper.

\section{Defining the Market}

The experts seem to agree that, at the present time, the best way to recycle wood waste is to convert it to energy by combustion. There is not a sufficient demand for alternative uses such as composting or animal bedding to absorb the large amounts of wood waste produced in the U.S. The primary forest products industry is already doing a good job of generating its heat and process steam requirements through the combustion of its wood waste. The secondary forest products industry could 
generate a good deal more of its heat and process energy needs by wood combustion. Beyond that, the potential market is determined by numerous factors that have been well researched for the economics and capacities of presently available systems.

Four market studies have been carried out in different areas of the country to define the existing and potential users of commercial and industrial wood fueled boilers. [5], [48], [48A], \& [77]

The SERBEP 1986 study [5], "Analyzing Market Constraints in Woody Biomass Energy Production", determined that there were about 5843 reported industrial wood energy users in the continental U.S.. A 1977 study [80] reported about 10,500 wood-fired boilers installed nationally. The discrepancy can be attributed mostly to the fact that close to half of these were smaller than industrial size. In 1977, wood-fired boilers represented only one-third of one percent of the total national boiler installations. Approximately $76 \%$ of fossil fuel boilers installed in the United states are rated at below 1.5 million Btu/hr.

The largest market for wood-fired boilers is below $1.5 \mathrm{MBtu} / \mathrm{hr}$, but this is generally below the cutoff considered cost effective for presently available systems and below the size of concern to half of the studies. Yet this is the most appropriate market for decentralized collection and distribution of biomass wastes and application of the Stirling engine linear alternator technology for cogeneration.

The SERBEP study [5] identifies five important constraints preventing wood energy use in the Southeast:

1. a general lack of knowledge concerning industrial wood energy and a poor perception regarding its application

2. high capital costs of conversion to a wood energy system

3. problems associated with wood fuel handling

4. concern over dependable long-term supply

5. lack of knowledge about the proper operation of a wood energy system
A major constraint identified by this study is a lack of knowledge about industrial wood energy and a poor perception towards its implementation.

The lack of confidence in the availability of outside sources of wood, of funding for conversion to wood, and of incentive to convert to wood (as well as industries requiring outside wood sources) are speculative reasons for the slow growth of the wood-fired boiler population. Costs of conversion to a wood energy system is perceived as the most significant barrier.[5]

Today, conversion to a wood energy system may be two to seven times the capital cost for an oil or natural gas energy system, and twice the capital investment of a coal energy system. Fuel handling costs are a significant part of this high initial investment. However, Northern Light R\&D has developed a much simpler low-cost option for automatic feed.

A study in South Carolina [77] concluded that if the cost per million Brus from wrood residue is at least $\$ 3.65$ less than the cost from fossil fuels, conversion for a minimum or larger industry becomes a real possibility. However, these figures were based on very costly feed system and boiler installation costs and on $65 \%$ boiler efficiencies, rather than the $90 \%+$ efficiencies of a Northern Light system.

This means that the wood residue prices can be $38 \%$ more for the same energy yield. Taking representative commercial fuel prices from the Pacific Northwest as an example, natural gas is around $\$ 4.44 / \mathrm{MBtu}$, which would give an appropriate cost for wood waste at $\$ 1.09 / \mathrm{MBtu}$. The most expensive wood chips are delivered in the area for \$0.94/MBtu. Therefore, even for presently available woodfueled boilers and costly feed systems, wood energy is a profitable investment in the region. 


\section{RESIDENTIAL COGENERATION}

Looking at the potential for residential cogeneration, we have a different set of economics. If a home or apartment energy system produces electricity and replaces a central heating system, hot water heater, cookstove, and perhaps also supplies refrigerator cooling and air-conditioning, hot air for the drier, and waste disposal, a more expensive system could be cost-effective. Adding up all the costs of the individual appliances that are replaced and their combined energy costs show a major investment indeed. This potential deserves serious R\&D work.

\section{Best Size System}

Because biomass fuel is available in decentralized locations, and transportation costs are a big factor in both disposal costs and potential fuel delivery economics, small commercial systems afford significant advantages.

There are over 1480 landfills in the 13-state Southeast Region. $55 \%$ of these are small $(<30,000$ cu.yd./yr.). In MS, WV, KY, and GA there are 537 small landfills and only 3 large $(600,000 \mathrm{cu} . y d . / y r$.$) . If one third of the waste$ going to these landfills can be cleanly burned for energy, the average size of incinerator needed by most Southeastern counties would be less than $10 \mathrm{MBtu} / \mathrm{hr}$. If a more decentralized cogeneration siting approach were taken, even smaller units would be appropriate.[72]

One Agni-sized boiler (1.5MBtu/hr) could serve a community of 1,500 people. (@ 5,000 Btu/lb with recycled beverage containers removed, and about $33 \%$ moisture.)

Small biomass combustion systems can have permitting advantages. In some areas, permitting for larger systems (over 12 tons/day) is much more difficult, due to classification as a potential industrial pollution source.
"Small, hospital-sized incinerators such as the Therm Tech in Fairbanks (Ho; pital) could provide opportunities for using solid waste to heat community buildings or schools in rural Alaska. Small communities in Alaska are experiencing difficulties in properly disposing of MSW, particularly where high water tables and lack of suitable cover cause landfill problems. Most waste-to-energy facilities use incinerators that are large, continuously fed systems that are too big for small communities. An incinerator the size of the Fairbanks unit could process 2.5 tons of solid waste per day on two shifts, providing adequate disposal for a community of 1,000 people." [3]

BioBurn Corp. of Utica, NY, is a sales representative and distributor for over ten different manufacturers of solid fuel combustion equipment ranging from $50,000 \mathrm{Btu} / \mathrm{hr}$ to 1000 boiler horsepower. They are constantly seeking and testing new equipment to find a good range of systems that can meet the needs of different users. They contend that there is no wood chip combustion equipment under $100 \mathrm{hp}$ (3.3 MBtu/hr) that is both economical and technically reliable. [93]

This observation is echoed by numerous authorities in the field. The report, "Stack Emission Standards for Industrial Wood-Fired Boilers" [80], concludes,

"After review of the current situation, it is apparent that efforts to promote wood energy use is best directed to small boilers. In addition to representing over $90 \%$ of the total number of boilers, the 0-1.5 million Btu per hour capacity boiler, and small (less than 10 million Btu per hour) regulated boiler, offers the following advantages for conversion to wood-firing:" $[80]$

* "The greatest number of wood-fired boilers are fueled using residue generated by production at the facility. This residue does not have to be hauled off-site, thus reducing the deleterious effects of other contributors of pollution e.g. 
fugitive dust. There are few large facilities which generate sufficient wood residue to be energy self-sufficient."[80]

* "Wood-fired boilers fired with residue from the production facility are immune from wood shortages and fu $\mathrm{el}$ transportation problems. "[80]

* "Small wood-fired boilers are easily switched to fossil fuel firing in an emergency situation compared to larger boilers of the same design and operation." [80]

* "Small boilers will have minimal impact on the local ambient air quality singularly or cumulatively (assuming normal distribution of small boilers). This conclusion is supported by modeling results."[80]

* "Small boilers will not impact local wood fuel supplies (assuming normal distribution of small boilers)."[80]

* "Small boilers are best suited for retrofit and are the most flexible compared to large boilers of similar design and operation." [80]

"Other findings of this study include:

* "A correlation between the wood-fired boiler population in a state and the state's particulate emissions standard is not readily apparent."

* "Potential users of biomass are not aware of the availability of wood, the operation of wood-fired systems, the applicable air pollution regulations, or the permitting process."

* "Efficient operation of the boiler and associated equipment will also result in the lowest emission rates."

* "Innovative methods of operation can eliminate the requirement for air pollution control equipment or at least reduce the cost of control equipment."

Each statement is supported by detailed discussion in the report.[80]
Greatest fuel savings and payback within 2 years can be realized in commercial installations such as greenhouses, hospitals, schools, county seats and other public buildings, laundries, factories, wood- and agriculturalprocessing facilities, shopping centers, hotels, resorts, and nursing homes, wherever there is nearby biomass waste and space to store the fuel.

\section{Cogeneration}

Sraall, efficierc, cost-effective cogeneration syste ns fueled with biomass promise the greatest near-term potential for solving the world's energy needs of any available renewable energy option. The energy and environmental crisis we are facing on all fronts has forced us Americans to reevaluate our "mega" approach to problem solving. Utilities are suddenly looking to conservation and efficiency as an alternative to building more power plants. Decentralized electric power cogeneration is preferred to wasteful large central power plants. We must use less, use it more efficiently, reuse it again and again. The operating principles are Conserve, Reuse, Recycle.

Applying these principles to energy and waste recycling, we must conclude that small decentralized settings are the best cogeneration sites. A community could recycle local biomass, household waste and low grade paper into energy for a recycling operation, providing heat, mechanical power, and electricity for transforming recycled glass into foamed building insulation and roofing tiles, for an aluminum foundry, pottery and glass blowing studios, etc. The waste heat, too, could be recycled first back into the combustion air, then into process steam or used in a Laundromat, car wash, sauna, heated swimming pool or greenhouses. 


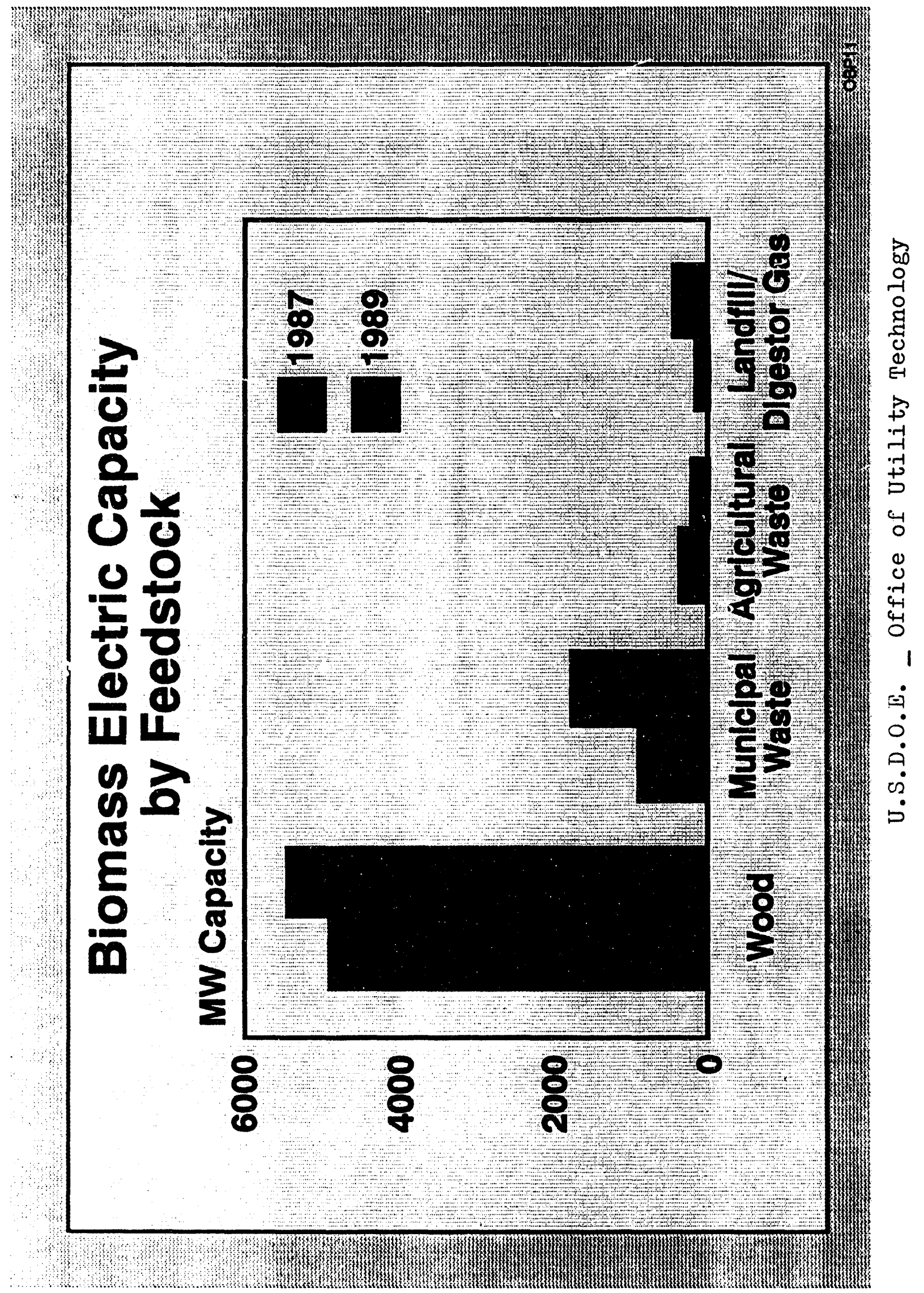


By recycling waste biomass into energy, recycling waste energy back into the combustion process, and using the waste heat again and again, increases in efficiency are possible that are many times what is presently achievable.

According to the Union of Concerned Scientists, "Buildings use more than one-third of the energy consumed in the United States. Heating and cooling systems account for $60 \%$ of this energy." Of that amount about $20 \%$ is reasonably recoverable with the use of appropriate heat engines. This amounts to about $15 \%$ of the electricity requirement of the country.[37A] There are 54 million single-family dwellings in the U.S. which could take advantage of cogeneration to generate much of its power from the nation's waste.

Electric utility customers at the end of the power grid are losers for the power company. Electricity that makes it to the end may be $15 \%$ less than the power sent out of the power plant, which in turn is only about a third of the energy stored in the fuel. It would be far more efficient to generate electricity right at the remote site, with no transformer or line losses, using most of the remaining valuable heat energy for space heating, hot water, etc., by burning locally generated and continually renewable biofuels. Economical, reliable residential cogeneration systems are the key, and this is what Northern Light \& Sunpower are currently investigating.

\section{Municipal Solid Waste}

MSW has become a major disposal problem worldwide, and burying it is no longer a viable solution. Incineration has just as bad a reputation, despite the costly gas cleanup technology employed. Part of the pollution problem is poor combustion (Dioxins, Furans, PAHs, PCBs, etc.), and part of the problem is heavy metal and other contaminants. With proper source separation, heavy metals can be eliminated from most waste streams. Poor combustion requires in most cases an entirely new combustion approach.

Pyrolytic gasifiers are much better technologies in this regard, but they are too costly and complex for small municipalities.

MSW incinerator plants presently tend to be very large (200 - 3000 tons/day) because of the complexity and cost of the equipment, but there are significant advantages to small, decentralized installations:

1. Waste is mainly produced in local, decentralized homes and businesses. Shorter hauling distances mean reduced disposal costs.

2. MSW is a valuable fuel which can best be burned in numerous smaller decentralized locations where heat and processing steam can be utilized, along with cogeneration.

3. Large garbage-collection sites have traffic congestion, odors, large volumes of emissions, and strong public opposition.

4. Many municipalities do not generate enough waste to support a large, expensive disposal installation.

There needs to be more thought and support given to the clean conversion of municipal waste to energy in small, decentralized community settings. Existing systems are prohibitively expensive and unreliable. Because Northern Light's technology is so clean and simple and capable of handling such a diversity of fuels, it should be ideally suited for such application.

The Biomass Energy Research Association (BERA) recently testified before the House Committee on Science, Space, \& Technology, Subcommittee on Environment,

"In combustion research, a need still exists
for improved solid waste incinerators that
meet environmental requirements and cost
goals. Research should be focused on sys-
tems that can be used for economic disposal
of MSWs in small communities. Research is
also needed to reduce the emissions of solid
waste disposal processes..." 
Northern Light R\&D has done this research and has come up with a number of major improvements. Gasification and combustion processes are separated by preheating to very high temperatures the fuel and the air for pyrolysis and combustion and by controlling primary and secondary air through a microprocessor linked to various sensors and dampers. This allows extremely wet material of diverse physical properties to be burned completely without carrying ash and other particulate out the stack. In tests burning RDF (Refuse-Derived-Fuel) pellets, excess air was brought down to $1 / 2 \%$, while maintaining low carbon monoxide emissions $(0.02 \%)$. This is unprecedented in biomass combustion. Only large state-of-the-art gas furnaces approach such efficiencies.
Further advantages to this staged combustion approach are reduced NOx emissions and elimination of ash-slagging problems associated with low melting temperature ash from MSW and agricultural fuels. This latter problem has plagued the industry and is aggravated by the larger system approach.

The smokeless, odor-free exhaust is further scrubbed of fly-ash in the condensing boiler, where moisture from the fuel is precipitated out as clear water. There is no need for the costly stack clean-up equipment currently used in the industry. Because the whole system is so elegantly simple, it should be able to meet the disposid and heating needs of small municipalities at one quarter the cost of systems now on the market and easily pass the most stringent emissions regulations.

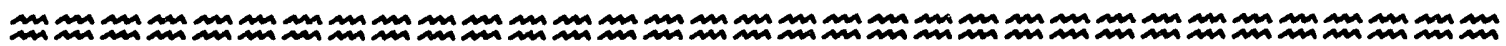


Flue gases are usually so cool that clear

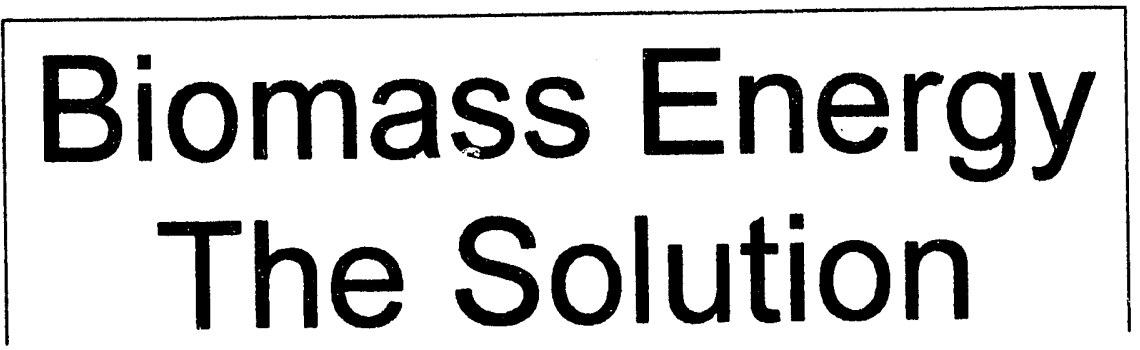
water is condensed out in the heat exchanger. This reclaims the heat of vaporization and allows wet fuels with over $70 \%$ water to be burned as efficiently as dry ones. No other combustion

Wood Burns Cleaner Than Oil.

A prototype residential cook stove developed by Northern Light R.\&D. (named "Helen") was officially tested by OMNI Environmental Laboratories for the U.S. Department of Energy/Bonneville Power in 1986 , burning green sawdust of $44 \%$ moisture content, with no catalytic afterburner or stack cleanup of any kind. [40]

Its particulate emissions were 65 times cleaner than the average state-of-the-art woodstove, several times cleaner than the best pellet burner, and considerably cleaner than the average oil furnace.

Carbon Monoxide emissions in the stack gases were 1/7500th of the Federal Auto Emissions standard, 1/100th of the gas industry's standard for "CO-free combustion", and 1/2 of the EPA's standard for acceptable 24 hour indoor air quality.

These emissions are less than half of the most stringent PSAPCA standards for new wood and refuse burners. Since this prototype, two improved versions have been built.

The most recent $150,000 \mathrm{BTU} / \mathrm{hr}$ hot air furnace (Vaagner) is capable of burning the wettest wood (logs, chips, sawdust, etc.) extremely cleanly and efficiently. Primary and secondary air is precisely controlled by a state-of-the-art microprocessor continually monitoring input from various temperature and position monitors and an oxygen sensor in the exhaust stream. system yet tested comes close to this capacity. (The condensate poses no disposal problems in sewers or septic tanks. It contains no sulfur and is less acid $\{\mathrm{pH} 4.5\}$ than rainfall near many fossil-fueled industrial areas of the world $\{\mathrm{pH} 3.5\})^{1}$ The unit can be fitted with a large hopper to hold several day's fuel at one loading. It will also burn pellets cleaner and more efficiently than commercial pellet burners, and can be operated without electricity if necessary.

Most commercial systems presently available in any size produce unacceptably smoky emissions and drastically reduced efficiencies when operated at half or third of rated cutput. In contrast, Northern Light furnaces burn as clean, and with higher net efficiencies (over $95 \%$ with wet fuels!) when turned down as low as $7 \%$ of full power output (14 to 1 turndown ratio). No other system can even approach this versatility. This feature alone opens up a much greater market than ever before for biomass energy applications.

State-of-the-art Silicon Carbide heat exchanger transmits heat to the incoming combustion air 6 to 10 times as fast as firebrick. Extremely strong, durable, fatigue- and shock-resistant refractory ceramics are used in the combustion areas, High-temperature ceramic fiber insulation is used along with concentric heat-exchanger shells to move the heat where it is needed to optimize pyrolysis

${ }^{1}$ Rainfall is naturally acidic, with a pH of around 5.6. 
and combustion and to eliminate excessive heat which produces slag buildup and ceramic fatigue.

Counterflow gravity-stratified condensing heat-exchangers, specifically designed for high-ash biomass fuels, scrub the exhaust $\&$ reclaim the heat of vaporization of the moisture in the fuel. Thereby wet fuels can be burned as efficiently as dry. The thermodynamic properties of these heat-exchangers increase natural draft and eliminate the need for exhaust fans (and their tendency to send unburned embers, soot and ash to clog up the heat-exchanger and increase particulate emissions). All soot is burned in the combustion zone. The remaining fly-ash is removed from the exhaust stream through a combination of centrifugal/gravity precipitation and stearn-condensation entrainment, which continuously scrubs the lower heatexchanger surfaces. We have built hot air and hot water systems and have designed a low pressure steam boiler.

A gravity feed nopper operates when the power is out and takes any size, shape and configuration of fuel without hang-ups. Counterweighted hopper flaps prevent uncontrolled combustion and heat loss in the upper hopper. They also incicate status of fuel reserves, turn on fuel feed in aitomatic feed systems, facilitate smoke-free loading of the hopper. The lower hopper is vertical sided with no constrictions to hang up stringy hogged fuel or logs.

We have developed a powerful but inexpensive central microprocessor control system with built-in analysis and correction routines and an alarm system. In both the commercial Agni system and the residential cogeneration system it will control the fully automated feed system, automatic 2 sh removal system, and dual-fuel switching functions.
With the new fuel feed system, the economics of the installed package is very favorable compared to natural gas, and no contest when replacing oil or electricity. We expect to offer a complete Agni $1.5 \mathrm{MBtu} / \mathrm{hr}$ system, with condensing boiler, fully automated computer control, ash removal and fuel handling systems for under $\$ 90,000$ installed. Eventually, with the development of an even more economical feed system and optimizing of all the components in the system, the total package installed cost could be substantially less. 


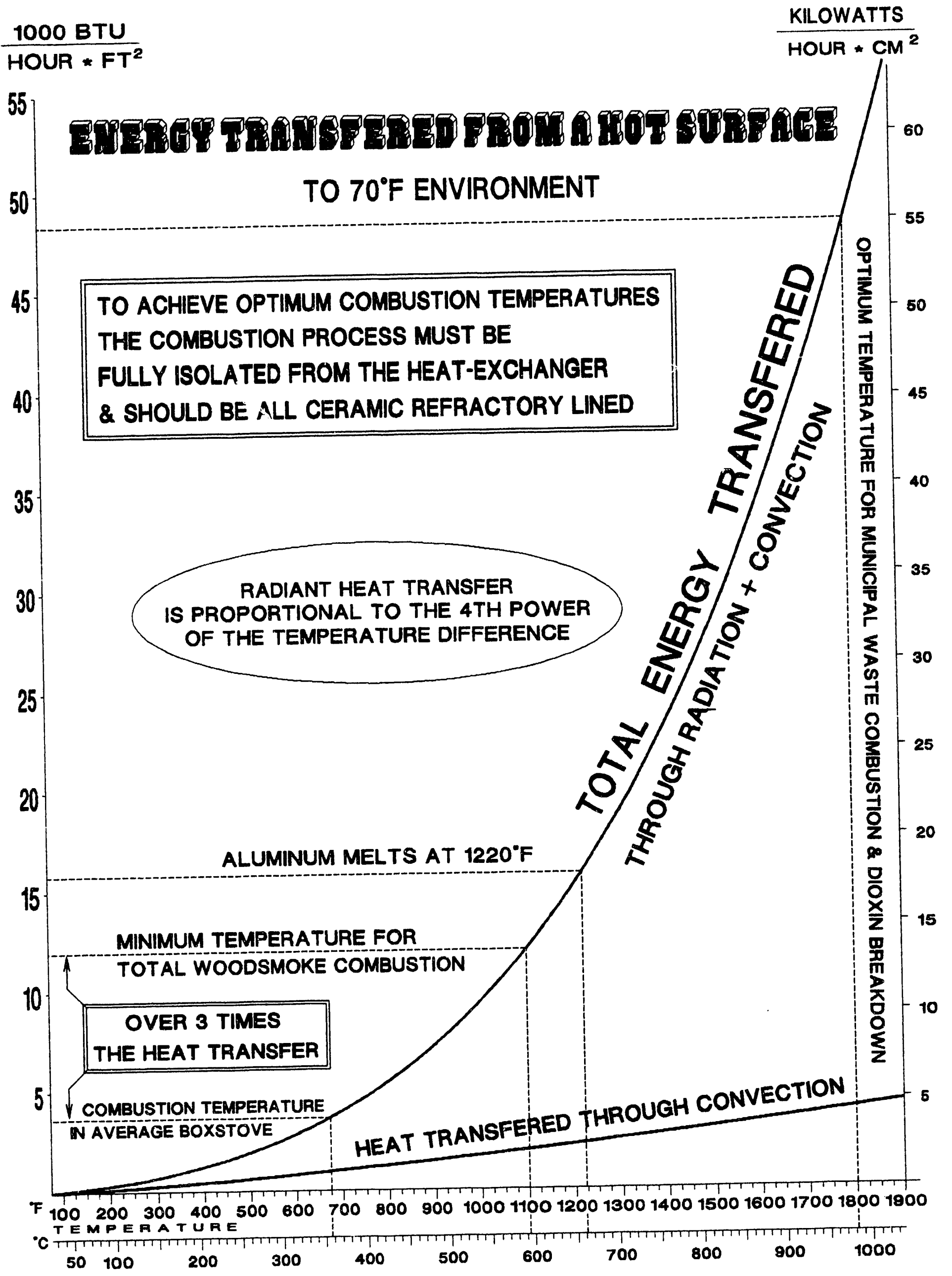



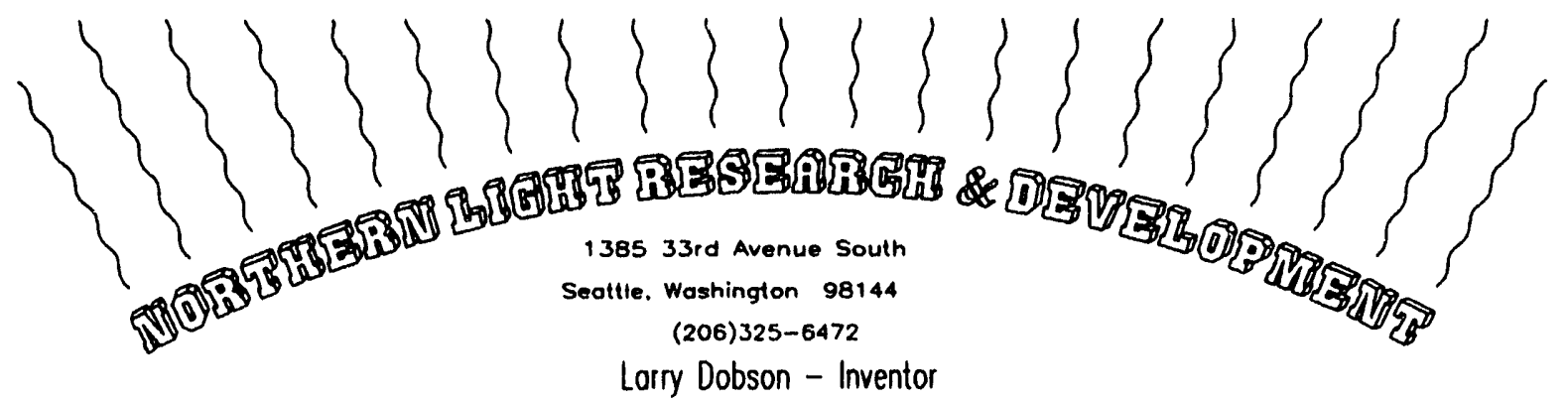

Lorry Dobson - Inventor

\section{EMISSIONS FROM GREEN FIR COMBUSTION}

Tested by OMNI Environmental Laboratories for Bonneville Power Administration \& USDOE, as reported in the BPA report, Environmental Impacts of Advanced Biomass Combustion Systems, 1988.

Tests were performed using green fir sawdust @ $44 \%$ moisture in a prototype cookstove model named "Helen" designed by Larry Dobson.

Due to very low draft caused by extremely hot summer test conditions, the maximum burn-rate of $50,000 \mathrm{Btu} / \mathrm{hr}(14.7 \mathrm{Kw})$ was not achieved during these tests.

\begin{tabular}{|ccc|}
\hline & @14,000 Btu/hr & @ 21,000 Btu/hr \\
(4Kw) Output & (6Kw) Output \\
PARTICULATE EMISSIONS & 0.28 & 0.23 \\
g/hr & 20 & 9 \\
ng/Joule & 0.018 & 0.008 \\
Grains/DSCF & 0.61 & \\
CARBON MONOXIDE EMISSIONS & 0.07 \\
g/hr & 0.65 & 0.04 \\
g/Kg & 160 & 4 \\
ppm & & 50 \\
NOx EMISSIONS & & 81 \\
ppm (actual) & & \\
ppm @3\%O2 & & ND \\
SO2 EMISSIONS were not detectable & & 9 \\
VOC EMISSIONS (mg/cu. meter) & 1 & 15 \\
Methane & 1 & 99.1 \\
Benzene & 25 & 4 \\
Total HC & 98.9 & 4.4 \\
PAH EMISSIONS (mg/hr) & & \\
ACIDITY of Condensed Emissions & 4.8 & \\
effective pH & & \\
\hline
\end{tabular}




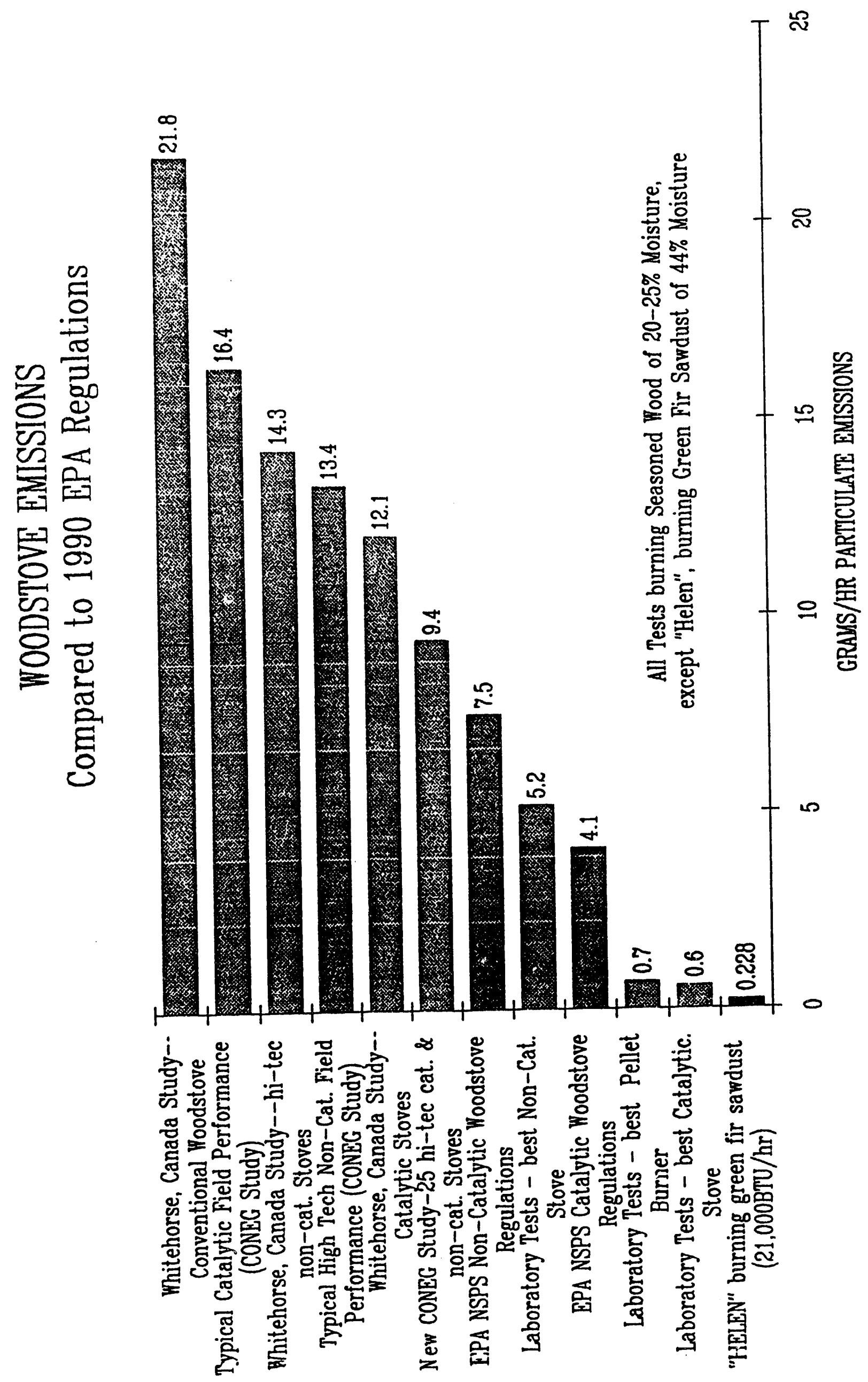




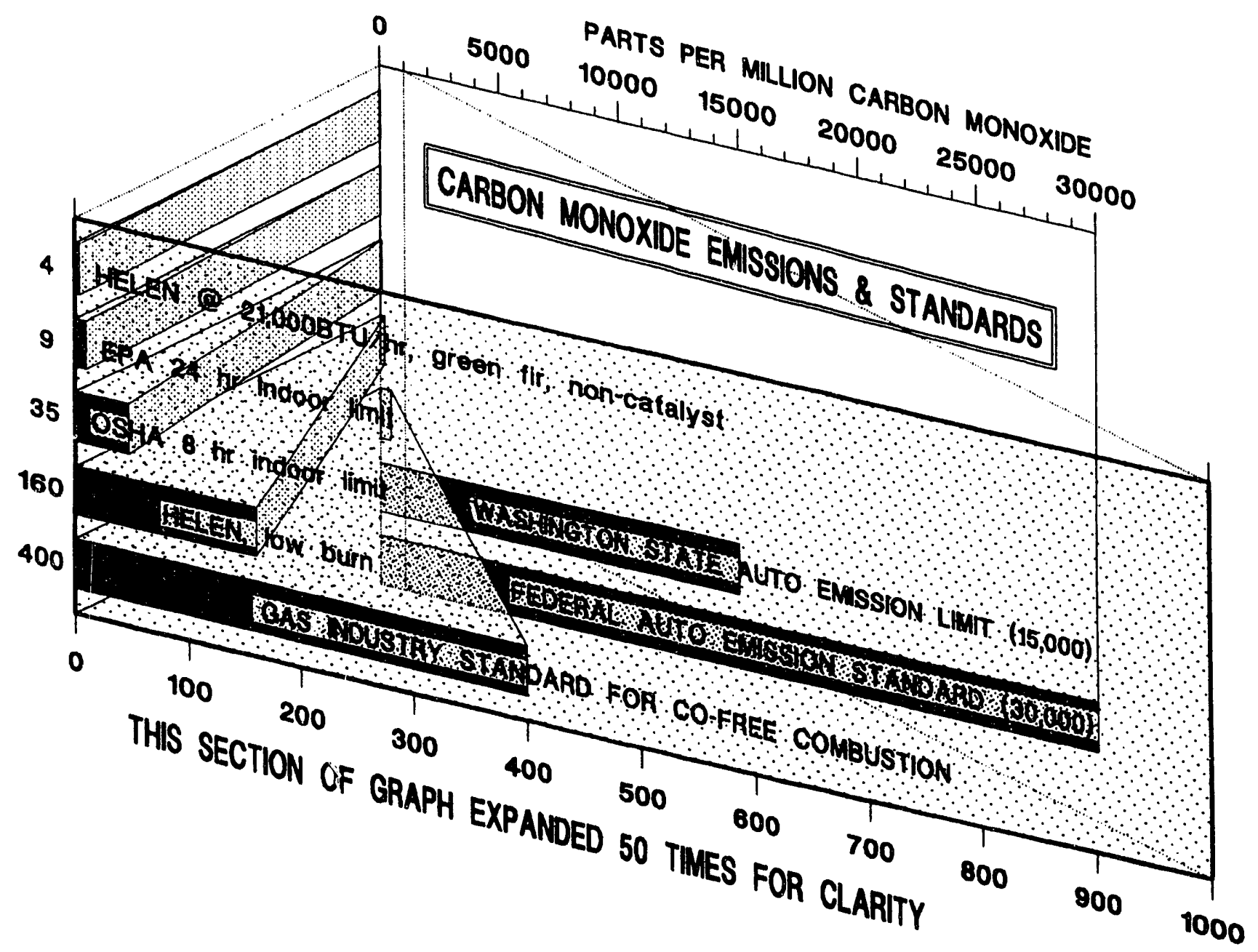

PUGET SOUND iTR POLUUTION CONTROL AGENCY
1990 Maximum Allowable Particulate Emission Concentrations

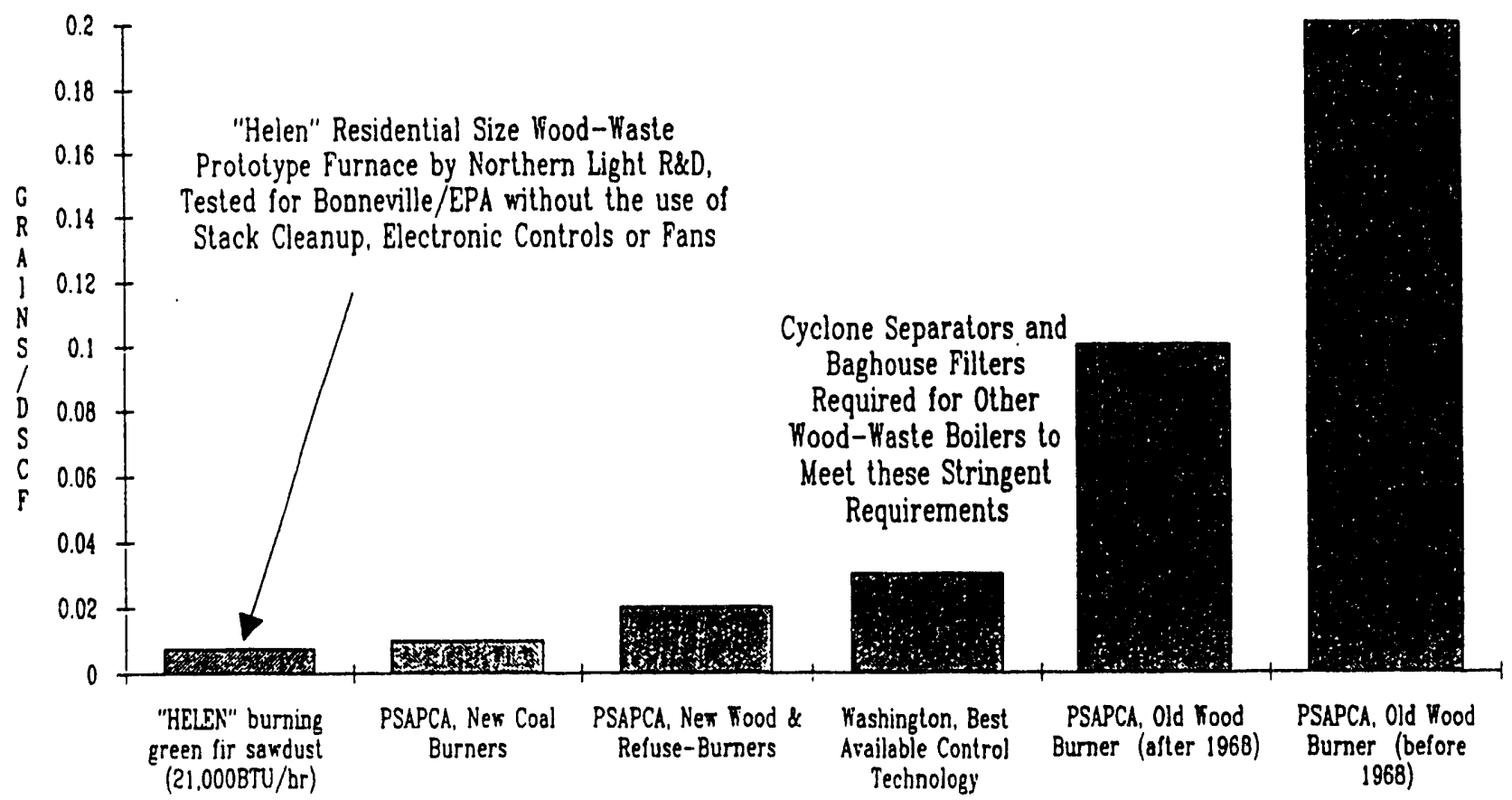




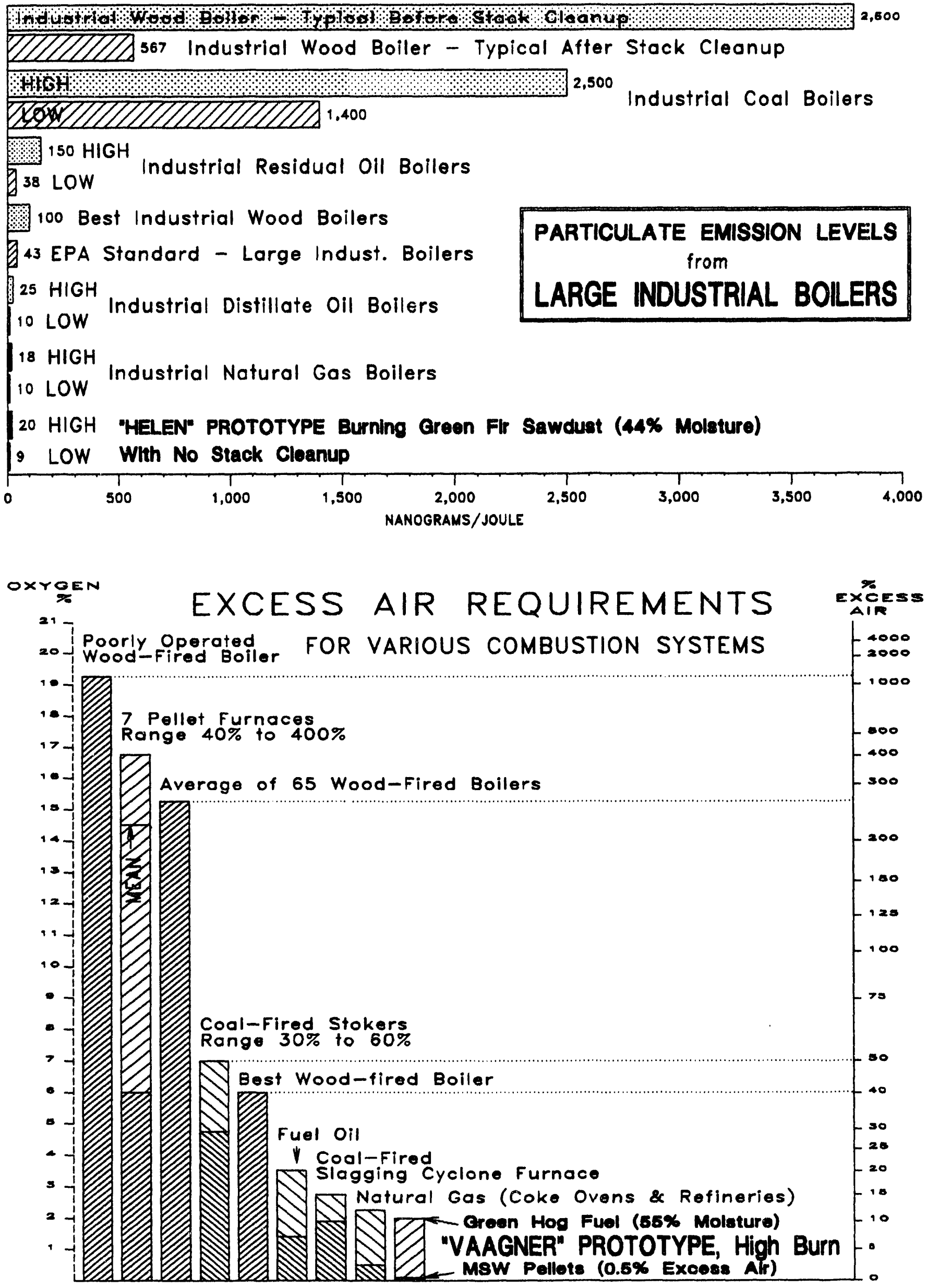




\section{FUEL COST COMPARISONS \& BIOMASS FUEL REQUIREMENTS}

FUEL COSTS IN THE SEATTLE AREA (As of March, 1992)

NATURALGAS:

Washington Natural Gas General Commercial Rate ( $\$ 0.5351$ st 100 therms, $\$ 0.4425$ thereafter) = $\$ 4.44 / \mathrm{MBtu}=\$ 5,992 / \mathrm{Month} @ 1.5 \mathrm{MBtu} / \mathrm{hr}$ from $80 \%$ efficient gas boiler.

1 "AGNI" equivalent $=\$ 35,950 /$ year

ELECTRICITY:

City Light rate for large commercial customers, yearly average $=\$ 0.032 / \mathrm{KWH}$ (Winter only = $16 \%$ higher $)=\$ 9.38 / \mathrm{MBtu}$ average $=\$ 10,125 /$ Month @ $1.5 \mathrm{MBtu} / \mathrm{hr}$.

1 "AGNI" equivalent $=\$ 60,750 /$ year MILL WASTE:

Varies greatly in nature and price

Representative figures are:

SAWDUST \& HOGGED FUEL - free to

$\$ 2.00 /$ yd at mill $=\$ 0.00-\$ 0.73 / \mathrm{MBtu}$

CEDAR BARK - free at mill

HAULING COSTS (large 24 ton load) $\$ 70$ for 10 miles $=\$ 0.345 / \mathrm{MBtu}$

Typical Cost of Delivered Hogged Fuel = $\$ 16 /$ bdt $=\$ 0.94 / \mathrm{MBtu}$

1 "AGNI" equivalent $=\$ 0-\$ 6713 /$ year

\section{AGNI CONDENSING BOILER}

by Northern Light $\mathbf{R} \& \mathbf{D}$

$100,000 \mathrm{Btu} / \mathrm{hr}$ to $1,500,000 \mathrm{Btu} / \mathrm{hr}$ output

Operating full capacity at $1.5 \mathrm{MBtu} / \mathrm{hr}$

burns about 355 cu.ft. of green wood chips per 24 hour day

$=8,511 \mathrm{lb} / \mathrm{day}=128 \mathrm{Tons} /$ month

$=13.1 \mathrm{cu} . y d . /$ day $=53 \mathrm{Units} /$ month

$=393 \mathrm{cu} . \mathrm{yd} . / \mathrm{month}=1,553 \mathrm{Tons} / \mathrm{yr}$.

1 "AGNI" = 1 year's fuel @ 50\% capacity $=777$ Green Tons $=420$ Bone Dry Tons $=2,400$ cu.yd. $=7.3$ Billion Btu

ASSUMED CONDITIONS:

Green chips/bark/sawdust @46\% moisture \& $8700 \mathrm{Btu} / \mathrm{lb}$ bone dry $=4700 \mathrm{Btu}$ Maximum Energy per pound green fuel.

$0.461 \mathrm{~b} \mathrm{H} 2 \mathrm{O}$ at $40^{\circ} \mathrm{F}$ converted to steam $=$ $626 \mathrm{Btu} / \mathrm{lb}$ of chips required to vaporize water. Most of this loss recovered by condensation in boiler. (1) $99.99 \%$ combustion efficiency \& $90 \%$ heat transfer efficiency $=4230 \mathrm{Btu}$ delivered $/ \mathrm{lb}$ wet fuel (= $2.74 \mathrm{MBtu} / \mathrm{cu} . y d$. @ $24 \mathrm{lb} / \mathrm{cu} . \mathrm{ft}$.)

ANNUAL FUEL SAVINGS (@ 1.5MBHU/HR) USING WOOD WASTE:

(@ \$16/bdt)

OVER NATURAL GAS $=\$ 58,474$

OVER ELECTRICITY $=\$ 108,074$

* Operating at $50 \%$ capacity would cut savings in half

1 Million Btu $(1 \mathrm{MBtu})=293.07 \mathrm{~kW}=1,000 \mathrm{lb}$ Steam $=29.875$ Boiler Horse Power

$=1000$ cu.ft. Natural Gas $=10$ Therms Natural Gas

$=7.14 \mathrm{Gal} \# 2$ Diesel Oil $=10.87 \mathrm{Gal}$ Propane $=80 \mathrm{lb}$ Bituminous Coal

$=76.9 \mathrm{lb}$ Charcoal $=114-120 \mathrm{lb}$ Bone Dry Wond

1 Unit Volume $=200 \mathrm{cu} . \mathrm{ft}$. of uncompacted volume $=3,430 \mathrm{lb} @ 30 \%$ moisture (wet)

* Chip Van Capacities vary from 18 units to 42 units. "Live bottom" (self-unloading) trailers only hold from 20 to 30 tons (12-18 units). Typical hauling costs for a 70-mile trip with no backhaul are $\$ 2.57 /$ unit or $\$ 1.07 /$ ton. For a live-bottom van, it would cost about $\$ 4.28 /$ unit or $\$ 1.78 /$ ton. 


\section{SECTION 2 \\ - MORE DETAILS}

\section{Grendle Family Lineage}

This unique technology evolved through 10 prototypes which were designed, built, extensively tested, modified and redesigned in a long lineage of blood, sweat and birth-pains beginning with Grendle's Mother 20 years ago. Let me introduce you to the Grendle Family before we go on.

Grendle's Mother was a sawdust-bolting barrel stove with monstrous lips and glowing thighs, who occasionally belched fire, but kept me toasty in a drafty barn one winter and ended her life baking cookies for the Daily Bread Bakery while racing in the Third International SoupBox Derby race in Langley. But that's another story.

Naturally, Grendle's Mother begot Grendle, who went through several metamorphoses before spawning Cornplanter I and Cornplanter II, two giant dragons who breathed life into Cornplanter's sprout farm on Whidbey Island. They reincarnated in Kodiak, AK, as Katmai, namesake of the volcano that blanketed that island with ash a few years back. II was thinking more of the heat than the pollution when I named her. besides, she was a petite new mutation with exciting features and sweet breath who changed the reputation of the Katmai lineage, and certainly added class to the Grendle family tree\}

Katmai begot Fanny Funnel and Gertrude Gretchen Grendle, both very different children. Fanny thrived on whole logs and had some delightful traits, but she was born out of her time. She awaits the rebirth of Prestolog to incarnate again. Gertrude was still sound and productive in her 10th year, working as a domestic air and water heater at a horse ranch on Whidbey Island.

Then came Helen,' named after her Godmother, Mount Saint Helen, who blew her top just before Helen got lit. Helen is a hot little unit, who, I must admit, is my sweetest flame. You will see her vital statistics plastered all over these pages because I am proud of her, and how else am I to get a job but on my daughter's reputation?

Then came Godzilla, a $900,000 \mathrm{Btu} / \mathrm{hr}$ monster who performed awesomely after undergoing total organ transplants. But, despite a scholarship from his Godfather, Washington State Energy Department, Godzilla was brain damaged from birth and died a fiery death, leaving miraculous legends behind.

I haven't even mentioned Wolf, Rick, Peltec, and the unnamed units who showed so much promise but could not survive the slings and arrows of outraged fortune. Only Vaagner, my most recent offspring, need be mentioned here. Vaagner was courted by the Vaagen Brothers, only to be jilted before he could show his prowess. Vaagner now lives at Deano the Clown's after the City forbade him to live in my basement because he lacked the proper papers.

But the name you see most often in this report is Agni, the culmination of the grand Grendle Family Lineage. Agni is named after the Sanskrit Fire Goddess and blessed by her venerable godfather, U.S. DOE. Although twice as powerful as Godzilla, she has none of the crudeness and unstable character of her grandfather. At least, this is how she is designed on computer, for she is awaiting financing of the limited production stage to materialize.

\section{Fossil Fuels}

Coal usually contains trace quantities of the metals Arsenic, Beryllium Cadmium Chromium, Manganese, Mercury, Nickel, and the radio nuclides thorium and uranium. Virtually all of the mercury leaves in the exhaust as vapor and is "extremely difficult to capture" with present APC equipment. While traces of metals including arsenic, cadmium, chromium, manganese, mercury and nickel have been detected in exhaust from wood combustion, the quantities are 
considered insignificant. [77] This means that as the EPA's more stringent emissions limits for these pollutants phase in tighter, wood fuel will be a more and more attractive alternative.

Landfill gas is 50 to $70 \%$ Methane by volume, with the balance being carbon dioxide, with only trace amounts of other gases. Collection of this gas is costly, and done for regulatory compliance, not profit. The process equipment necessary for the conversion of the landfill gas to a pipeline quality product is costly and expensive to operate, and only feasible for extremely large sites.[77]

No matter how we look at it, we humans are buming up the earth's fossil fuel reserves far faster than we should. Just focusing on the 45 billion tons of carbon we Americans release into the atmosphere annually by burning fossil fuels, it is hard to see how the greenhouse effect can be reversed without drastically curtailing our energy consumption. Biomass plantations are capable of fixing the most carbon in the shortest time of any

\section{Biomass Fuels}

\section{Global Patterns Of Fuel Use}

Except for nuclear power, all our energy comes ultimately from the sun. Our little earth gets only $1 / 5$-millionth of the sun's radiation, which reaches us in 8 minutes and then mostly reflects off into space again. Of the solar energy that does penetrating the earth's atmosphere, only about one quarter of $1 \%$ is converted to biomass each year and yet this small fraction is about seven times the total flow of nonbiomass energy sources used by humanity.[9B] ${ }^{2}$ This biomass flow is equivalent to about 75 TW (1 terawatt $=10^{12}$ watts) or 75 billion tons of coal equivalent in energy per year. About $10 \%$ of this

2 A 1979 Scientific American article, "Silviculture", gave a much higher figure than this. It estimated that forests represent only about $7 \%$ of all annual biomass energy stored each year, the grand total equivalent to over sixty times the amount of energy harnessed by humanity. natural mechanism. Such tree farming can capture 4 or 5 tons of carbon per acre per year. [83A] If half of the 200 million acres of marginal and unproductive land in the U.S. were dedicated to tree farming, one billion tons of carbon per year could be removed from the atmosphere. This is still only $4 \%$ of the fossil fuel carbon we must recapture to keep atmospheric carbon in balance.

"Tests on oil wells in the South found that the oil and water mixture pumped to the surface has radiation levels 5 to 30 times higher than the level allowed at nuclear power plants. Oil drilling over the decades has brought radium to the earth's surface, causing contamination in oil-producing regions in the U.S. and worldwide. This discovery has led the federal government and industry to investigate the seriousness of the situation, which could prove costly for oil industries." [The Energy Report, A comprehensive, weekly review of energy policy, 12/17/90]

total is directly tapped by humanity in the form of food, fiber, feed, fertilizer, fuel, or feedstock. ${ }^{3}$ The remainder, however, provides critical services for global ecosystems by moderating climate, recycling water and essential nutrients, and performing myriad other ecosystem functions. These functions are no less vital to the economy and to human well-being than those provided by the more obvious societal uses of biomass. In addition, humanity has directly or indirectly co-opted as much as $40 \%$ of the prehuman biomass productivity of the world by disrupting natural ecosystems (Vitousek et al., 1986). "[9B]

"The total energy directly supplied to humanity by biofuel is small compared to that supplied by fossil fuels although exceeding the energy supplied together by nuclear power

3 Another source, [8A] estimates that, of the $1.7 \times 10^{11}$ tons of biomass produced annually throughout the world, only about $1 \%$ is used for fuel and fiber and $1 \%$ for food and feed. 
and hydropower. These biofuels are largely used in developing countries and, within these countries, predominantly in rural areas. They are the traditional fuels-fuelwood, crop residues, dried animal dung, and scrub plants-that have supplied human energy needs for tens of thousands of years (Smil, 1983)."[9B]

"Although such fuels today supply a relatively small fraction (somewhat over $10 \%$ ) of global energy requirements in terms of total energy content, they meet the direct fuel requirements of a majority of the world's population. Most of the people in the world depend on these traditional fuels for most of their energy supply. Even more biomass combustion energy is used in indirect applications, as in clearing land by fire (Rambo, 1986). In consequence, it is fair to say that most of the energy used by most of the people throughout history has been in the form of biofuels, a situation as true today as since the discovery of fire.'[9B]

"Most of this fuel today is used for the same tasks for which it has traditionally been neededcooking and space heating-although as much as one-fifth may be used in industry (Ramsay, 1985). It is estimated, for example, that about half the world's households cook daily with biofuels (see figure 1.4). Approximate 30\% of urban households and $90 \%$ of rural households in developing countries rely on such fuels for cooking (Hughart, 1979). Also true today is the observation that it is mostly women who participate in the biofuel cycle-usually sharing or having primary responsibility for fuel gathering, particularly when collecting is done for household use and not for sale. In nearly all cultures, of course, women do most of the cooking (Cecelski, 1985). In those many developing countries with relatively small urban industrial centers, biofuels not only supply the most people, they constitute the largest source of energy - exceeding in energy content the fossil fuels. Even a country with as large an industrial sector as India still relies on biofuels for nearly half of its total energy supply and more than $80 \%$ of its residential energy consumption. Poor countries such as Nepal, Bangladesh, and Potswana rely on biofuel for close to $90 \%$ of their total energy needs (Wood and Baldwin, 1985)."[9B]

Each year over 60 million acres of tropical forests, an area the size of Florida, are degraded and destroyed and an area the size of New England changes from forest to desert. [statistics from Trees For The Future, Inc.] Every year we continue to lose forest lands the size of New York State and New Jersey combined. (New Forests Project Newsletter)

The Winrock International Institute For Agricultural Development estimates that biomass energy could provide $10-20 \%$ of the new (electric) capacity needed by developing countries, and could do so relatively quickly. [10, 12/91]

"In Britain alone 250 million tonnes of collectable organic wastes are generated each year from homes factories farms and forests with a total energy content equivalent to at least 25 million tonnes of coal or $8 \%$ of (British) energy needs." [45a]

At the Weltkongress Alternativen Und Umwelt, Vienna, it was proposed that 1/5 of earth's unproductive land (i.e., desert \& tundra) can be made to yield a renewable biomass harvest suficient to supply most of the world's energy needs. [98A]

"Bioenergy currently supplies $2 \%$ to $15 \%$ of the total energy demand in the 11 countries responding to a recent survey. Finland reported the highest contribution, $15 \%$. The United States ranked tenth with a $4 \%$ contribution. Most surveyed countries projected significant growth in the development and use of biofuels; for example, the United States forecasts a $14 \%$ contribution by 2030." [75]

In 1995, Sweden will begin phasing out the country's 12 nuclear power reactors. To replace this energy, Sweden is turning to trees. "Already, cull trees removed while improving 
forest stands, pruned branches, sawmill waste and bark account for 60 terawatt hours, or about $13 \%$ of Sweden's total energy supply. But with reduced crop subsidies to farmers and new taxes on industries that foul the air with $\mathrm{SO}_{2}, \mathrm{CO}_{2}$ and NOx, the nation is also finding that planting and using fast-growing trees can add as much as 35 more terawatt hours to the electricity grid with far less pollution than most other fuels. "Energy forests' may soon replace approximately one fifth of the country's grain production as farmers find trees to be a more economical use of their land." [National Arbor Day Journal, Jan/Feb, 1992]

\section{Economics of Logging Cleanup}

Research shows that one forth to one half of the total above-ground biomass of cut trees is not removed during conventional logging operations. This is too much biomass to leave on most sites. At the same time, environmental concerns for clean air dictate no broadcast nor pile burning in many locations. Here, then, is a huge supply of energy wood, provided it can be economically accessed.

Using new prototype logging equipment designed for this integrated harvesting and multiple-product marketing approach, a test near Port Angeles, WA, showed that whole-tree harvesting can be profitable at a site that could not have been economically harvested previously.

"In some parts of the country broadcast burning is avoided through cleanup credits for harvesting excess wood for energy...Dense brush in forests at urban-forest interface areas is being successfully harvested for energy, thereby providing a significantly decreased fire hazard to houses at the forest perimeter."[77]

A 1988 study made in eastern Oregon found that logging residue recovery was quite profitable if done right. The study suggests that second-growth thinnings could supply five times the present consumption, given more efficient harvest methods. And it forecasts that the decline of old-growth logging in national forests will accelerate change, as equipment is perfected for harvesting second-growth small trees. In all, the residue supply was judged to be adequate for doubled or tripled wood-fired energy generation for the next few decades.

"Timber sales contracts require the sale purchaser to remove logging residue to the land manager's specifications. Contracts will call for Yarding or Piling of all unmerchantable Material (YUM or PUM) exceeding a contract-specified size...YUM and PUM requirements significantly reduce the costs of logging residue to a fuel user. The common perception that logging residues are too expensive to use for fuel fails to take YUM and PUM contract requirements into consideration." [77]

The volume of wood fiber available after harvest of a old growth timber sale in western Washington and Oregon is very large. From a typical 25-acre sale in the Willamette National Forest in Oregon, $30 \%$ of the total wood tonnage logged was chip culls and wood fiber logs. From this one timber sale, the weight of chip cull logs and larger wood fiber logs totaled almost 97 green tons per acre.

Public agencies see advantages in encouraging energy markets for wood fiber, and are frequently willing to work out desirable contract terms as long as residue recovery does not delay reforestation. Some of their perceived benefits are the following:

Energy markets provide a new source of revenue.

- The risk of soil damage and the fire danger posed by slash burning are minimized because debris volumes are reduced.

- Air quality regulations and public opinion frequently restrain slash burning. Removing wood residue may reduce the need to bum.

- Collecting forest residues provides a stable, new source of employment in the otherwise cyclical wood products industry.

- Energy markets may permit earlier thinning and stand conversion sales.

About one-fifth of all hardwood trees are cull trees in the SERBEP area, and these cull trees 
comprise the single most important unused source of woody biomass which could be harvested for use as an energy material. According to a recent study conducted under the auspices of SERBEP, hardwood cull trees comprise $47 \%$ and logging residues constitute $29 \%$ of the annual wood energy available in the region. [44]

\section{Urban Wood Waste}

Several counties in Washington have been forced by new landfill regulations to truck their solid waste hundreds of miles to Oregon, and other counties will soon follow, paying $\$ 53.00 /$ ton for the privilege and forcing tipping fees above $\$ 100 /$ ton.

This new situation is creating new opportunities for source separation of waste materials suitable for fuel. Urban wood waste recycling businesses are springing up throughout the region that take in tree trimmings and stumps from landscapers, excavation contractors, tree surgeons, etc. for a tipping fee considerably less than the local landfill. Some of these processors are amassing large piles of biomass with no place put them.

Yard waste represents about 15-25\% of the total municipal waste stream, and urban landscape services produce significant amounts of chipped tree prunings throughout the U.S.. There are over 200 tree service companies in the Seattle-Bellevue area, collecting an average of 10 cu. yd./day of chipped branches and trees. Most of this "waste" is currently delivered free to anyone who will take it. There are several large gullies and swamps that are being filled, but that practice is becoming illegal, dramatically changing the economics of disposal. This is ideal fuel for a Northern Light furnace, and represents the equivalent of 210 "AGNI".

Wood recovered from urban landscaping, construction and building demolition has become an important fuel in Califormia, where more than $800 \mathrm{MW}$ of biomass capacity has been added at 57 plants since 1980 for an accumulated demand of 7.5 million dry tons per year. Independent power producers are adapting to urban wood fuels in increasing quantities. [Biologue, Sept,'91]

Urban wood waste is available everywhere. Until recently. its separation and use as a fuel was limited to a few wood working industries. However, as landfill space for solid waste has diminished, incentives, uses and markets have been found for wood wastes in composition board, compost and fuel. Fuel markets in California have created an urban wood waste industry almost over night.

\section{Agricultural \& Food Processing Residues}

Agricultural residues, including hulls, pits, straw and stalks, are not used in biomass power facilities because they are difficult to burn and cause problems with deposits in furnaces. [Biologue, 9/91] [Northern Light combustion systems are specifically designed to burn this vast fuel resource without the slagging problems.\}

The most likely wastes from the food processing industries for fuel use are: [72]

* Peanut \& sunflower hulls; rice and other grain husks; walnut, almond, pecan and other nut shells; and other dry shells. Moisture content is generally $4-10 \%$ (wet).

* Pit waste from fruits which contain hard pits, such as apricots, cherries, peach, olives, etc. Moisture content is typically about $50 \%$ (wet).

* Bagasse (pressed sugar cane fiber). Generally, quantities of this waste and process heat needs are much larger than the commercial size systems we are interested in, although there should be a sizable third-world market.

\section{Pelletized Fuel}

Pelletized biomass fuels have advantages in dryness, uniformity, increased density, ease of handling and feed, and controllability of combustion. Since the pelletizing operation involves extensive fuel preparation $\&$ drying, and 
expensive equipment and labor in handling, considerable cost is added to the raw fuel. Pellets have the disadvantage of costing 5 to 10 times as much as lower grade unprocessed biomass fuels. Because the damp low grade fuels can be burned as efficiently as pellets in a Northern Light system, there is no reason to pay the additional expense for fuel.

"A detailed account of the failure of a well-financed fuel-pellet venture in Livingston, Montana, was described (at the 1986 Washington Wood Utilization Conference held in Bellevue) by Hal Holtquist, managing partner of Mountain Energy Co. He said the firm made major marketing mistakes; mainly, 'tunnel vision' in not recognizing that dry hog fuel is an attractive alternative to pellets and should have been offered as a product. 'The institutional market will grow,' he said, 'and not by pelletizing dried fuel, by selling it in bulk.' Then he will be able to compete with any fossil fuel."

\section{U.S. Statistics}

During the last decade of the eighteen hundreds in the U.S.A., wood from our abundant forests was the primary fuel used in our factories, railroads and homes, totaling approximately 60 million tons per year. [11]

"Recent studies (1980) by the U.S. Forest Service have shown that on an annual basis in the U.S. there are 600 million dry tons of unused wood available for energy use, enough to replace 1,675 million barrels of oil $\{143,000$ "AGNI" $\}$. The bulk of this wood exists in the form of logging residues (160 million tons) and excess tree growing stock (215 million tons). Timber harvesting systems that utilize this excess wood represent an ideal opportunity to improve the wood energy situation in the U.S." [33A] \{U.S. Forest Service estimates tend to be far lower than other estimates.\}

The Federal Office of Technology Assessment forecasted in 1984 that this contribution could be increased sevenfold by the year 2000. Dr. James Duke of the U.S.
Department of Agriculture's Beltsville Research Facility claims that the U.S. could replace fossil fuels and be entirely self-sufficient in renewable energy from the biomass grown on the 62.5 million acres of deteriorated marginal land in this country. Other studies show that dedicating just $6 \%$ of our agricultural land to sustained yield biomass crops, from hybrid poplar to hemp, could replace all our present reliance on fossil fuels and nuclear power.

In 1980 , less than $200 \mathrm{MW}$ of electricity were produced from biomass. In 1990, the figure was $7500 \mathrm{MW}$ produced from biomass, primarily wood. This figure represents about five percent of all energy used in the U.S. and is comparable to our use of hydropower and nuclear power. Solar, wind and geothermal now account for 5,800 megawatts equivalent of energy. [Biologue, 12/91]

Wood energy is the single largest use of wood in the U.S. About 2.7 quads of our energy comes from 160 million dry tons of wood consumed annually. [22, '91] \{381,000 "AGNi"\} This could be increased to about 10 quads or about $13.5 \%$ of our current usage."[77]

"According to a 1989 U.S. Department of Energy study, solar and biofuels account for $\mathbf{8 7 . 8 \%}$ of the economically accessible fuels of the future...Not only does biomass represent a massive resource base, but this resource base can be accessed now, not like many of our other alternative energy options that may have impacts 20 years or more in the future."

"The United States has the potential to easily meet half of our liquid fuel needs and half of our electricity needs from this diverse resource that can be derived from direct combustion, gasification and liquification."

"Fast-growing biomass takes up more carbon than any other process and yields oxygen. In taking into account the total fuel cycle, several studies show that biomass energy is the only option that has a net gain over the carbon/oxygen cycle. This net gain has the capacity to preserve our planet." [Biologue editorial by Scott Sklar, Sept, 91] 
Although detailed analysis of all sustainable biomass energy sources is just beginning to be accumulated, especially from the agricultural sector, the U.S. Department of energy (DOE) estimates that the sustainable energy potential of biomass in the U.S. is $\mathbf{4 2}$ quads, equivalent to $55 \%$ of total U.S. Energy consumption. [10] $\{5.7$ million " $A G N I$ " $\}$

Slash burning in Washington State alone wastes 34 trillion BTUs annually (equivalent to 5.4 Million Barrels of oil... $\$ 194,000,000$ F.O.B. Kuwait, or 2.7 Billion Dollars of residential heating oil!* $10 / 90)$. This wasteful practice contributes far more acrid smoke to the atmosphere than woodstoves do. Increasing restrictions on slash-burning, mounting costs of logging clean-up, and greater efficiencies of residue handling/chipping/delivery systems are making slash chipping a necessity and wood waste a significant energy option. The future availability of wood-chip fuel will increase within areas 50 miles from logging and land-clearing operations. Wood waste and tree trimmings, along with other yard waste, have typically made up a third of landfill. Wood waste dumps leach concentrates into the soil that can contaminate the ground water supply for decades. Increasingly restrictive environmental regulations and disposal costs are causing tree trimmers, wood-products manufacturers, etc. to seek other outlets for their waste. This represents a vast decentralized source of cheap biomass fuel for energy.

Wood fuel use by the forest products sector has increased markedly over the last 20 years, and it is generally assumed that the pulp \& paper industry, large sawmills, plywood mills, and other large wood processing facilities will continue to use their waste for process energy, and that these fuels will not be available outside these industries. [5]

"Public pressure is forcing environmental regulators to further restrict open burning as a residue disposal option. If environmental regulations become more restrictive, land managers will be forced to seek alternative residue disposal methods including increased utilization. If part of the removal cost for residues is paid by the user of the commercial timber, then the cost of logging residues for electric generation should decrease."[6]

The most prevalent type of fuel used by respondents to the National Wood Energy Survey was: hogged fuel - $24 \%$, chipped mill waste - $22 \%$, sawdust - $22 \%$ slabs from mill waste - $9 \%$, whole tree chips - $7 \%$, logging residue - $5 \%$, wood pellets - $4 \%$, uncut logs $2 \%$, other - 5\%. [5] Green sawdust comprises about $13 \%$ of the wood waste of a mill. [13]

\section{Regional Statistics}

\section{Pacific Northwest \& Alaska Region}

"The five western States representing the pacific Northwest and Alaska Regional Biomass program of the U.S. Department of Energy, cover about 256 million acres of land and contain approximately one-third of the Nation's timber resource (U.S. Department of Agriculture 1981). This vast resource is concentrated on approximately $30 \%$ of the total area ( 80 million acres), referred to as timberland; land supporting timber that is generally considered to be available for continuing production of woody fiber. This resource supports a large forest products industry, accounting for a significant share of the wood products consumed in the United States. This resource also represents a source of supply for a potentially significant wood using industry energy. Energy production based on woody biomass grew considerably following the fuel shortages of the mid-seventies. This growth occurred primarily within the forest products industry and residential sectors of the economy. New legislation, advancing technology, and the renewable nature of wood provide the basis for greater reliance on biomass as a contributor to the region's energy needs in the future."

Nearly 19 quads of potentially available woody biomass residues have been identified in the bioregion. This is equivalent to 25 percent of current U.S. energy consumption. Annual logging residue alone accounts for 0.3 
quad, and is now the main source of biomass fuel.

Washington State's forests store far more energy from the sun annually than all the energy needs $c$ ? the state, and this biomass energy is perpetually renewing itself. Depending on conditions, forests in the Pacific Northwest produce on the average 5 dry tons of above ground woody biomass per acre per year, and at least that much below ground, 175 Billion BTU of stored solar energy per acre. In some locations four times that growth has been recorded, and some species suitable for biomass farming yield 8 times this aviage.

The 5 northwest states of WA, OR, ID, MT, \& AK consumed energy from all sources (petroleum, coal, gas, electricity, etc.) totaling 3,896 Trillion Btus in 1988, equivalent to the biomass energy stored annually in 23,000 square miles of Pacific Northwest forest land, or $\mathbf{2 . 5 \%}$ of the land area of these 5 states.

The following information in from Biomass Estimates for Five Westem Stares [16]:

In addition to woody biomass currently being converted to energy, primarily in the forest industries and for residential heating, the forests of the Pacific Northwest and Alaska represent a siznificant opportunity to help meet future energy needs. The extent to which these forests contribute is a function of a complex set of criteria, and varies considerably from one geographic area to another. Expanding the use of woody biomass for energy holds promise not only for meeting growing demands, but may provide an economic incentive for intensifying management of the region's forests. Obviously only a small portion of the nearly 19 quads of energy from the sources in this report will be physically available in any given year. Even less may find its way to markets because of critical economic factors. But, the amount that does reach conversion facilities can make a significant and lasting contribution to the region's energy requirements. Unlike other sources of energy, woody biomass is a renewable resource.

There are other sources of forest biomass not addressed by this report. The largest such source is biomass occurring on what are frequently referred to as non-commercial forests. Juniper stands in eastern Oregon and Washington are examples of this type of forest. There are just over 25 million acres of "other forest land" in the 5-State area. Much of this land is covered with trees that are not generally considered to be of commercial value - Eastern Oregon alone has over 3.6 million acres of other forest land, most of which is occupied by non-commercial species (Farrenkopf 1982). The very definition of these stands indicates that few products are removed from trees growing on these sites. In some cases products such as posts, poles, and firewood are taken from these forests. Large scale removal of biomass from these forests may not be reasonable for a number of reasons. They do, however, represent a potentially large source of biomass, particularly for products that do not require high quality wood--such as energy.

The logging residue produced annually in the Pacific Northwest bioregion, about 0.3 quad, is almost 10 times the energy output of the Trojan nuclear plant operating at $80 \%$ of capacity. [16]

The annual logging residue production in Washington is 315 trillion tons [90] The Washington State Biomass Data Book [90A] estimates a realistic availability of 143 trillion Btu annually, at competitive energy prices. Washington's industrial sector uses 200 trillion Btu of fuel per year.

The Biomass Energy Project Development Guidebook [13, 1989] compares the logging residues generated to the amount that can be chipped \& delivered to a site 50 miles away for less than $\$ 3.30 / \mathrm{MBtu}$, for possible electric power plants in WA, OR, MT, \& ID, from the present to 2010. The amounts generated are 4 to 9 times greater than the amount economically available close to a potential power generating facility. This leaves a current logging residue, 
uneconomically located for power generation in the 4 state region, of $18 \%$ trillion Btu/year, declining to 117 trillion Btu $\left\{16,027\right.$ " $\left.A G N I^{\prime \prime}\right\}$ by the year 2010 .

To get an idea of the market potential of this fuel source, using the average of these two figures and assuming that all potential power plants have been built and are using the surrounding wood waste for fuel, and only $10 \%$ of the remaining residue is potentially available to decentralized commercial boiler installations, 15 trillion Btus of logging residue would still be available, enough to fuel 2,055 AGNI sized boilers.

\section{Agricultural Field Residues}

According to the Biomass Energy Project Development Guidebook [13, 1989], the average amount of energy from agricultural field residues available for fuel in the Pacific Northwest Bioregion is 132 trillion Btu per year. This is a tremendous energy potential $\{18,000$ "AGNI"\}, equivalent to the energy available from logging residue in the 4-state region.

However, it is not as desirable for fuel because of its higher delivery cost, lower bulk density, and generally higher ash content (with lower ash-slagging temperature). Some residues also have value as green manure fertilizer. Costs of collection and delivery within 50 miles averaged $\$ 33 /$ ton, or $\$ 2.20 / \mathrm{MBtu}$. This is still half the price of natural gas.

To put this in perspective, compare the total annual average quantity of residues generated in Washington (315 trillion Btu) $\{43,000$ "AGNI"\} with Washington's total industrial fuel use for 1986 (284 trillion Btu)" [6]

One study of potential power plant siting in Washington found 8,000 acres of fruit orchards in one area, which could supply 17,500 tons of tree prunings within a 50 mile radius of the proposed plant site. "Residues from orchards have two particularly desirable characteristics.
They are most available during the winter months when logging residues are scarce, and recovery costs are generally very low." [13]

\section{Typical Installations In Washington}

Greenhouse heat is an ideal application for the Agni-size system, and I have found considerable interest from that sector. Many of the existing facilities use hot water heat circulating through tubes in the benches, so conversion is simple. Those in outlying areas use oil or propane rather than natural gas, so the conversion economies are very good, and heat is a large part of their expenses. Their greatest concerns are dependability and up-front system costs, since many seem to be operating on a tight budget. Mountain View Greenhouses in Woodenville is a typical conversion candidate, replacing a 1.5MBtu/hr natural gas hot water boiler. The owner has heard too many horror stories of unreliable wood-fueled boiler installations to trust a prototype installation, but he is eager to know when it will be manufactured. Briggs nursery in Olympia is very interested in heating with hog fuel, as they have a large and expanding operation and a ready supply of fuel. Their major concern is meeting the strict Olympia air emissions standards, and are particularly interested in getting emissions data on cofiring polyethylene plastic and lunchroom waste with the hog-fuel.

Tim Newcomb, of Seattle City Light Energy Management Services Division has been very supportive in my earlier endeavors to find a site for the Agni prototype. City light produces about 6 "AGNI" of chips annually from their transmission line right-of-way tree trimming operations. They would be interested in some cooperative deal to deliver their chips to several centrally located facilities.

M.J. Macdonald, Deputy Superintendent, Engineering and Utility Systems of Seattle City Light, stated in a letter to me (6/90) that, although City Light has determined that largescale wood-fueled power plants are not practical due to decentralized fuel sources, "Wood might prove to be an attractive alternative source of heat for other applications requiring smaller 
supplies if emissions are minimized by your concept. To the extent that such applications might replace electrical energy and nonrenewable resources, City Light would be interested and might pursue a demonstration project at some time in the future."

Of the 143 Washington State facilities listed by the State Energy Office in 1987, one third of them (47) have heating systems of $5 \mathrm{MBtu} / \mathrm{hr}$ or less, most of these are low pressure hot water or steam systems, fueled with \#2 diesel oil @ $\$ 4.88$ - $\$ 6.48 / \mathrm{MBtu}$ (5 yr. old figures). Many of these facilities are rural and would be good potential customers.

The State Energy Office has just recently cataloged hundreds of potential wood-energy users, from the wood products industries and other likely industries. Secondary wood processing facilities in the state offer a large potential customer base.

There are 37 public schools in rural Skagit County alone, 16 of them with an existing low pressure hot water heating system. There are 34 hospitals in the state with heat needs from 1 to 6 MBtu/hr. These are predominantly small rural hospitals that would be most likely to have the space for fuel storage and a cheap local source. The State Energy Office is interested in promoting the use of bioenergy in hospitals and schools, and there may be state funds to assist the conversion.

The great potential for bioenergy applications lies in the diversity of likely customers, from a fish-processing plant in Anacortes to the Glue Extender Company in Marysville. Seattle Disposal has tons of low-grade paper fines that are costly to landfill, and several large warehouses and other facilities to heat. The Whidbey Island Naval Air Station has begun an extensive recycling program that is including the city of Oak Harbor. Since their landfill will be closing in July, all refuse must then be trucked to Oregon, so they are serious about optimizing recycling and including waste-to-energy as an efficient way to heat their various buildings as well. They will soon be collecting 400 to 500 tons/month and purchasing a chipper to process their woody yard-waste. They also collect a lot of low-grade waste paper that they want to burn.

\section{Western Region}

Crop residues examined in the report, "Resource Assessment of Waste Feedstocks for energy Use in the Westem Regional Biomass Energy Area" include: wheat, barley, oats, rye, rice \& flaxseed straw; corn stover, huskage \& cobs; sorghum \& sunflower stalks \& leaves; whole cotton plants after seed collection; and orchard prunings.

"There are nearly 35 million dry tons of waste biomass in the WRBEP region that can be economically collected and delivered to energy plant sites in volumes of 50,000 dry tons per year or more.

The total waste paper and agricultural residue resource for the WRBEP region is 175 million dry tons per year (including 14.8 million tons of waste paper and 1.7 million tons of orchard trimmings). $\left\{417,000\right.$ " $\left.A G N I^{\prime \prime}\right\}$

The potential deliverable resource approaches 36.5 million tons per year or $21 \%$ of the total resource. This figure is based on deliverability to large energy facilities. Decentralized utilization patterns could make use of a much larger percentage of the available resources.

According to the Western Region biomass energy report, Biologue, Mr/Ap'91:

Biomass contributes about $1 \%$ of California's energy supply, increasing from $100 \mathrm{MW}$ in 1979 to slightly less than $500 \mathrm{MW}$ in 1988 , to exceed $500 \mathrm{MW}$ by 1994 . Although California has seen unprecedented demand for biomass fuel, with power producing facilities paying as high as $\$ 50 / B D T$ to get premium chips from Canada, prices are expected to fall in the future, as the market stabilizes and more biomass becomes available. "In general, biomass fuel is projected to be less available from the wood products industry and more available from nontraditional sources of fuel. One exception is that more fuel is expected to be derived from forest 
stand improvement thinnings and logging residue recovery. In the future, some fuel will likely be obtained from Eucalyptus, Salix or other energy plantation species."[77]

A study of coastal California (I.C.R.W.E.) concludes, "Improved biomass utilization would have significant benefits from the viewpoint of fire and resource management (reforestation, wildlife habitat management, recreation area management, range management) and jobs."

In Nebraska there is much interest in ethanol and concern with sizing mass-burn waste-to energy facilities to the needs of rural communities. The present efforts are on separation of recyclables \& producing RDF for remote boilers. Nebraska's Arbor Day Foundation plans to build wood-chip processing facility \& wood-fired boiler room for educational use Two state colleges plan wood-fired boilers for steam heat.

Kansas agribusiness generates $\$ 9$ billion in goods and services antiually, making it the largest revenue-producing industry in the state. It also produces large volumes of waste that may have value as feedstocks for biomass energy. A database characterizing this waste is presently being prepared. More than 600 agribusinesses associated with the meat packing, grain milling, and food processing industries have been identified in the state.

A recent study (1991) estimates the amount of agricultural crop residue that can be removed for energy purposes in Kansas without adversely affecting soil productivity. The crops considered in this study were com, grain sorghum and wheat. Available biomass from the three crops considered varies from $0 \%$ to roughly $72 \%$ of the above-ground crop residue produced. Estimates of removable residues for sorghum and wheat totaled 4.7 million tons. (Corn was not estimated.) [77] $\{6,700$ "AGNI" $\}$

\section{Southeastern Region}

"Eight of the top 10 industrial wood using states are located in the Southeast United States with Georgia the number one state."[77]
Georgia's goal is to supply $20 \%$ of its energy needs with biomass. [First National Fuelwood Conference, 11/91, Lincoln, NB]

In the TVA region, approximately 3.4 million tons of wastes were produced by the wood products industries in 1979, with a heat content of about 51,163 trillion Btus, or 7.1 million barrels of oil. About $50 \%$ of these wastes are now (1986) being burned to produce energy. Each year approximately 33 million green tons of wood and bark are potentially available for use as fuel in the region $\{42,500 " A G N I "\}, 10$ times the amount of mill wastes. [11]

\section{Nonforestry Related Biomass Fuel}

"The Southeastern Region of the United States can produce approximately the annual equivalent of 897 trillion Btu of energy from nonforestry wastes such as agricultural crop residues, animal excreta from confined feedlots, crops that could be grown on agricultural setaside land, MSW, and sewage sludge. Of the total resources, $53.5 \%$ are in the form of crop residues, $25.3 \%$ in $\mathrm{MSW}, 18.7 \%$ available from grasses that could be grown on agricultural setaside lands, $1.8 \%$ from sewage sludge and $0.7 \%$ from animal excreta."[72]

"In conclusion, available biomass waste and residues in the SERBEP region can annually provide about 897 trillion Btu \{123,000 "Agni"\}."[72]

"Mississippi could reasonably expect to obtain from 20 to $30 \%$ of its energy needs from biomass resources. [10, May/June,' 9 ?]

About $60 \%$ of raw cotton ends up as cotton gin trash, consisting of stems, leaves, hulls, and immature bolls. Comprised primarily of cellulose, gin trash has a 6,000-7,000 Btu/lb energy content, which can be used for drying the cotton and sold for fuel.

\section{Northeastern Region}

A 1984 report titled, "Wood Chips: an Exploration of Problems and Opportunities," prepared for the Northeast Regional Biomass Program, offers the following insights: [93] In 1983 , more than 30 million tons of wood, the 
equivalent of 30 million barrels of oil, were used in the region. Despite the increase, wood currently comprises less than $4 \%$ of the total energy consumed by residences, businesses, institutions, and industries in the northeast. Current usage is estimated at less than $10 \%$ of the potential contribution of wood. ...the market for whole tree chips is evolving more slowly than the production side of the operation. If the economics of burning chips were thus improved, and that information disseminated, it is likely that the market for whole tree chips would escalate. Once demand increases, operators will have incentive to solve the problems of production and delivery, creating the necessary infrastructure for a successful wood chip industry. Before the end of this century, whole tree chips may be the primary wood product used for energy.

Surveys conducted in 1979 and 1985 indicate that approximately $30 \%$ of the residences in Connecticut use wood for energy. With 1.8 million acres of forested land, Connecticut has a significant supply of wood. Research completed by professional foresters in the state indicates that substantial volumes of fuel wood could be harvested. Many foresters believe the use of wood for fuel can create markets for low-quality wood that is otherwise unmarketable. The use of integrated forest management techniques produces the opportunity to harvest low-quality wood while simultaneously improving the quality of the forest.

After a recent period of only modest increases in the amount of wood fuel used by industries, it now appears that wood use by Connecticut firms may grow substantially during the next few years. This is primarily due to two factors: independent power producers have received favorable power sales agreements with electric utilities serving the state; and skyrocketing landfill costs are encouraging the recycling of wood wastes. There are currently three wood-fired power plants proposed in Connecticut totaling 69MW. All three facilities plan to burn a mixture of recycled wood waste and harvested wood chips.[10, 6/91]
Main is the most heavily forested state in the union, $86 \%$ of it being covered with trees. In 1989 , thirty-one biomass operations in the State of Maine were non-utility power producers. Of these, one burned peat, four burned municipal waste, and the remaining twenty-six plants burned wood - either mill residues or whole tree chips. Of these 31 operating biomass plants, 22 were classified as cogeneration and 9 as small power producers. Presently, $640 \mathrm{MW}$ or $23 \%$ of Main's electric capacity, is fueled by wood, and six new ones are being built.

In the early 1980's over half of the households heated with wood, wholly or partially. By 1986-87, with lower oil prices, annual surveys indicted a leveling off at about $42 \% "[10,1991]$

"There are substantial excess quantities of wood in Maryland that could be used as an industrial energy resource, but only a small fraction of the potential is currently being used." [10, 1987]

Approx. $64 \%$ of the state of Massachusetts is forested. $=3.2$ million acres. The noticeable increase in wood burning in late 70's \& 80's was stopped by cheap fossil fuels. in 1988 industrial/ commercial wood fuel use totaled 65,000 tons/yr., residential wood fuel use 95,000 tons/yr. A substantial source of biomass energy comes from the incineration of MSW; totaling 7,000 tons/day in Mr,'89.[10,1991]

New Hampshire has built 6 new wood-fired small power plants with a combined capacity of $90 \mathrm{MW}$ in the past 3 years. Six older ones bring the total to $130 \mathrm{MW}$, or $8 \%$ of peak demand in the state (2.4 million tons fuel annually). Another 60 smaller commercial \& industrial systems (mostly sawmill $\&$ other wood product manufacturers burning their waste) burn 200300,000 tons/yr. Residential heating use has dropped from high of 640,000 cords in '84-'85 to 400,000 cords in '87-'88. [10, 1991]

The New York State Energy Research and Development Authority has evaluated and published an assessment of wood energy sources in the state. "...NY state could produce 400 to 800 MW of electric power on a continuous basis over 
the next 20 years using relatively low-cost wastewood materials at a price competitive with conventional power generation technologies. In addition, traditional forest materials combined with processed clean wood waste could generate an additional $2800 \mathrm{MW}$ of electricity at higher prices. NY state's forest resource has been expanding, according to a 1980 U.S. Forest Service Survey, with 18.5 million acres of land area forested. An additional 4.5 million tons of construction and demolition debris are generated annually, $40 \%$ of which is waste wood that could generate energy \{equivalent to 8,600 "AGNI"\}.

Vermont (the "Green Mountain State") is $80 \%$ forested. Residential heating with wood has dropped from a high of $50 \%$. Over 75 stateowned and commercial buildings utilize biomass energy for process steam or space heating. [10, 1991]

\section{Great Lakes Region}

In the Great Lakes Bioregion, some companies refused to reveal their use of cheap wood energy by taking part in a case study. "The food processing and canning industry, because of its highly competitive character, is understandably reluctant to reveal those secrets that contribute to its competitive edge. Wood burning has enabled several companies to stay abreast-or ahead--of the competition." [92]

"Whole tree chips are probably the largest available source of wood fuel due to the extensive amount of waste wood present in the forests of the Great Lakes region. Green mill residues at $\$ 5$ to $\$ 10$ per ton are the cheapest source of wood fuel available on a bon-by-ton basis, though their lack of uniformity and the possibility that dirt and stones will be mixed in with the residue are important considerations for purchasers."[92] This price means natural gas is $\mathbf{8}$ to 12 times as costly as wood-waste fuel.

"Currently Iowa imports $98 \%$ of the energy it uses, including the coal \& natural gas burned to generate electricity. Under a recent ruling by the Iowa Utilities Board, utility companies will pay alternative energy producers for the electricity the generate at a uniform statewide rate."[10A]

Although Iowa is not a heavily forested state, it does produce considerable wood waste that could contribute to its energy needs. "For years there have been problems in marketing or disposing of this wood waste. With additional environmental regulations, wood waste disposal may be even more difficult to handle economically in the future." [97]

WOOD WASTE IN IOWA [97]

\begin{tabular}{|c|c|c|}
\hline SOURCE & $\frac{\text { AVG. }}{\text { TONS }}$ & $\begin{array}{l}\text { TOTAL } \\
\text { TONS }\end{array}$ \\
\hline Sawmills(50) & 2,635 & 131,750 \\
\hline${ }^{*}$ Large Cities(3) & 2,295 & 6,885 \\
\hline **Medium Cities(54) & 64 & 3,456 \\
\hline$* * *$ Small Cities $(532)$ & 32 & 17,024 \\
\hline $\begin{array}{l}\text { Wood Using Industries } \\
\text { (244) }\end{array}$ & 27 & 6,588 \\
\hline
\end{tabular}

\section{TOTAL}

$\underline{165,703}$

*****POPULATIONS:*****

*Large Cities $>100,000$

**Medium Cities 5,000 - 100,000

***Small Cities $800-5,000$

Additional wood waste is generated by private tree services, land clearing and construction projects and by individual homeowners.

"For city forestry work, wood waste will also increase as Iowa's city trees, which are old and large, are gradually removed and replaced. Wood waste can be a particular problem after major storms-as the recent ice storm in Des Moines proved by yielding 18,000 dump truck loads of wood waste. Up to $40 \%$ of an lowa community's land surface is covered by street, park and yard trees." [97] 
This is the situation in many cities throughout the US. Tree trimmings and land-clearing debris could be diverted from landfills to produce significant energy.

Presently, only 25 firms in Iowa have installed wood energy systems. Iowa Department of Natural Resources predicts that wood waste in Iowa has the potential to produce about $10 \%$ of the state's energy needs. This could replace about $\$ 300$ million in fossil fuel energy expenditures now flowing out of the state every year.

"The U.S. Forest Service estimates national forest wastes at one billion dry tons $\{2,400,000$ " $A G N I$ "\}. In Minnesota alone, 7.2 million tons of wood residue is available every year for fuel...Hennepin County in Minnesota (part of the seven-county metropolitan Twin Cities area) produces almost 5,000 tons per day of burnable paper garbage. This waste could be effectively converted to briquette fuel that would provide $\mathbf{8 0}$ billion Btus of heat energy daily...This 80 billion Btus of daily untapped heat energy is equivalent to that produced by 500,000 gallons of fuel oil, which, at $\$ .90$ per gallon, would cost $\$ 450,000$ per day, or $\$ 2.5$ million per week!" [From a brochure by BMSI, Briquetting Marketing \& Services, Inc., Lee Machines, 7126 Newton Ave. S, Richfield, Minn. 55423]

Minnesota has a vast biomass resource of six million acres of peat, equivalent to 12 billion barrels of oil. [10] This is another untapped resource which should burn well in an Agni boiler.

Jim Fisher of Energy Resource Systems, MN, (they install wood-fueled boilers in the region) says, "There are 'islands of opportunity' for wood users. 'A lot of people think they have to be located in the woods to burn wood and that's just not true.' Fisher estimated that in the Great Lakes region, more than one half of all the states contain wood supplies that could be utilized within a 100-mile radius at prices competitive with conventional fuels. 'The main thing is that a user has to know the fuel: its moisture content range, the correct particle size for the burner chosen, and so on.' Fisher added that it's worth paying $\$ 2$ more per ton for clean fuel. 'We've had an entire 1958 Buick emerge from old sawdust piles' If the bumper gets through the system--or even a bolt--Fisher said the system will have to be shut down, costing far more than the savings the company attempted to achieve by purchasing a cheaper, dirtier fuel."[92] [That is a big advantage to Northern Light's belt-feed, gravity-feed hopper and non-auger ashremoval system combination. Bolts, rocks and dirt in moderation are no problem.

Aitkin Iron Works in northern Minnesota has developed a district heating plant fueled with wood. Dave Haaskamp, the plant manager, is enthusiastic about the concept: "It's the logical next step in state economic development. Why send all the revenues associated with fuel oil out of state? Haaskamp points out that timber is already a vital industry in Minnesota. It accounts for one half of the state's economic base, employs approximately 55,000 people and generates $\$ 2$ billion in revenues from wood products sold each year. Haaskamp believes 'the state could increase the number of employed to 100,000 just in the fuels, forest management sector alone,' by utilizing wood in small heating plants. He concludes that any community that has a business that is burning 75,000 gallons of oil 'ought to be looking into wood.' Each community could develop its own energy farm or hybrid aspen lot to produce an assured supply of fuel." [92] $\quad$ 75,000 gallons of oil would be just about the heat output of a 1.5MBtu/hr Agni at average $50 \%$ load.

Corn cobs in the midwest are an extremely attractive fuel source, selling for $\$ 5-\$ 10$ a ton (\$0.36 - \$0.71/MBtu) in Ohio. [10, 1987]

In 1990 Wisconsin's Wood Waste Energy Incentive Program awarded grants for 26 wood energy projects, 19 involving installation of new wood energy systems. [96, 10/90] 40,000 tons of wood waste are consumed annually by these projects, retaining over $\$ 1$ million a year in local energy expenditures. Through surveys conducted by the Energy Bureau, it was 
determined that 250 to 300 businesses in the state are generating a significant amount of excess wood waste which could be used as fuel. Many of the respondents indicated that they were beginning to experience difficulties in eliminating their waste economically. Major concerns were rising landfill costs and/or reduced landfill availability. [96]

An entire school district in northern Wisconsin heats with wood, paying $\$ 21 /$ ton for wood chips in 1985. Superintendent Tomasich is enthusiastic about wood heat and its future potential: "The farther north one goes in Wisconsin, the lower the fuel costs, as there are more sawmill operators. A lot of wood is just stockpiled in the field or hauled to the swamp as unwanted waste." Tomasich said he's disappointed that more industries and institutions haven't investigated wood burning. "It's true, there's a relatively high first cost, but the benefits -- cheaper costs over conventional fuels in the long-term and recycling of waste wood -outweigh this."

\section{Emissions Control}

\section{Effect Of Wood Combustion On Climate Change}

"Just as there is controversy in the need for mitigation of climate change, there is controversy over the benefits of using wood fuel for mitigating climate change. There are those who look at wood combustion as part of the problem rather than part of the solution. The most efficient way to obtain energy from wood by direct combustion is to recover heat, steam or electricity. Combustion of wood does return carbon to the atmosphere. however, if the wood burned is continually replaced through reforestation, this carbon is continually recycled and there is no new carbon added to the atmosphere or carbon sinks. To the extent that wood is used to replace fossil fuels, there is a direct reduction of new carbon in the atmosphere from fossil fuel combustion. Thus wood that does not have other uses should be used for energy to replace fossil fuels."

"However according to Rogers and Fiering (Rogers, 1989), man's involvement in contributing excess carbon to the atmosphere is minimal and of the contributions from civilization, contributions from biomass are a significant portion. Their reasoning is based on net primary productivity of terrestrial ecosystems of 60 billion tons of carbon per year. This anthropogenic "excess" is composed of fossil fuel combution ( $58 \%$ ), biomass fuel combustion $(12 \%)$, crop residue burning $(1 \%)$, grassland burning (20\%), shifting agriculture (4.2\%), cement production (1.4\%) and solid waste production (1.1\%). Total excess is estimated at $6.5+/-1.5$ billion tons of carbon. these annual fluxes are viewed against an estimated stock of $560+/-100$ billion tons in the living biomass systems. Viewed in this perspective, man's contribution from burning biomass are in the same category as burning fossil fuels, and man's contribution to atmospheric carbon is small in comparison to nature's."

"Viewed from another context, such as that expressed by Houghton (Houghton, 1989), the atmospheric carbon dioxide balance hinges on the annual anthropogenic emissions of this gas, which are about $70 \%$ from fossil fuels and 30\% from forest abandonment from shifting agriculture. Burning biomass from forest lands that are managed on a sustained yield basis is part of the solution, since the carbon dioxide released from burning and otherwise consuming wood is constantly recycled over a short time frame. I believe this scenario is more realistic."

"Regardless of the source, carbon has been accumulating in the atmosphere at the rate of about three billion tons annially (Houghton, 1989). If we can reduce the carbon dioxide flux into the atmosphere by three billion tons annually, the carbon dioxide level would stabilize around the present livel. The major sources of which man has some control is reducing the level of combustion of fossil fuels which releases 5.6 billion tons of carbon into the atmosphere 
annually, halting deforestation which releases 2.5 billion tons of carbon, and implementing a reforestation p!an which might store 2.5 billion tons of cerbon (Hovghton, 1989)." [77]

"Despite squibbles over the cost, the 1970 clean air ast and subsequent amendments went a long way toward cleaning up industrial emissions. But they failed to neutralize the rain. From 1970 to 1988 man-made emissions of sulfur dioxide in the United States decreased between $28 \%$ and $30 \%$, according to the U.S. National Acid Precipitation Assessment Program (NAPAP). The 1990 amendments to the act mandate that by the year 2000 such emissions be reduced to $50 \%$ of 1980 levels. It seems scrubbers installed to remove fly ash from smokestacks also removed the alkaline calcium that used to help neutralize acid rain. [62A, 1992] $\{A$ condensing boiler largely eliminates this problem. Burning sulfur-\& chlorine-free biomass solves the rest.\}

Germany will reduce its $\mathrm{CO}_{2}$ emissions by $25 \%$ by 2005 , it was announced at the Second World Climate Conference. [The FAO review, Ceres (via Delle Terme de Caracalla, 1-00100 Rome Italy).] Japan \& the European Community agreed to stabilize $\mathrm{CO}_{2}$ emissions in the same period, but not the U.S.A. Denmark is aiming for a $20 \%$ reduction by 2005 and $50 \%$ thereafter. [World Watch, 7/93]

Fossil fuels supply $85 \%$ of the energy in the European Community. [source: EC Energy Monthly, June'91]

Seri (the Solar Energy Research Institute) just completed a 14-nation survey for the IEA (International Energy Agency) on the status of bioenergy and greenhouse-gas reduction programs. "Most of the countries responding to the survey lack a formal policy on the greenhouse effect. But seven of them specifically noted that reducing or stabilizing carbon dioxide emissions is a national environmental goal. Five countries mentioned a plan or policy to levy emission fees or pollution taxes as an incentive to limit greenhouse-gas buildup. Only three, including the United States, mentioned setting emission standards." Member countries are Austria, Belgium, Canada, Denmark, Finland, Italy, Japan, the Netherlands, New Zealand, Norway, Sweden, Switzerland, the United Kingdom, and the United States. [75] (Why not England, France, Australia?\}

Eleven cities from three continents are negotiating proposals for actions to reduce the risk of global warming. Portland, San Jose, Miami, Denver, Minneapolis-St.Paul, Ankara, Turkey; Copenhagen, Hannover \& Saarbrucken, Helsinki, Toronto \& Ontario. [Source: Calgary Herald, quoted in Clearing Up, June, 1991]

The push is on in California, Europe \& elsewhere to substantially reduce $\mathrm{CO}_{2}$ emissions. This should favor biomass, especially in conjunction with landfill methane (a worse greenhouse gas) problems. [10, May/June,'91]

\section{Cause of Emissions In Biomass Combustion}

"The amount of particulate matter leaving the stack depends primarily on fuel type and boiler operation. The type and amount of fuel and ash content, as well as size and consistency, affect boiler operation and emissions. Oversize pieces burn slowly and are difficult to distribute in the furnace. These factors contribute to higher particulate loading."[11] $\quad$ A wide variety of fuels are burned very cleanly in the Northern Light systems, with combustion parameters optimized by the microprocessor controls, high ash automatically removed, and suspended particulates precipitated throughout the system.

"The worst possible example of inappropriate fuel feeding is to slug load or batch feed a furnace. \{like a woodstove or hand stoked boiler\} The best situation is to carefully meter and control feed rates for each fuel that is fired on a continuous basis and further, to ensure that the air/fuel ratio for each fuel fired is in an appropriate range to assure complete combustion. These goals are often very difficult to achieve, particularly when solid fuels are cofired. A major limitation in feeding of solid 
fuels is that there is currently no accurate technology available to measure the feed rate of solid fuels on a continuous basis."[77]

\{Northern Light's continuous gravity-feed hopper is perfect metering without measuring. It feeds exactly what it burns. The burn rate is controlled by the primary combustion air, not the fuel feed. The air-fuel ratio is precisely controlled in the secondary combustion zone by the microprocessor in conjunction with the oxygen sensor.\}

"Boiler design specifications - firing methods and fuel distribution in the furnace, air distribution and furnace configuration, furnace heat release, residence time, and upward velocity - are set to increase the efficiency of combustion and limit emissions. For example, lower gas velocities in the boiler reduce emissions by increasing the fuel residence time in the combustion zone and decreasing entrainment of fine particles by high speed air. One way to decrease gas velocity is to decrease air flow by designing a larger grate area. These kinds of boiler design parameters should be investigated when selecting for low emissions." [11] [These are fundamental design-principles of the Northern Light systems.\}

"Time and temperature are interdependent parameters for controlling PICs (Products of Incomplete Combustion). It appears from the literature that 1 second residence time at 1500 $1600^{\circ} \mathrm{F}$ is adequate to control PICs (Lee, 1988). However, where co-fired fuels include any hazardous wastes (i.e., waste oils), BACT may well require 2 seconds of residence time at 1500 - 1600'F"[77] \{NL systems exceed these specs.\}

"Finally, operator maintenance availability and level of expertise must also be considered. Because boiler operating and firing methods have a direct affect on emissions, maintenance personnel available on site must be factored into the boiler selection decisions."[11] [The fact that the Agni system is fully computer controlled, with automatic fuel feed, ash removal and alarm system, and that it is a low pressure hot water or steam system means that operator involvement is minimal.\}

\section{Air Pollution Control (APC)}

"Pollution controls should be considered as an integral part of the design of a wood energy system because emission rates are influenced by the type of fuel and the design of the wood combustion equipment. Five major types of pollution control equipment are available--cyclone collectors, wet scrubbers, dry scrubbers, baghouses, and electrostatic precipitators."[11] [With the universal fuel capacity and condensing boiler design of Agni, emissions clean-up equipment becomes unnecessary.\}

"Cyclone collectors are the most widely used emissions control device for wood-burning systems...cyclone collectors are more suitable for the removal of large particulates--collection efficiency decreases in direct proportion with particulate size. The smallest particles efficiently removed with cyclone collectors are approximately five microns in diameter...a more efficient secondary collector is often used behind a cyclone collector to improve the overall collection sufficiently to ensure compliance with air quality regulations."[11] "Several cyclones may be placed parallel to one another to form a multicyclone. These devices are often used with systems for which boilers are rated up to 50,000 pph (48 MBtu/hr). Multicyclones have relatively low initial and operating costs. A multicyclone and collector for $42,000 \mathrm{pph} \mathrm{(40}$ $\mathrm{MBtu} / \mathrm{hr}$ ) costs approximately $\$ 42,000$. [92, '86]

"Baghouses are the most widely used type of secondary collector for wood energy systems. They are not normally required nor economically feasible on small-sized systems. (Yet some state and regional (PSAPCA) regulations are so strict that a baghouse must be used with existing systems to ensure compliance.\} A baghouse contains rows of cylindrical bags that filter the particulates from the flue gas stream. The trapped particulates are removed by temporarily reversing the gas flow or by shaking the bags. Baghouses have a very high 
collection efficiency - removing more than $99 \%$ of the particulate from the flue gas stream." "The high temperature of the particulates associated with wood energy systems can lead to fires and explosions of the filters. Baghouses are expensive to maintain: while baghouse suppliers often claim the bags will last four to five years, most users find it necessary to replace them every year 0 : two." [92]

"Wet scrubbers and dry scrubbers are seldom used on wood energy systems because of their higher capital cost and higher operation and maintenance (O\&M) cost. They may be needed, however, in areas not meeting air compliance in particulates. When scrubbers are used, the byproducts of combustion are passed through a device that contains a chemical, such as limestone. The sulfur oxides react with the chemical and are trapped before emission into the atmosphere. Electrostatic precipitators are ineffective on wood-fired energy systems."[11] (They are now used extensively, however, on large wood-fired power plants.?

Recent improvements in wet scrubber technology offer strong competition to baghouses, as argued by Garry P. Isaacs of Procom Environmental Inc. [77, '91], "Recent clean air legislation has provided a necessity for serious flue gas cleanup. As a general rule, the baghouse has been recognized by the enforcement authorities to be the best available control technology (BACT) for a biomass combustion process. Since baghouses commonly burn down or explode, they have been largely undesirable for biomass flue gas cleanup. For this reason, in the BACT top down analysis, a wet system is usually opted as best technology for wood waste combustion. (The most effective scrubber is a mist scrubber, which emulates the way a cloud precipitates out raindrops, formed on nuclei of particulate - a costly and less effective copy of Agni's condensing heat-exchanger.\}

"While it is theorized that lower temperature will have a positive impact on condensation and collection of PICs (products of incomplete combustion), the literature contains no references to plant sites which do this purposefully. An offsetting consideration is that temperatures above the acid dew point must be maintained for fabric filters and for some ESPs (Makansi, 1987)."[77] (This feature is purposefully built into the Agni system)

The level of particulate emission (lb/MBtu) attainable with the various APC techniques are listed below:[80]

\begin{tabular}{|ll|}
\hline \multicolumn{1}{|c|}{ APC Technique: } & \multicolumn{1}{c|}{ Lb/MBtu } \\
Cyclone (MC) & 0.6 \\
Multicyclone (DM) & 0.4 \\
Wet Scrubber (VS) & $0.05-0.3$ \\
Electrostatic Precipitator (ESP) & $0.02-0.05$ \\
Baghouse (FF) & $0.01-0.02$ \\
& \\
Helen (green fir; no cleanup) & 0.017 \\
Helen (organic particulate only) & 0.007 \\
& \\
\hline
\end{tabular}

"In order to meet state particulate emission standards cofiring with a fossil fuel is a reasonable alternative to APC equipment in some cases."[80] Note that even cofiring with $95 \%$ natural gas and $5 \%$ hogged fuel does not approach the strict 1990 PSAPCA standard.

"Typical flue gas scrubbing and conditioning equipment costs average from 25 to $40 \%$ of the total capital costs of coal-fired plants and consume large amounts of power (approximately $3 \%$ of the total unit output)."[10]

Analyzing figures for typical APC equipment costs (1984) for larger systems in Stack Emission Standards For Industrial Wood-Fired Boilers, if we extrapolate the figures down to an Agni size 1.5 MBtu/hr system, we arrive at the following costs in 1980 dollars: 


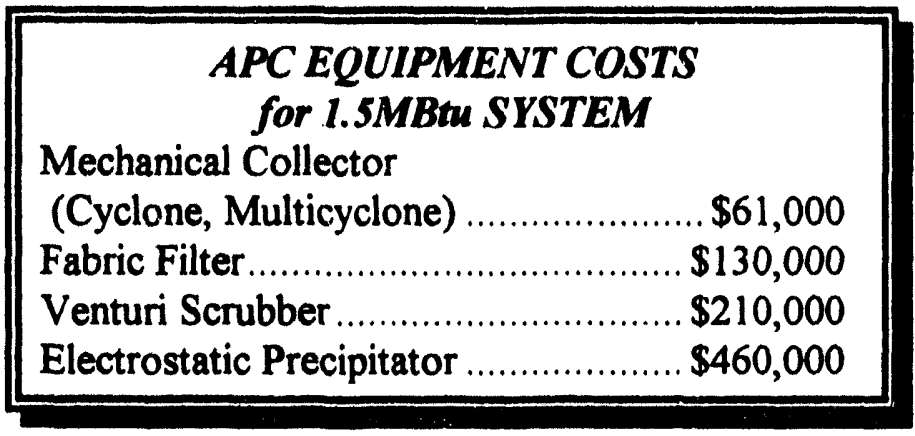

These figures are higher than those from [11]. These are additional costs over and above the boiler and feed handling systems, and the figures are low because there are economies of scale not factored in! This is the main reason why there have been no small wood-fueled boiler installations in any heavily populated areas (with strict emissions regulations) in recent years.

"Based on the available literature, it is apparent that for industrial sized wood boilers (less than $100 \mathrm{MBtu} / \mathrm{hr}$ ) $\mathrm{SO}_{2}, \mathrm{CO}, \mathrm{NO}_{\mathrm{x}}$, and VOC emission control equipment is not required but particulate control equipment will be required in a majority of cases for new installations to meet allowable state emission rates."[80] 


\section{Emissions Statistics}

The following chart compares emissions from Helen (burning green fir sawdust, $44 \%$ moisture) to emissions from large uncontrolled industrial boilers burning wood, coal, oil and natural gas (per identical energy input). Figures given are calculated from "Stack Emission Standards for industrial Wood-Fired Boilers".

\section{RELATIVE EMISSIONS COMPARISONS}

\begin{tabular}{|c|c|c|c|}
\hline & PARTICULATE & $\mathrm{CO}$ & NOx \\
\hline \multicolumn{4}{|l|}{ Grendle burner, model Helen } \\
\hline burning green fir sawdust & 1 & 1 & 1 \\
\hline \multicolumn{4}{|l|}{ burning hog fuel (wood chips) } \\
\hline \multicolumn{4}{|l|}{ Large industrial boilers } \\
\hline burning coal & 275 & 38 & 5.5 \\
\hline \multicolumn{4}{|l|}{ Large industrial boilers } \\
\hline burning oil & 0.76 & 6.25 & 1.4 \\
\hline \multicolumn{4}{|l|}{ Large industrial boilers } \\
\hline burning natural gas & 0.35 & 8.3 & 6.9 \\
\hline \multicolumn{3}{|l|}{ Proposed EPA standard for wood-fueled } & \\
\hline \multicolumn{4}{|l|}{ Proposed EPA standard for residential } \\
\hline woodstoves (average, based on g/hr std.) & 30 & & \\
\hline
\end{tabular}

"More than $10 \%$ of Washington's air pollution comes from outdoor burning: land clearing debris, logging slash, leaf burning, agricultural. field burning: According to the Department of Ecology, outdoor burning is a major source of citizen complaints, including 3,000 - 5,000 agricultural fires annually, burning more than 300,000 acres. All in all, outdoor burning contributes 256,000 tons of $\mathrm{CO}, 21,000$ tons of VOC, 32,000 tons particulate, 10,000 tons toxic air pollutants.

\section{Wood Ash:}

"Ash content and chemical composition are variable among tree species and also depend on soil type and climate. Temperate climate woods yield $0.1-1.0 \%$ ash, while tropical and subtropical woods yield up to $5 \%$. Hardwoods, in general, contain more ash than softwoods. Ash content is highly variable within the tree, being highest in the foliage and then decreasing in the bark, twigs, roots, branches and stem. Within the stem, ash is highest in the pith, earlywood (springwood), and juvenile wood. Bark contains a much higher ash content than wood, as indicated by the 1-3\% ash content in hog fuel.

Ash is composed of major and minor elements needed by the tree for growth. The major elements are calcium (7-33\%), potassium (3-4\%), magnesium (1-2\%), phosphorus (0.3$1.4 \%$, manganese $(0.3-1.3 \%)$, and sodium (0.2$0.5 \%$ ). Essential trace elements for plant growth include zinc, boron, copper, molybdenum, and others at $\mathrm{mg} / \mathrm{kg}$ (ppm) levels. Heavy metal concentrations are typically low...Wood ash is substantially different from coal ash which has a lower alkalinity but higher silicon, aluminum, iron and heavy metal content. The combustion temperature directly affects the total yield and chemical composition of ash. Some elements, 
particularly potassium, are volatized at high combustion temperatures thereby lowering their content in the ash.

The alkali metal and alkaline earth elements in the wood ash are present mainly in the form of oxides, hydroxides, and carbonates such as potassium oxide, calcium oxide, potassium carbonate, and calcium carbonate. The oxides react exothermically over time with moisture and carbon dioxide to form hydroxides and carbonates. These components produce a highly alkaline ash with a typical $\mathrm{pH}$ range of 11-13. The soluble potassium hydroxide and potassium carbonate react rapidly with acids, while the less soluble calcium hydroxide and calcium carbonate react more slowly. [77]

\section{Potential Problems:}

Science News reported (Aug. 10, 1991) that Stewart Farber, an environmental lab manager for a nuclear energy plant in Massachusetts, found that wood ash contains high levels of radiation, apparently the result of nuclear weapons tests in the 1950s and '60s. Tests of ashes from his fireplace showed concentrations of radioactivity that "was easily 100 times greater than anything (our lab) had ever seen in an environmental sample."

"He has since obtained radioactivity assays from 16 other scientists representing 14 states, and the data suggest that fallout in wood ash is a major source of radioactivity released into the environment.' With the exception of some very low readings in California, Farber says all measures of ash with fallout exceed - some by 100 times or more - the fallout that may be released by nuclear plants."

The trace element Cadmium can be a limiting factor on the amount of wood ash that can be used in agricultural applications. [from talk at the National Fuelwood Conference, 11/91, Lincoln, NB, by Nels Christopherson, Research Mechanical Engineer, USDA Forest Service]

\section{Ash Disposal \& Utilization:}

"Until recently, ash was a valuable raw material, but today ash wastes have a negative value due to their disposal costs. For the most part, ash is either landfilled (90\%) or land applied. In the Northeast, approximately $15 \%$ of wood ash is landfilled, $80 \%$ is land applied, and $5 \%$ is disposed of in some other way, mainly as a sewage sludge composting agent. Most other areas of the country landfill wood ash. In Europe, ash is used as a feedstock for cement production, a soil amendment on forest lands, and a roadbase material." One study suggests that $\mathrm{wood} / \mathrm{coal}$ ash could be valuable in neutralizing acid landfill leachate."

"Ash has been used effectively in four Northeastern towns as a bulking and odor control agent in composting of municipal sewage sludge in aerated static piles. In addition, ash has been granulated to yield a fertilizer and liming agent. Land application appears to be one of the best methods for ash disposal, as the nutrients that were taken from the land during harvest are recycled back to the land. Ash has a low fertilizer equivalent (NPK ratio of $0: 1: 2$ ), but it can be used as an excellent substitute for lime and limestone to neutralize acidic soils and to add $\mathrm{Ca}, \mathrm{K}$, and $\mathrm{Mg}$. Liming with wood ash may also reduce the toxic effect of aluminum and manganese in acidic soils. Ash will probably be sold in the future as a liming agent/soil amendment."

"Wood ash has shown positive benefits in forest and agricultural land application in a variety of tests: Yields increased (superior to limestone), even at high application rates because the elements in ash are released more slowly than those in fertilizer, showing a higher release in the second growing season. In one study, the wood ash increased all microbial activities that were examined: nitrogen availability, mineralization, cellulose decomposition, nitrogen fixation, and denitrification."

"In Maine, wood ash is classified as a specified waste which requires regulatory approval prior to land spreading... The approval process takes approximately 6 months. The State of Oregon DEQ does not require permits for each individual property but does require 
quarterly and annual reports identifying which properties are being utilized. County governments regulate ash utilization to the extent that they are responsible for land use issues and solid waste disposal. Some counties require that every adjacent property owner be notified by mail that the ash is to be utilized on a given site.

The state of Washington classifies wood ash as a dangerous waste when its $\mathrm{pH}$ exceeds 12.5. This classification necessitates special handling and disposal procedures which have caused major problems for several ash generating facilities. for example, a pulp and paper mill in Washington attempted to neutralize its ash for three months with sulfuric acid, but the cost was prohibitive." If this proved to be a problem, the mildly acidic condensate from the Agni boiler could be run through the basic ash to neutralize it on site.\}

Wood ash is a good liming agent. This makes ash land spreading feasible where the agricultural soils tend to be acidic, as they are in the Yortheast. Four northeastern states, Maine, Nev Hampshire, Vermont, and New York have de',eloped land spreading regulations for wood as $n$. In the other northeastern states as well as in r lost of the rest of the country, wood ash is still landfilled. This practice will undoubtedly change as landfill tipping fees increase. [22] In the SERBEP region, ash disposal in landfills does not require a solid waste permit. [65]

\section{Condensate:}

Some states in the SERBEP region issue general permits to cover minor discharges that are not likely to cause serious water quality problems, such as boiler blowdown water. [65] The boiler condensate should be covered in this category, and "when a general permit has been granted for a source category, any additional source conducting the same activity is pernitted...", which means that after the first installation in a state, future permitting in this area would be automatic.

In a paper titled, "Comparative Analysis Of Gasification/Pyrolysis Condensates" [68], Douglas C. Elliott of Pacific Norihwest
Laboratory, Richland, analyzed the aqueous phase of the condensate from three different gasifiers, which were "highly contaminated with organics". "The more contaminated aqueous streams have a lower (more acidic) pH (as low as 2.1!) which indicates the presence of water-soluble organic acids. Although the more contaminated streams show increases in viscosity and density as well as being highly colored they can easily be handled in systems designed for water if proper consideration is given for the streams with corrosive potential."

"For a modern efficient coal-fired plant, exhaust gas temperatures. are typically maintained near $300^{\circ} \mathrm{F}$ at full load because of the acid nature of the flue gas. At lower temperatures acids form that damage gas path components.

Due to the low levels of $\mathrm{SO}_{2} \& \mathrm{NOx}$ products associated with the whole tree burner, the flue gas condensate can actually become basic. thus, it is prudent to install waste heat recovery equipment to bring the exhaust gas temperatures down to as low as $150^{\circ} \mathrm{F}$, resulting in increased plant efficiency." [Biologue, Dec '88/Jan '89, "The Whole Tree Burner: A New Technology In Power Generation"] [NL systems also have relatively neutral condensate, around pH 4.5, which can be further nutralized with the basic ash.\}

Robert Boucher developed a condensing biomass combustion system in the early ' 80 's. the condensate, according to his description in private conversations with me, was the color of "dark beer". He admitted in correspondences that my combustion system was cleaner and the condensate less contaminated. In 1984 he had the condensate tested by Laucks testing laboratories in Seattle, for NEA, Inc., and Omni Environmental Services, both of Beaverton, Oregon. Paul Tiegs of Omni had the following comments:

"I have reviewed the results of your wood smoke condensate analytical testing...the data indicate that although traces of some potentially hazardous organic compounds are 
present in the condensate, they do not occur at concentrations that would be considered of significant danger to the activity and health of digesting bacteria in septic or municipal sewage treatment systems. In addition, the concentration of inorganic elements measured poses no serious threat to biological treatment systems."

"The presence of those organic compounds considered potentially hazardous is mitigated to a great extent by the high measured BOD which indicates a relatively high natural activity of biodegradation of the condensate itself. The BOD levels measured result from autooxidation from atmospheric oxygen or biodegradation by bacterial activity. In either case, degradation of the original condensate organic compounds takes place without initiation by induced means."

"As I mentioned in our conversations it would be difficult to estimate the assimilative capacity (volume and contact time) of any specific treatment system to handle the condensate but this could be determined by relatively simple experimental procedures (e.g., sewage or septic contact at various concentrations - incubation - and analysis)."

Peter Kosel, an engineer from the California Air Resources Board concurred with this analysis, stating in a letter to Mr. Boucher, "It seems (the State Water Resources Control. Board) think it would be very unlikely that your condensate would have an adverse impact on a sewage plant or it's effluent because by the time the condensate reached the sewage plant it would be diluted enough by other sewage to be innocuous. Only in improbable situations where undiluted condensate was the only sewage reaching the plant or where a plant was running on the ragged edge of it's ability to cope with the materials in your condensate would a problem be expected."

\section{Governmental Regulations \\ U.S. Federal}

EPA announced tough new rules "...that could put half the USA's garbage landfills out of business. "'This will be the end of the town dump,' says scientist Richard Denison of the Environmental Defense Fund. 'A lot of our landfills are definitely going to end up closing,' says Austin Buckingham of the Colorado Health Department. Experts say the new EPA rules could:

Create regional landfill shortages.

Increase pressure for recycling programs.

Raise disposal costs.

Nationwide, 5,499 landfills handle 120 million tons of garbage annually. Local governments own $56 \%$ of those sites. By 1996 rules will require:

Building landfills with synthetic liners \& rainwater collection systems to cut risk of ground water contamination.

Monitoring to detect ground water contamination \& methane gas buildup.

Random checks on haulers to keep hazardous wastes out of landfills. Impact will be biggest in those states, most in the South \& West, without tough laws."

"Only 25 of Colorado's 120 landfills 'potentially' can meet the new regulations..." Louisiana is already strict. 770 mostly rural dumps have been closed since 1981, leaving 31 . In Georgia, "This will put more pressure to accelerate recycling \& find better environmentally suited alternatives," says Don McCarty of the state compliance office. In New Mexico, nearly all the state's 130 landfills won't meet the new laws.

According to the National Solid Wastes Management Association, about $75 \%$ of U.S. garbage goes into landfills: 5,499 in 1990 are predicted to go down to 2,157 by 2000 . 
Ownership: $3 \%$ Federal, $14 \%$ private, $57 \%$ local $\&$ county government, $25 \%$ other.[USA TODAY, Sep.11,'91, "EPA Signals End of the Town Dump'" "Federal Landfill Regulations Bring New Set of Problems"]

Landfill costs on the east coast have increased 1,000-fold, from $\$ 1,000 /$ acre 15 years ago, to $\$ 1$ Million/acre today under the new EPA regulations. [1st National Fuelwood Conference, 11/91]

\section{EPA's Woodstove Regulations}

The new EPA woodstove certification program was created with the best intentions, but it has done a disservice to the industry. Even though official testing of the Helen prototype showed emission levels 1/30th of the EPA standard, EPA will not certify this stove because it will not operate properly with their small stick crib fuel loading and other artificial conditions of their test protocol.

This regulation has several fatal flaws that have not only put $3 / 4$ of the woodstove manufacturers out of business, but have dangerously crippled new woodstove designs by forcing them to conform to laboratory conditions not representative of the real world. Several recent field studies of certified woodstoves in normal household use have shown their emissions to be two to four times higher than the EPA and Oregon DEQ laboratory certification test results, and some stoves that failed certification performed as well or better than certified ones. The highly artificial fuel load and draft conditions required for certification testing are the chief culprits, and my lengthy battles with EPA on this front has left me with little hope that they will ever acknowledge this fact, much less modify the test procedure.

Certainly, emissions are lower with certified stoves, but their performance has been crippled by requiring air settings and other design parameters to be determined by artificial laboratory conditions, not real world conditions. They have been forced to evolve along lines that lead to a future dead-end. Washington State had included provisions for granting exceptions to woodstoves that could be certified to pass the EPA emissions levels with different operating procedures, but they have entirely eliminated that option in the final form of the law.

\section{New Source Performance Standards (NSPS)}

The NSPS for municipal waste combustors regulates combustors burning at least 50 percent municipal waste and having a design capacity of 50 tons/day or greater. The standard sets the limit of particulate matter that can be discharged to the atmosphere at $0.08 \mathrm{gr} / \mathrm{dscf}$ corrected to 12 percent $\mathrm{CO}_{2}$. Existing facilities that undergo modification and increase the amount of particulate matter emitted are also subject to this NSPS. Tests at two domestic and two European combustors equipped with ESPs to control particulate matter were performed to establish the value of the NSPS. The particulate emissions from these tests ranged from 0.07 to $0.09 \mathrm{gr} / \mathrm{dscf}$ corrected to 12 percert $\mathrm{CO} 2$ at the U.S. municipal waste facilities and 0.05 to 0.07 $\mathrm{gr} / \mathrm{dscf}$ corrected to 12 percent $\mathrm{CO} 2$ at the European facilities. [These emissions are 10 times Helen's particulate emissions of 0.008 gr/dscf\}

In addition, the NSPS for industrial, institutional, and commercial steam generating units would apply to municipal waste combustors that produce steam and that have a heat input capacity of more than 100 million Btu/hour. The particulate emission limit for those combustors is $0.1 \mathrm{lb} / \mathrm{MBtu}$ (O.046 gr/dscf corrected to 12 percent CO2). ${ }^{4}$ The level of $0.1 \mathrm{lb} / \mathrm{MBtu}$ was based on tests at four steam generating units ranging in heat input capacity from 47 to 290 million Btu/hour which fire municipal waste. All units were controlled by ESPs. The emission levels measured at these facilities ranged from 0.2 to $0.05 \mathrm{lb} / \mathrm{MBtu}$ and indicated that properly

\footnotetext{
${ }^{4}$ Conversions from $\mathrm{gr} / \mathrm{dscf}$ to $\mathrm{lb} / \mathrm{MBtu}$ assume a municipal waste feed higher heating value of $4500 \mathrm{Btu}$ per pound, and an F-factor of 10,003 dscf/MBtu.
} 
designed ESPs can reduce particulate emissions from these units to levels below $0.10 \mathrm{lb} / \mathrm{MBtu}$.

\section{Prevention of Significant Deterioration Requirements (PSD)}

In addition to NSPS, PSD provisions were established in the Clean Air Act for stationary sources of air pollution to maintain clean air and yet allow new industrial growth. The PSD applies only to construction or modification of major sources. Municipal waste combustors capable of charging more than 250 tons per day of refuse are one of 28 named PSD source categories. The PSD regulations required that, for new major stationary sources, best available control technology (BACT) will be required for each regulated pollutant emitted in excess of minimum specified levels. BACT is also required for major modifications to existing stationary sources for each regulated pollutant emitted for which there is a significant net emission increase. The mean BACT rates for PM at the 22 facilities listed in the table range from a low of 0.015 to $0.043 \mathrm{gr} / \mathrm{dscf}$, or approximately 20 to 50 percent of the current NSPS emission limit. (While emissions from the Northern Light systems are half of the best of the large existing facilities, this small size system will not fall under PSD jurisdiction.\}

\section{SUMMARY OF MSW CRITERIA POLLUTANT EMISSION RANGES}

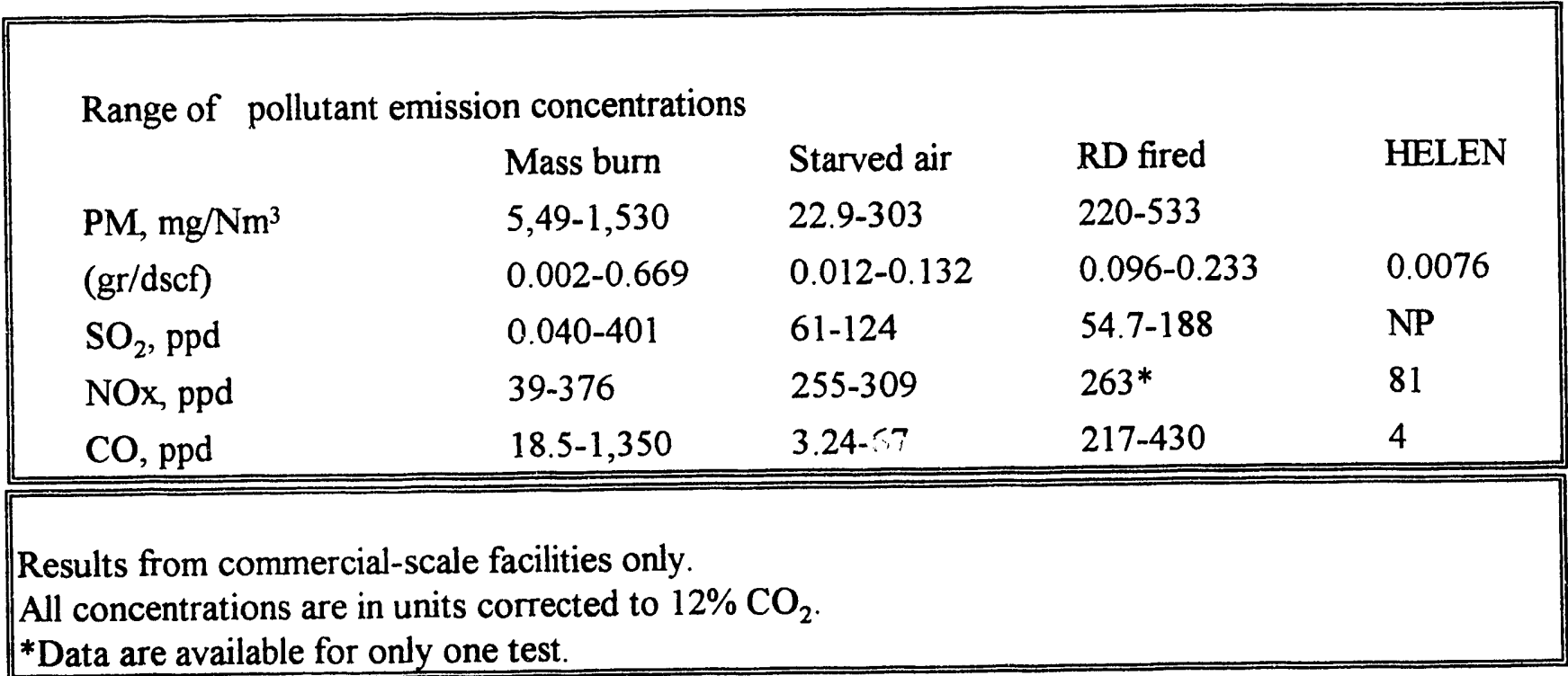

Unacceptable emission levels have plagued the waste combustion industry in Europe as well, and from the literature, they do not seem to have much better technology than that currently being built in the U.S..

\section{The 1990 Clean Air Act Amendments}

"The 1990 Amendments to the Clean Air Act have been called the most comprehensive piece of environmental legislation ever passed by the congress." [77, 3/91]

Title I: "Congress designated new or expanded nonattainment areas for ozone, $\mathrm{CO}$, and particulate matter (PM10). Existing stationary sources in nonattainment areas will be required to employ reasonably available control technology (RACT), or even the best available control technology (BACT) in highly polluted areas. New major stationary sources will need meet the lowest achievable emission rate (LAER)...In some areas this may result in restrictions on, or even the elimination of, open burning as well as restrictions on the use 
of wood for home heating. Material that was formerly considered to be a 'waste' will be available to the biomass industry as an energy source."

Title III: Many of the pollutants emitted by biomass facilities will be regulated under title III. These include: PAHs, dioxins, furans and chloroform. The strict standards will be phased in over the next 10 years. "Compliance with the Title III emission standards will mean meeting MACT (Maximum Achievable Control Technology) limits. For new sources, MACT means the best of the best, or similar to reductions required for sources subject to LAER, limits that are applied to sources located in nonattainment areas for criteria pollutants."

Title V: "The operating permits program required by Title $\mathrm{V}$ is the most significant procedural reform in the Amendments. Under this program, most industrial sources will need to obtain renewable operating permits and pay permit fees in order to operate their facilities. Operating permits are required for all "major" sources...It is almost certain that any biomassfired facility will be required to have a permit to operate under this program. It is also possible that residential wood stoves and slash burns will need to have operating permits. In accordance with the schedule established by Congress, affected sources will need to have operating permits and will need to submit operating permit applications by no later than November 31, 1995, although many states will require applications much earlier."

Title VIII: "Miscellaneous provisions of the Amendments include requirements to address regional haze, perform a study on incentives for renewable fuels. Positive opportunities therefore exist for the biomass industry. "[77]
The implications of this regulation are major: It will be increasingly difficult for small, individually engineered systems to obtain permits. Standardized controls in a well integrated system with a solid track record and multiple installations in the same region will be the only efficient way to go. The firm must be large enough to have a "permits expert" on staff. Official emissions testing through EPA or DOE will facilitate permitting and commercialization of biomass energy systems.

Since EPA stack emission standards only apply to large (100 MBtu/hr?) size wood-fueled systems, emissions from small to moderate sized boilers are covered by highly variable state standards. "...some state Air Quality Boards, interested in establishing particulate guidelines, adopt standards developed for coal or oil boilers, for lack of EPA test data."[5] These much stricter particulate emission standards require the addition of cost-prohibitive baghouse filters and other stack clean-up devices to presently available wood-fueled systems. The result is that the existing smallscale combustion technology will not be economical for many areas of the country. The likelihood is that these local regulations will become more strict in many areas, rather than more lenient, considering "...the fact that half of all Americans live in areas that fail to meet Federal clean air standards..."[74 p.3]

\section{Financial Assistance}

"The majority of financing done by states is in the form of interest payment subsidies on equipment loans for wood-fueled boiler and cogeneration systems. In California, up to $50 \%$ of project costs can be financed through the state. If the project is successful, the firm buys back the state funded equipment at no interest....California's financing arrangements are available to all biomass energy projects and are not wood energy specific.... Other financial 
incentives include matching the department of energy's institutional conservation program funds for school and hospital wood energy projects (Minnesota And Missouri)....generally, direct state financial assistance for industrial wood energy developers is scarce...It appears that state tax incentives for wood energy have become less popular in recent years." [5]

These trends seem to be reversing in some areas, as more states are becoming concerned with landfill problems and discovering from studies that there is a gold mine of potential energy in the various biomass waste streams. In an effort to promote the utilization of this potential, several states are now offering grants for demonstration projects.

\section{Regional}

\section{Northeast Region}

"Federal air pollution regulations generally do not apply to industrial wood-fired boilers. State regulations are generally directed to particulate emissions although other pollutants are addressed. The range of allowable particulate emissions generated by wood-fired boilers varies from 0.03 to 0.6 pounds per million Btu in the northeastern states. The state regulations are not typically applicable to small (less than 1 to 3 million Btu) boilers. The specific allowable emission is dependent on the state and area within the state of the boiler installation, the boiler capacity, and the boiler construction date." [80]

"All of the state regulations, while not consistent within the northeast region, appear to be attainable but at different levels of fuel conditioning and flue gas treatment. For the most part, the format of the regulations is such that the only available means of complying with the allowable particulate emission standards is via the use of Air Pollution Control (APC) equipment. Credit is not generally extended for reductions caused by economical fuel or steam use, which have some positive effect on emission reduction. [80]
"Of those installations which meet the state particulate emission levels (of 0.1 $\mathrm{lb} / \mathrm{MBtu}$ ) it is reasonable to suggest that wood boilers with capacities of less than 60 MBtu/hr will not be subject to PSD review."

"Many states have recognized that smaller installations cannot be controlled as well at a reasonable cost and adopted to their particulate emission standards based on a sliding scale, i.e., the allowable particulate emission is higher on a per unit basis for low capacity wood-fired boilers and is marginally reduced as the boiler capacity increases. This allows the reduction of particulate emissions to the allowable limit by simple APC equipment or means other than APC for the smaller wood-fired boilers.

MAINE: Maine is one of the few Northeastern states which specifically addresses wood-burning sources, but they do not apply to equipment with rated input heat capacities of less than 3 million Btu/hr. [80, 1982]

MARYLAND: New low capacity $(<13$ $\mathrm{MBtu} / \mathrm{hr}$ ) fuel burning equipment construction is prohibited in certain areas of Maryland (I, II, III, IV $, \mathrm{V}, \&$ VI) when designed for use of solid fuel $[80, ' 82)$

MASSACHUSETTS: Over a boiler capacity of $3 \mathrm{MBtu} / \mathrm{hr}$, particulate emissions are limited to 0.1 to $0.2 \mathrm{lb} / \mathrm{MBtu}$, depending on the heat input and boiler location within the state.[80, '82]

\section{Southeast Region}

\section{Permit Requirements for Direct} Combustion of Wood and Agricultural Residues in the SERBEP Region: [65, 1986-9]

"All plants, air heaters, furnaces and crop dryers must have local building permits and environmental clearance before construction...All furnaces and boilers with a heat input greater than 30 million Btu/hr must apply for an Air Contaminant Discharge Permit (ACDP). Smaller sources, greater than $400,000 \mathrm{Btu} / \mathrm{hr}$, must notify their air quality agency but may not need an ACDP...A permit is usually granted or denied within 60 to 180 days of the receipt of a completed application by the State permitting 
agency...Large wood-fired boilers proposed for sites classed as non-attainment areas must guarantee certain emission levels before an ACDP will be issued....Some small furnaces need special equipment to control particulate emissions (TSP). Large plants must also control other categories of pollutants, such as $\mathrm{CO}$ and NOx. Plants near Air Quality Maintenance Areas (AQMAs) must control Volatile Organic Compounds (VOC), because they lead to the formation of ozone...Agricultural crops and field residues burned in large boilers will increase emissions and are subject to the same standards as wood."

\section{MSW Combustion in SERBEP}

"The environmental impacts described for wood and agricultural residues will apply for MSW as well, but MSW's more varied content causes additional concerns...Regulating agencies insist on the control of very fine particulates from refuse burning because they often contain "criteria" pollutants such as lead and cadmium...Ash or solid waste from MSW combustion must pass the EPA leachate (EP Toxicity) tests prior to approval for landfilling...Furnaces burning more than 50 pounds per hour of MSW need an ACDP...Federal law prohibits State rules from being less stringent than Federal rules...Class I areas \{under PSD (Prevention of Significant Deterioration) standards $\}$, such as national parks and wilderness areas, receive special protection. The increment for such areas is much smaller than for other areas." [65]

The federal particulate matter staridard, now based on PM10 tests (particle size $<10$ microns) for PSD Class I areas is $10 \mu \mathrm{g} / \mathrm{m} 3$ for a 24 hour maximum, and an annual geometric mean of 5 $\mu \mathrm{g} / \mathrm{m} 3$ for ambient air measurements. [65] Unfortunately, because ambient air quality is determined by geography, population density, weather, etc., there is no way to translate this into meaningful stack emission regulations. Nevertheless, the Helen prototype tests produced particulate levels less than half of the toughest regional (PSAPCA) emissions standard. Outside of non-attainment areas, PSD standards only apply to major sources that emit more than 250 tons/year of a regulated pollutant (particulate, in the case of biomass combustion). Extrapolating Helen's emissions, AGNI will emit only about $110 \mathrm{lb}$ of particulate a year, and is obviously exempt from this criterion. The Federal New Source Performance Standards (NSPS) likewise do not apply to such small biomass combustion installations as we are considering, and in most cases state and federal standards are identical.[65]

Areas where air quality does not meet national ambient quality standards are called Non-attainment areas (NAA), and the State is mandated to strictly control further polluting sources. Although individual state requirements differ, emissions must be generally controlled to LAER levels. This level is stricter than BACT required by the PSD, and is generally defined as the lowest rate any system has achieved for the pollutant in question. The most stringent standards are demanded of the larger installations, and permitting in such locations is a long and complex process. [65] Nevertheless, I know of only one wood-fueled installation in the nation that has achieved cleaner emissions than Helen, a large power plant in California, using extremely costly and complex APC equipment. Both the Federal Environmental Protection Agency and Department of Energy have expressed keen interest in getting the Agni prototype tested, possibly to establish a new BACT standard.

\section{Municipal Solid Waste (MSW)}

The nation is overflowing with waste which coincidentally has the potential of solving much of our energy crisis. Landfills are filling up and closing down at an unprecedented rate, spurred by new, strict and costly EPA regulations. Waste is being trucked further and further afield to find a new dump site. Of the 180 million tons of MSW dumped annually in this country, $44 \%$ is 
biomass-based residue suitable for burning for energy. fat 33\% moisture, this is equivalent to only $2.2 \%$ of the DOE estimate of the sustainable energy potential of biomass in the U.S.\}

\section{Nature of the Fuel}

Every individual in the U.S. produces approximately 3.5 pounds of MSW daily. Of this, paper products \& paperboard wastes comprise $35-40 \%$, or $1.25 \mathrm{lbs}$. [64A] MSW averages $44 \%$ wood-based constituents. [77]

Approximately 5.2 million tons of MSW are generated in Washington state each year $\left(6^{1 / 4} \mathrm{lb}\right.$ of garbage/person/day). About 1.2 million tons are recycled. Of the 4 million tons disposed of in landfills, a potential of 3.1 million tons $(77 \%)$, or 40.6 trillion Btu $\{5,561$ " $A G N I "\}$, can be consumed for energy.[90A]

According to a phone survey of paper recycling firms in the WRBEP region, unsorted (mixed) paper waste, including newspapers, office paper, phone books, etc., sold (2/91) on a delivered basis for $\$ 10$ to $\$ 15$ per ton throughout large parts of the WRBEP region.[74] That is $\$ 0.67$ to $\$ 1.00$ per MBtu, or $15 \%$ to $23 \%$ of the cost of natural gas.

\section{Landfills}

"Landfills are closing at a frightening rate. According to the Environmental Protection Agency (EPA), the United States had 20,000 landfills in 1978. By 1988 that number had dropped below 7000. During the same interval, the country's volume of municipal waste increased from 150 million tons to 180 million tons. Each person in the United States now throws away an average of $3.5 \mathrm{lbs}$ of solid waste a day.

Today, 16 states have less than five years of landfill capacity left...Chicago will run out of space by 1994, Los Angeles by 1995. Community resistance has made new dumps nearly impossible to site.

EPA safety regulations passed in September (1992) will also add to the expense of building a facility. They require that new landfills have liners, wells to detect groundwater contamination, monitors to detect methane, and a means for monitoring leachate for 30 years after the site closes."(1992), [62A]

"Missouri, like other states, is facing a desperate environmental issue with its daily production of 16,000 tons of household and industrial waste.

Missourians generate each day waste equal to a railroad train of 160 hopper cars. In one year, such a train would stretch 421 miles running from the Missouri/lowa border via I-29 to Kansas City and then via I-70 to St. Louis.

Ninety-three percent or 3.1 million tons of this waste material is buried in Missouri landfills. It is estimated that the minimum value of this waste approaches $\$ 31$ million annually." [2]

"Under a waste management reduction program mandated by the Iowa Legislature, yard waste, including trees, will no longer be accepted at state licensed landfills after January 1, 1991. Although this regulation does allow licensed landfills to accept processed wood waste, such as chips and sawdust, most landfills are attempting to meet a state goal of $25 \%$ reduction by 1994 by composting yard wastes or encouraging utilization. Some landfills may not accept any wood waste."[97] The report states that the increasing cost of landfill disposal of wood waste makes this option too costly, and many businesses and small communities are disposing of these wastes by open burning. But the Iowa Legislature has just made this practice illegal.

\section{Projected Growth Of MSW Combustion}

\section{EPA Study}

The following information is taken from the EPA Municipal Waste Combustion Study. [56, $57,58,59,60]$ There are many issues which 
could potentially affect the growth of MSW. Four general categories are: air emission regulations, land disposal regulations and programs, materials separation and recycling, and other issues such as tax law changes, energy prices, and public resistance to the location of resource recovery facilities near residential areas.

There is considerable variability among the growth estimates generated by various sources. However, all the estimates indicate a significant growth of municipal waste combustion through the year 2000 . The capacity of municipal waste combustion facilities will reach 242,342 tons per day of installed capacity by sometime in the 1990s.

Mass bum facilities are expected to account for between 60 and 70 percent of the total projected capacity by the year 2000 . Facilities that combust RDF will constitute between 20 and 30 percent, and facilities with modular combustors will account for approximately 10 percent of the total projected capacity by the year 2000. Though modular systems will make up the smallest segment of the installed capacity, they will make up the majority of the number of plants due to their small size.

Plants over 1000 tons per day in size will make almost half of the new capacity added through 1993. However, facility manufacturers indicated that more plants will begin to be built in the $500-1000$ tons per day size. This is because the number of cities which generate enough waste to require over 1000 tons per day plants is limited.

The air emission regulations for MSW may affect the growth of the industry because as emission regulations become more stringent the cost of controlling the emissions increases. Depending on the level of increased control costs, the competitive balance of MSW versus direct landfill or materials recycle could be affected.

In general, high $\mathrm{CDD} / \mathrm{CDF}$ are associated with high $\mathrm{CO}$ concentrations and low $\mathrm{CDD} / \mathrm{DCF}$ concentrations are associated with low $\mathrm{CO}$ concentrations. \{See graphs showing comparative $\mathrm{CO}$ emissions from various sources?

It is hypothesized that there are 3 main ways that organics (pollutants) may appear in the exit gases from combustors:

1. Lack of destruction of organics originally present in the feed refuse,

2. Conversion of precursors present in the feed or formed in the combustion processes to organic compounds emitted from the stack, \&

3. Lack of destruction of precursors in the combustion system and conversion of the precursors to other organic substances downstream of the combustion zone at low temperatures.

While it is not certain which, if any, of these basic mechanisms dominates, all three basic formation mechanisms would be minimized by achieving complete combustion, thereby converting all organic species to $\mathrm{CO}_{2}$. Thermodynamic considerations indicate that under excess air conditions and temperatures characteristic of municipal waste combustors, there is no theoretical barrier to achieving essentially zero emission levels for these species. In spite of this, emission measurements have shown the presence of significant quantities of organic species in exit gases from some municipal waste combustors. Existence of these species (either in the flame or in the exhaust) indicates a failure in the combustion process caused by insufficient mixing and characterized by escape of local fuel-rich pockets of gas.

Optimum combustion (destruction of organics) should have the following conditions:

1. Mixing of fuel \& air to prevent the existence of fuel-rich pockets in the combustion gases,

2. Sufficiently high temperatures in the presence of sufficient oxygen for destruction of organic species, and

3. Prevention of quench zones or low temperature pathways that would allow partially 
reacted or unreacted fuel from exiting the combustion zone of the furnace

(All three of these criterion are optimized in the Northern Light systems. The latter condition is far superior to any other system we are aware of.?

Without proper source separation of municipal wastes, levels of heavy metals such as lead and cadmium in the ash could be high enough to classify it as hazardous waste. If the ash generated by a municipal waste combustion facility must be managed as a hazardous waste, the cost of managing that ash can be expected to increase substantially.

Cost of ESP's (electrostatic precipitators) designed for an emission level of $0.01 \mathrm{gr} / \mathrm{dscf}$ are approximately $35 \%$ more expensive than ESP's designed for $0.03 \mathrm{gr} / \mathrm{dscf}$ for new MSW model plants. This makes MSW combustion uneconomical for most small communities in the more stringent regulatory regions. Emissions from the "Helen" prototype during the Bonneville/EPA test were $0.007 \mathrm{gr} / \mathrm{dscf}$ without any stack cleanup.

"Speaking of waste-to-energy, if the situation
in Europe is any guide, then the US
counterpart will have its nettle tested in the
coming years. Environmental control has
become so strict in Germany for example
that the 'energy' generated in these plants
hardly surpasses the energy consumed
internally to meet discharge limits." [67A,
$12 / 91]$

\section{Market Studies}

\section{SERBEP Study}

The national survey, conducted 11/84 - 3/85, poled the 119 nonforest products industries listed in NEDS. a Southeastern Regional Energy Survey was then conducted (10/85-12/85) to identify the perceived constraints to wood energy use by conventional-fuel-using industries (forest products industries \& nonforest products industries using wood energy were not included, nor were industries in retail trade, transportation services, mining and agricultural production). Based on the 90 respondents to the national questionnaire, the 535 respondents to the regional questionnaire and the input from experts in the field, a "most likely" candidate for wood energy conversion in a nonforest products industry was determined to satisfy seven criterion:

1. use of a boiler for energy production

2. boilers with turndown ratios (base to peak operating rates) of $3: 1$ or less

3. a minimum to maximum response time of at least 20 minutes

4. a process heat temperature not exceeding 800 degrees Fahrenheit

5. a boiler capacity greater than one million and less than 280 million Btu/hr

6. operation of the energy system for at least 6000 hours per year

7. boilers that are at least 20 years old

The rationale for the above list are as follows:

1. $96 \%$ of the respondents to the national survey use a boiler for energy production. "In addition, expert opinion indicates that market penetration in the industrial wood fuel market will be most rapid in the boiler sector."[5, p. 16]

In fact, non-boiler use of wood fuel do exist on a limited basis, i.e. kiln drying of lumber, direct drying of grain and green chips for pelletizing, and direct firing of bricks. these applications have often been prevented because of contamination of the product by heavy carryover of ash, soot and cinders from the combustor. The Agni combustor design is a major breakthrough in the elimination of this problem, and there should be a significant number of new applications for this technology. I have been approached by a company interested in my technology for the direct drying of sewage sludge. the use of an air heat exchanger tends to be uneconomical over 2 $\mathrm{MBtu} / \mathrm{hr}$. 
2. In the national survey, the predominate turndown ratio in wood-fired boilers was 2:1. this is a severely limiting factor, requiring in some cases the installation of two or more boilers to allow a greater turn-down. It is often the limiting factor for economical use of a woodfueled heating where seasonal heating requires a wide variation in heat output, such as in schools, manufacturing facilities, etc. The extremely large turn-down ratio of Agni (14 to 1 or more) is not even approached by any system of any size now on the market. This advantage will attract a much larger customer base than are now considered "likely candidates".

3. The minimum to maximum response time of Agni is quicker than the average system now on the market, but not as fast as gas or oil, mainly due to the protection of the ceramic refractory from thermal shock by the digital controls. This is not a major determining factor for most potential customers, especially after considering the advantages of "smart" anticipatory control logic used in the sophisticated control system.

4. Of the 303 respondents to the regional survey using boiler technology for energy production, $36 \%$ have a process heat temperature ranging from 251 to $400^{\circ} \mathrm{f}, 24 \%$ have a process heat temperature of $100-250^{\circ} \mathrm{F}$. Lower process heat temperatures are associated with food and kindred products, and textile mill products industries, as well as with institutions such as schools and hospitals. The great majority of applications that the Agni system would be most suited for would be low pressure hot water or steam.

5. The majority of the national survey respondents produced process steam via direct combustion in relatively small boilers (less than $50 \mathrm{MBtu} / \mathrm{hr}$.) The $1 \mathrm{MBtu} / \mathrm{hr}$ lower limit for "most likely candidate" is lower than previous research indicated, and the smaller jystems seem to be increasing in numbers.

6. "It is generally accepted that a potential candidate for wood energy conversion will have to operate the energy system for at least 6000 hours per year to recover the cost of conversion." [5, p.17] Many factors can change this figure:

- It was learned through several woodfueled boiler installations in Georgia school districts that the limited turndown ratio of the combustors (3:1) required much of the spring and fall heating requirements be met by the backup oil/gas system. This created an over-long payback period. [from a presentation at 1991 national fuelwood conference] [This universal problem in space-heating application (which make up the majority of wood-fueled boiler applications under $10 \mathrm{MBtu} / \mathrm{hr}$ ) would be eliminated with the Agni system.?

- The initial cost of the boiler, fuel storage and handling systems, the operating costs and boiler efficiency, all play an important role in changing this 6000 hour figure. As detailed in other parts of this paper, all of these factors can be substantially reduced from present levels, thus opening up a much wider market.

7. For the classification of "most likely" to convert to wood energy, it was assumed that it would be uneconomical to convert from the present fossil fuel or electric system unless the boiler is near the end of its life. This study does not address new wood energy systems.

The study also noted additional factors that may be important in defining the competitive market segment for industrial wood fuel: location with respect to physical wood fuel supply and existing distribution channels for supplying industrial wood fuel; and price of wood fuel in the market area with respect to the price of conventional fuels. These factors have already been covered in detail.

Other statistics of interest from the southeastern regional energy survey of potential users are as follows:

$43 \%$ of the respondents use natural gas to provide at least $80 \%$ of their process steam, process heat, and space heat $(22 \%$ process steam with space \& process heat, $15 \%$ process steam with space heat, $14 \%$ process steam only). $36 \%$ of energy systems are over 20 years old. $50 \%$ indicated that energy costs comprise no more 
than $10 \%$ of total production costs; $7 \%$ said energy costs were over $75 \%$ of total production costs. $20 \%$ plan to change energy systems within 5 years (only one was planning to convert to wood fuel).

"If one accepts our bases for segmenting the industrial fuelwood market, it is apparent that, at least for the population analyzed in this study, technological factors relating to the systems used for producing energy appear to be the limiting factors which prevent the conversion to wood energy. Eighty-eight percent of the potential candidates (266 respondents) are eliminated from consideration of using wood energy because their energy needs cannot be met by wood-energy-combustion technology." $[5, \mathrm{p} .22]$

Of additional interest from the national wood energy survey:

"The 55 wood energy using companies responding to the survey consistently indicate that inexpensive wood fuel is the principal incentive for using wood energy. Most used hogged fuel, $84 \%$ of these converting nonuniform wood fuel to hogged fuel at the point of fuel consumption. $65 \%$ have a contract, most with forest product firms, for less than 3 years, with a mean hauling distance of 27 miles.

The respondents were asked to rank a number of constraints regarding wood energy use by degree of importance, in 4 groups:

(1) Technological - The percentage of respondents ranking 'very to extremely important' for: 'proper operation of the energy system' $77 \%$; 'maintenance of the energy system' - $62 \%$; 'wood fuel handling' - 50\%; 'wood fuel storage' $37 \%$; 'efficiency of the energy system' - $31 \%$

(2) Institutional - 'very to extremely important' for 'management's acceptance of the system' - $42 \%$; 'availability of long-term supply' $47 \%$; 'finding a wood fuel supply source' - $36 \%$. "The responses to these two constraints indicate that cbtaining a wood fuel supply source may not be as important as constraints relating to the cost of installation, operation, and maintenance associated with a wood energy system."[5]
However, when the respondents who use wood parts in their production process (wood toys. bowling pins, burial caskets, musical instruments, etc., classified by sic code as "miscellaneous mfg. industries") are discounted, these 2 percentages went up. "In essence, the availability of wood supply is a constraint, sometimes a very important one, to the wood energy users surveyed in this study that did not use their own residues."

(3) Financial - Capital cost of installation' is considered to be very to extremely important by $63 \%$ of the respondents. Other studies have also documented that the most severe birier to industrial wood energy use is the high capital cost of equipment."

(4) Environmental - 'very to extremely important' for 'cost to comply with air pollution regulations' - $52 \%$

Perceptions of wood fuel as an energy source as identified by the southeastern regional energy survey:

"The results of this survey regarding industrial perceptions of wood energy indicate that wood fuel is not perceived by respondents as a source of energy which could meet the energy needs of their companies. This 'poor' perception of wood fuel may be a significant barrier in itself, to wood energy use."

"Among all respondents to the survey, 'conversion costs to a wood energy system' is perceived as the most significant barrier to using wood energy... This perception may be somewhat accurate as other studies indicate that conversion to a wood energy system may be two to seven times the capital cost for an oil or natural gas energy system, and twice the capital investment of a coal energy system." "Wood fuel handling" was considered to be the second most constraining factor to wood energy use. Other inportant constraints were "cost of wood fuel transportation", "availability of longterm supply", and "compliance with air pollution regulations." In general, the less aware of wood energy the respondents were, the more 
formidable they considered the barriers to wood energy conversion.

The age of wood-fueled boilers in service by the respondents to the national wood energy survey were: $<5$ years: $30 \%, 5-9$ years: $20 \%, 10$ 14 years: $12 \%, 15-20$ years: $3 \%,>20: 25 \%$.[5] this shows that the majority of installations are new, but a quarter of the existing systems are over 20 years old and ready for replacement.

IN the SERBEP Region,"...there is a wide range of potential users from small organizations similar to Maryville college that uses several thousand tons of wood per year to relatively large organizations similar to the Russell corporation which uses more than 100,000 tons per year. The most prevalent characteristic of potential users (not existing users) is their lack of knowledge regarding supplies, costs, and uses of biomass fuels. in particular, converting from a fossil fuel to a wood fuel involves severing connections with well-known, established supply channels, and establishing business relationships with unknown firms that are primarily producers of lumber and other wood products."

"...Manufacturing residue is the most widely used and most convenient source of fuel at this time. If a reliable supply of manufacturing residue is available within a reasonable distance of the potential users, then the first criterion is satisfied for adopters who are willing to deal directly with the producers. In some areas, brokerage systems have come into existence to simplify the purchase of wood fuels. Potential users often see biomass fuels as a way of saving money and/or insuring a supply of fuel in case of a shortage of oil or gas. But these considerations have become less important during the past three years than they were 5-10 years ago. For example, the price of coal is competitive with the price of wood in some areas of the southeast."

"Many potential users do not have the capital required for installing a wood burning system, and, in many cases, do not have the credit available to invest in a wood burning system. Moreover, during the years 1981, 1982, and
1983 interest rates were quite high which increased the cost of capital, but these rates have declined since 1983."[44]

\section{Great Lakes Study}

A similar survey was conducted in the Great Lakes Region in 1986. [48] Of 291 surveyed, 194 completed the questionnaire, of which $46 \%$ were fuel-wood users (all with equipment installed after 1970).

"This survey found three areas of information needs that were seen as important \{by both fuel-wood users and non-users $\}$ when making the decision to convert to fuel wood. These areas were economic analysis; storage handling and combustion equipment; and pollution control. Information about economic analysis was felt to be at least moderately difficult to find by $51 \%$ of the fuel-wood users. This ranked it 4 th in difficulty among the items mentioned on the survey."

At the second level of importance were: 1 . specific information about fuel-wood combustion equipment and operation, 2. fuelwood handling equipment and operation, 3. fuel-wood storage equipment and operation

"Respondents from Iowa reported extreme difficulty in locating information about combustion and handling equipment. In other states, especially Indiana and Minnesota, this information was reported to be relatively easy to find."

"Two items, emission requirements and pollution control devices, were combined into the third category of important information." Respondents from the wood products industries said that these items were extremely important while respondents from schools, hospitals and public agencies found them only slightly or moderately important." All the fuel-wood nonusers ranked information on these two items very important or extremely important. These 2 items were ranked 1 st and 2 nd in difficulty of obtaining information. 
The reasons given by the non-fuel-woodusers for not converting to wood fuel were, in order of importance:

1. the cost of converting

2. the need for increased labor

3. a lack of storage space

4. unavailability of wood fuel

5. the inconvenience of wood fuel

\section{Washington Study}

A recent survey of three hundred manufacturing industries in Washington State by the State Energy Office discovered that $72 \%$ of the respondents would consider converting to wood fuels if the fuel-related savings were $50 \%$. The predominant factor influencing their decision to convert would be demonstrated savings. Both of these conditions are currently met in Washington, which underscores the survey finding that $48 \%$ of the facilities had not investigated wood fuels because they were not aware of its potential.

"This means that an educational program could be very beneficial in increasing the use of wood fuels by industry. the fact that $40 \%$ of the firms would be interested in receiving more information confirms our belief in the growth potential for wood fuels." [48A]

\section{South Carolina Study}

A survey was conducted by the state of South Carolina, to assist in promoting the use of wood as energy. [77, p. 183] 108 industries were located that appeared to satisfy their qualifications for a likely candidate for conversion. These criterion were:

1. use at least $30,000 \mathrm{mcf}$ natural gas or its equivalent annually

2. could feasibly use wood residue to replace fossil fuel

3. used fuel primarily for a non seasonal process rather than winter building heat

4. primary \& secondary wood products industries were excluded
"In screening industries it is necessary to determine their fossil fuel cost in relation to the potential cost of wood residues. There must be enough savings from burning wood to pay for the conversion and give a good return on the investment. If the cost per million Btus from wood residue is at least $\$ 3.65$ less than the cost from fossil fuels, conversion for a minimum or larger industry becomes a real possibility. table 1 shows the relationship between the cost of wood residues, natural gas and number 2 fuel oil necessary to retire the normal cost of conversion and give a $25 \%$ return on the investment."

\begin{tabular}{|c|}
\hline fuel costs necessary for conversion \\
\hline to a wood-fuel system $[77,1990]$ \\
\hline
\end{tabular}

\begin{tabular}{|c|c|c|}
\hline green wood & natural & no.2 \\
\hline residue & gas & fuel oi \\
\hline \$/ton & $\underline{\text { S/mcf }}$ & \$/qal \\
\hline 6.00 & 3.65 & 0.54 \\
\hline 8.00 & 3.92 & 0.58 \\
\hline 10.00 & 4.20 & 0.62 \\
\hline 12.00 & 4.47 & 0.66 \\
\hline 14.00 & 4.74 & 0.70 \\
\hline 16.00 & 5.01 & 0.74 \\
\hline 18.00 & 5.28 & 0.78 \\
\hline 20.00 & 5.55 & 0.82 \\
\hline
\end{tabular}

dry wood

residue

$\begin{array}{lll}6.00 & 3.25 & 0.48\end{array}$

$\begin{array}{lll}8.00 & 3.39 & 0.51\end{array}$

$\begin{array}{lll}10.00 & 3.53 & 0.53\end{array}$

$\begin{array}{lll}12.00 & 3.67 & 0.55\end{array}$

$\begin{array}{lll}14.00 & 3.80 & 0.57\end{array}$

$\begin{array}{lll}16.00 & 3.95 & 0.59\end{array}$

$\begin{array}{lll}18.00 & 4.10 & 0.61\end{array}$

$\begin{array}{lll}20.00 & 4.25 & 0.63\end{array}$ 
It should be noted that these figures are based on the very costly feed system boiler installations in the region, and the increased efficiencies of a condensing boiler produce a third mare energy from the fuel.

\section{Public Opinion}

In a December 1990 national poll, a vast majority of Americans ranked renewable energy as their \#1 priority for government funding (75\%), conservation \#2 (67\%) and Nuclear last (25\%). [Safe Energy Communication Council]

In the spring of 1991, "...top lev el executives from the world's largest and most influential corporations, including Alcoa, Exxon, Union Carbide, and AT\&T, converged to achieve a unique objective. Over 750 delegates convened at the second World Industry Conference on Environmental Management (ViCEM)..to exchange insights and ideas regarding the future of planet Earth...The world's corpinrate head honchos shuttled between seminars e:tpostulating the joys of environmental management and promulgating the notion that businesses work with governments and environmental groups...The very fact that CEOs and VPs represented their companies clearly shows that in the nineties, big business considers the environment an important issue."[62A]

Biomass energy needs publicity and good press now. Concerned parties at all levels of government and industry are waiting for statistics to show that biomass energy can compete with gas and oil in cost, cleanliness and reliability. If they see the figures in official reports, they will be our best support.

\section{Fuel Feed, Storage, Transport}

\section{Fuel Transport}

The live-bottom semi-trailer truck is widely used for hog fuel transporcation. A standard size is $8^{\prime}$ wide $\times 13^{\prime} 6$ high $\times 42^{\prime}$ long, tarpaulincovered, with 20 ton capacity, capable of unloading in 15 minutes. "Chip vans' capacities depend upon trailer design but vary from 18 units to 42 units. Trailers vary both in outside width and sidewall height from $8^{\prime}$ to $8^{1} 2^{\prime}$, and are up to $50^{\prime}$ in length. Self-unloading units are heaviest and have maximum capacity of about 18 units (or less with wet fuels). (2400 lbs/unit_ $200 \mathrm{cu}$. ft.) The standard rate for contracting for a 30-unit chip van on good roads with no backhaul is cbout 1.10 per mile. A 70-mile haul will cost $\$ 2.57$ per unit or $\$ 1.07$ per ton. A live bottom van for the same trip will cost $\$ 4.28$ per unit or $\$ 1.78$ per ton. (in WA, 1987)

\section{Weather Considerations}

In cold climates, freezing conditions have an adverse impact on fuel availability, storage and feeding. High rainfall areas produce damper fuels when stored outside for extended periods. The latter is not of great concern to the Northern Light systems, due to their capacity to handle very wet fuels.

"In 1982, an economic analysis was done for investors interested in retailing firewood through supermarkets in Denver. The study showed that, while the supply of dead, standing Englemann spruce was enormous, weather patterns limited the annual harvest period to 100 days. the cost of harvesting in $3 \frac{1}{2}$ months and storing inventory for $81 / 2$ months defeated the project.

Interruptions in supply for two-thirds of the year are unusual, but periods of inventory shortage due to weather are common. Adequate inventory and storage space must be planned."[13]

\section{Fuel Storage}

Wood handling equipment and storage is a major portion of system expense, ranging between 20 and $40 \%$ of the total cost on large installations, and even more for a small installation. \{As described earlier in this report, Northern Light has developed a low-cost fuelstorage/delivery system. Because it is still under development I will not describe the design in greater detail at this time. It is much simpler 
than what is currently "state-of-the-art", as described below.

In designing a fuel storage facility, several factors must be considered:"[11]

- the storage area available and its location in reference to the boiler room

- the properties of the wood fuel, i.e., moisture content, particle size, etc.

- what additional fuel preparation facilities are required

- the reliability of the wood fuel source

- the weather conditions at the site

- availability of additional personnel

"The moisture content affects the bulk densities and therefore, the heating value of wood fuel types. Moisture is significant not only in the combustion characteristics...but also in required fuel amount, which has direct influence on:

- the volumetric feed rate to the boiler

- volumetric storage requirements

- delivery truck capacity

"Although densified (high bulk density) or dry wood requires less storage, it also creates some handling problems as small dry particles easily become airborne. The use of small dry particles must also be considered in designing the boiler receiving hopper."

"Some typical conceptual designs for wood fuel facilities are as follows:

1. Silo storage and prepared fuel- This design ...is common for a moderately sized plant and for locations where storage is limited, or where the wood fuel is dry and must be protected. The system requires little maintenance when the silo is equipped with devices for breaking up bridged fuel (vertical shaft with chain flails). The size fuel is somewhat limited because of potential bridging problems. These systems are often designed for three days storage and, therefore, a reliable fuel source is imperative.
2. System using prepared fuel and open and covered storage- This is the least expensive system and may require no conveying equipment, The front end loader is used for wood handling to an outdoor reserve holding area, which is based on a concrete slab. This open outdoor area can be designed to hold a 30 day supply of wood. The covered storage area is for "active" storage and may be based on a concrete slab with an open sided metal building designed to hold three days worth of fuel. A truck receiving unloading system may have to be included depending on the type of fuel delivery.

3. An open and covered storage system using a fuel preparation section- This system would be applicable to a large industrial application. The fuel is received from a hydraulic truck dump into a live bottom pit. The material is then conveyed to a wood preparation system that uses a magnetic separation system to remove tramp metal, a screen to remove large pieces, and a hog to reduce pieces to uniform size. Material is transported by conveyors to covered or open storage. A front-end loader is used to handle special transport problems and spills.

"The fuel-feed system, which transports wood waste from storage to furnace distributors, must be designed to be reliable in delivering a controlled amount of fuel to the boiler. Fuel is loaded from the primary storage site, either manually or with an automatic conveyor, to the fuel silo (a fuel hopper), which is the operational storage area or daily inventory for the boiler. Fuel is metered from the hopper into the furnace, and the hopper must be dimensioned to match a desired interval between refills and the available space."

"Several things have to be considered in the design of the fuel hopper or silo to keep fuel flowing and to avoid bridging (clogging). Negatively sloped walls $\left(2-4^{\circ}\right)$ help to keep fuel from becoming stuck. The hopper cover must be sturdy and tight so that the flue gases, or possibly sparks or fire, cannot escape to the storage space. The forced air fan should be stopped, automatically or manually, as soon as the cover 
of the silo or hopper is opened in order to prevent smoke from spreading to the storage room. Silos are normally constructed of $1 / 16$ $1 / 8$ inch $(2-3 \mathrm{~mm})$ steel plate, with outside strengthening strips. It is essential that the walls do not yield to the weight of fuel as this will increase bridging (a type of clogging in the silo)."

"Sometimes the inside walls of a silo are painted to improve the fuel flow properties. Agitators are used in larger silos to further improve the flow of small particle fuel."

"More elaborate fuel feed silos, such as surge hoppers, provide a variety of benefits leading to greater efficiency in maintaining the fuel inventory needed for operating flexibility. Live bottom surge hoppers discharge fuel using multiple screw feeders as well as drum rolls with staggered lugs and spikes."

"Once delivered to the front of the furnace, the fuel must be distributed evenly to feed chutes supplying the furnace distributors. The distribution system, depending on system size and cost, may include flight conveyors, swinging spouts, or vibrating conveyors. Smooth flow of fuel is dictated in part by chute design. Sharp bends or turns should be avoided."

"When uniform sized particles are sent into the furnace, both fuel handling and combustion are more efficient. If fuel is not delivered in a uniform size, a screen and hog system can be used to provide uniformity."

"With these systems, correctly sized fuel passes through the screen and oversized fuel is sent to a hog device. Shaker and disk screens are used, although disk screens, which are self cleaning, are less maintenance intensive. The hog may be a knife hog, which chips the wood, or a hammermill, which beats and grinds particles against a screen."

"Similar systems exist where unhogged material passes under a magnetic metal separator that removes tramp iron or steel. The material then passes onto the top of a disk screen, consisting of a series of disks rotating on parallel shafts. Material over a certain size will pass over the disks into the hog. The hog will then reduce pieces to the required size. The screen functions to reduce the horsepower requirements of the hog by screening out the material that is of proper size. In the usual configuration, the fuel is then passed onto a conveyor and to storage. Experience indicates that this is preferable to hogging all oversize pieces before storage."[11]

\begin{tabular}{|c|c|}
\hline \multicolumn{2}{|c|}{$\begin{array}{l}\text { CAPITAL COSTS FOR STORAGE } \\
\text { SYSTEMS }\end{array}$} \\
\hline Method & Cost/sq.ft. \\
\hline \multicolumn{2}{|l|}{ OPEN } \\
\hline on-ground & $\$ 0.00$ \\
\hline on-slab & $\$ 1.00$ \\
\hline \multicolumn{2}{|l|}{ COVERED } \\
\hline plastic, on-ground & $\$ 0.02$ \\
\hline plastic, on-slab & $\$ 1.02$ \\
\hline silo (without conveyors) & $\$ 1.60 /$ cu.ft. \\
\hline open shed & $\$ 5.50$ \\
\hline closed shed & $\$ 7.00$ \\
\hline air bag & $\$ 3.50$ \\
\hline * Source: Levi, M. and 0 & ly, M., 1980 \\
\hline
\end{tabular}

\section{APPROXIMATE COSTS OF WOOD FUEL STORAGE SHEDS [11, 1986]}

Floor Area ft2 Cost (\$/ft2)

\begin{tabular}{|ll}
\hline 1,000 & 7.50 \\
5,000 & 5.00 \\
30,000 & 3.50 \\
\hline
\end{tabular}

\section{Fuel Handling Equipment}

"Wood energy systems employ a wide range of conveying equipment, including front-end loaders; pneumatic, screw, belt, and drag/flight chain conveyors; and bucket elevators. Each 
type can be advantageous under certain conditions. Because wood is an acidic, abrasive material, all wood-handling equipment should be of very rugged design in order to avoid corrosion and prevent excessive maintenance outages, hindering acceptable operation of the wood energy system."[11]

\section{Front-end loaders}

"Front-end loaders are used in many wood energy systems to place wood in storage, retrieve it, and feed it into the system in-feed hopper. These front-end loaders should be equipped with oversized buckets for handling a large volume of low-density wood."[11] Approximate cost of such a front-end loader ranges from $\$ 19,500$ to $\$ 25,000\{1986\}$, depending on size \& type.

\section{Pneumatic conveyors}

"Pneumatic conveyors using high velocity air are well suited to conveying small particles of wood fuel such as sawdust, sander dust, finely hogged processed bark, etc. Pneumatic conveyors are the most economical systems that can be used to transport this type of wood fuel, especially over long distances. The energy requirements and the equipment wear of pneumatic conveyors increase significantly as the particle size of the fuel increases. "[11]

\section{Screw conveyors}

"Screw conveyors (augers) have two distinct advantages over other mechanical conveyors-they can convey up steep inclines, and they can meter the amount of fuel being conveyed. The metering capability makes them extremely useful in boiler fuel feed applications. The major disadvantage is cost. Screw conveyors also have difficulty in conveying stringy wood or wood fuel particles larger than 2 inches square." [11] "They experience high wear, may jam frequently and require frequent maintenance." [92]

\section{Belt conveyors}

"Belt conveyors are the least expensive fuel transport equipment and have the lowest energy requirement. The major drawback is that they should not be inclined more than 15 degrees due to spillback of the wood fuel."[11] "Belt conveyors have low operating and maintenance costs."[92] [However, cleated PVC conveyor belts are now available that offer superior wear, less friction, smooth surface interfaces to prevent fuel fiber snagging and dust buildup, and capacity to operate at steeper than $60^{\circ}$ angle.\}

\section{Drag or flight chain conveyors}

"Drag or flight chain conveyors can transport wood fuel up a steeper incline than belt conveyors. These conveyors are versatile and very rugged, and their operational energy requirement is relatively low. The primary use of chain conveyors is in live bottom equipment and in feeding fuel to the boiler stoking system. The cost of chain conveyors falls between that for belt and screw conveyors."[11] "Slopes up to $45^{\circ}$ can be accommodated, but the wear and energy requirements of the systems are greater than those of belt and bucket systems."[92]

\section{Bucket elevators}

"Bucket elevators are used to provide vertical lift, usually in areas of confined space. Their operational energy requirement is also relatively low, but they are very susceptible to wear."[11] "Bucket conveyors offer the most economical means of lifting materials vertically and will accept small pieces of wood fuel."[92]

\section{Oscillating conveyors}

"Oscillating conveyors move fuel by the upward and forward motion of the conveyor trough. They will accept a wide variety of wood fuels."[92] However, their power requirements are high for large surfaces, they require a rigid but light-weight \& freely suspended trough, and the noise level is very high. (The latest designs from one vendor are actually quite quiet and 
are operated with a relatively low power motor.\}

APPROXIMATE INSTALLED COSTS OF MECHANICAL CONVEYORS $[11,1986]$

Conveyor Type Capacity Cost/Linear Foot (ton/hr)

Screw
8 50

Drag Chain 8

50

Continuous Belt

Bucket Elevator

\section{8}

50
220

240

150

150

200

160
"The degree of automation depends mainly on boiler feed rate, capital money available, and existing labor rates. Additionally, an automatic feeding system can easily be more expensive than the boiler itself. Manually loaded systems are feasibie only with smali capacities (typically under $400,000 \mathrm{Btu} / \mathrm{hr}$ ), and fully automatic only with large capacities (typically over 1.5 MBtu/hr)."[11] (This has been a stumbling block until now.\}

\section{Screens}

Shaker screens, disc sizing equipment, and metal removing equipment are commonly needed for systems that can't handle non-uniform, contaminated (with rocks or pieces of metal) fuel. "This equipment has high maintenance characteristics and should not be included in the system design unless absolutely necessary. For smaller installations, the use of a wood fuel supplier may be more economical than purchasing screening and sizing equipment...As an additional safeguard, the combustion equipment selected for these applications must be capable of burning wood with a wide range of particle sizes."[11]

For smaller installations, such equipment is also cost-prohibitive. Disc screens are at least $\$ 21,000$ for a small, 20-ton/hr unit. A small shaker screen (10 ton/hr) starts at about $\$ 9,000$, excluding installation costs.[92, 1986]

Since no combustion equipment currently on the market can handle the wide variations in fuel type, as well as rocks $\&$ metal debris, that the Agni system can, small installations must often at present be limited to sites serviceable by a fuel broker who can guarantee such quality control. This has eliminated, until now, a large potential free fuel source, such as from tree-trimming businesses and small chipping operations that cannot afford to further process their waste.

\section{Canadian Fuel Feed Research}

B.C. Research has researched low-cost fuel handling systems and developed a couple of unique approaches at B.C. Research. Tests done on a variety of wood-derived biomass materials showed that a major problem with biomass is its enormous resistance to flowing over itself. If the hopper walls are not sufficiently steep or smooth, biomass can bridge over very wide openings. The discharge feeder is another common source of bridging and plugging problems. Most discharge feeders tend to feed primarily from the rear of the bin and consolidate or compact material against the front vertical wall of the bin. This consolidation often results in severe bridging of the material at the bin outlet. Stagnant material in the front part of the bin gains additional strength over time, particularly during freezing conditions, unless the storage system is periodically emptied. To solve these problems, B.C. Research developed a nonconsolidating feeder, which consists of a storage bin with the fuel resting on two wide belts on traveling rollers, with an opening in between the two belts for fuel to drop through onto a conveyor belt. The opening rolls along without moving the sections of belt that lie under the fuel, so low power is needed and the fuel is not compacted. This system requires at least two more belt feeders and must be located underground for direct loading from a chip van. 
They have also incorporated this principal into a low cost small drum feeder for residential applications. Another unique concept under investigation is a folding belt conveyor using a low cost fabric belt which folds up when loaded and travels inside a PVC pipe conduit. Materials costs are considerably less than a screw conveyor for the same distance. This system still needs to be perfected. [9B]

\section{Current Combustion Systems}

"Although the chemistry of combustion for wood is similar to that for fossil fuels, three unique characteristics of wood combustion must be considered in furnace design. First, the high moisture content of wood causes large volumes of superheated steam to be generated in the firebox and depresses the temperature of combustion. Secondly, depending on fuel quality, large amounts of excess air are required for combustion. Thirdly, combustion equipment that burns wood as a primary fuel must have a large furnace volume in order to provide sufficient fuel retention time for complete combustion of the wood fuel particles before they are carried out of the furnace by the hot flue gases. In addition, because of the higher moisture content of the wood, the combustion chamber must be lined with refractory to reflect heat back into the combustion chamber in order to sustain combustion."[11]

"Three basic types of direct combustion equipment are used in wood energy systems today--pile, suspension, and fluidized bed burning equipment. Pile burning equipment combusts the wood fuel in either a thinly spread pile or a heaped pile supported on a grate. Combustion air is provided both under the grate and above the fuel pile. Suspension combustion equipment burns dry wood fuel particles suspended in a turbulent air stream. Fluidized bed combustion equipment burns the wood fuel on a high-temperature bed of finely-divided inert material, such as sand, that is agitated by air blown from beneath the bed. Each type of combustion equipment has distinct advantages and disadvantages that encourage or limit their use in specific applications.

\section{Pile Burning Equipment - Dutch Oven}

"The Dutch oven furnace represents the oldest wood combustion technology available on the market today. This furnace burns wood fuel in a heaped pile supported by a grate...This arrangement was used extensively in large field erected boilers until the early 1950's. Modernized versions feature an inclined reciprocating grate where the wet fuel is dried before it enters the primary combustion chamber. The Dutch oven is an efficient method of burning wood fuel with a high moisture content. Sites with abundant green wood are ideal for the Dutch oven. It is, however, relatively insensitive to load changes because of the thermal inertia of the deep fuel pile and the massive refractory lining of the furnace. Another drawback is low combustion efficiency due, in part, to heat losses through the large furnace wall area.

\section{Conifer Furnace}

"A modern development of the Dutch oven furnace is the conifer furnace, also a deep pile burning furnace. The grate, however, has been divided into two sections--an inclined step grate and a flat floor grate. The wood fuel is gravity fed onto the top of the inclined step grate. As the fuel moves down the grate, the moisture content is driven off and combustion begins. Combustion is completed on the flat floor grate. The hot combustion gases exit the combustion chamber and pass through the boiler section to produce steam or hot water.

The conifer furnace is an improvement over the Dutch oven furnace in that the inclined step grate permits better distribution and control. This practically eliminates the formation of "blow holes" that can be a nagging problem caused by improper operation of a Dutch oven furnace. The relatively poor response to load swings, low turndown ratio (the lowest load at. which a 
boiler operates efficiently), and reduced overall combustion ratio of the Dutch oven furnace are also disadvantages of the conifer furnace. The conifer furnace, however, is a very good arrangement for burning poor quality fuels.

Northern Light has experimented extensively with the conifer design, and found two major flaws with this approach:

1. The lack of another set of grates on the hot side results in poor control over the conformation of the coal bed. A large charge of fuel can suddenly fall down, quenching the flame temperature or creating a too-rich gas mixture. Then it can burn through easily-creating too-lean combustion conditions before a new slug of fuel suddenly drops.

2. The flat horizontal grate rungs quickly collect ash and need to be cleaned off frequently. This design works best with clean sawdust or small, well sized chips, and quite poorly with stringy bark or sticks.

\section{Horizontal Return Tubular (HRT) Industrial Boiler}

"The wood-fired boiler most commonly used today is the !orizontal return tubular (HRT) industrial boiler. As late as the 1920's, the HRT was the standard industrial boiler, and today it is regaining much of its past popularity. About half of the boiler installations under 35,000 pounds per hour steaming capacity, and operating pressures up to $270 \mathrm{psi}$, are of this design."[11]

"The HRT is basically a fire tube boiler positioned horizontally above a refractory brick furnace that gives the needed large combustion volume. Fire tube boilers have straight tubes that are surrounded by water. The products of combustion pass through the tubes for heat transfer to the water. A typical HRT boiler is shown in Figure 5. The major advantages of this design are a lengthy history of successful service, relatively low capital cost, and easy low-cost maintenance characteristics. The major disadvantage is the relatively low combustion efficiency when burning wet or green wood fuel with varying particle size.

\section{Modified Firebox Industrial Boiler}

"A second type of boiler that is finding increased acceptance in wood-burning applications is the modified firebox boiler. This is a fire-tube design in which the upper portion of the refractory-lined combustion chamber is replaced with water walls. This substantially increases the heat transfer area, gives a more compact design, and is particularly suited to installations requiring up to 20,000 pounds per hour of saturated steam at pressures up to 125 psi. A typical modified firebox boiler is shown in Figure 6 . The primary disadvantage of this boiler is the inability to sustain combustion of wood fuel with a moisture content above 35 percent.

\section{Watertube Industrial Boiler}

"A third type of wood-fired industrial boiler is the water-tube boiler coupled to a waterwall furnace. These are boilers in which the tubes themselves contain steam or water, and the heat is applied to the outside surface of the tubes. This type of boiler has a tall firebox that allows sufficient retention time for complete mixing and combustion, and accommodates the fireside superheated steam resulting from burning wet or green wood fuel. It is used primarily in facilities requiring more than 20,000 pounds per hour or superheated steam at pressures above 125 psi. This type of boiler usually features char reinjection to prevent unburned carbon from exiting with the flue gases. A typical boiler of this type has a high capital cost and is suitable for only unusually large facilities.

\section{Suspension Burning Equipment}

"Small, dry (1/4-inch, 19-percent moisture, maximum) wood particles may be burned while suspended in a turbulent air stream. Compared to pile or grate burning, suspension burning improves overall combustion efficiency, \{as high as $80 \%$ [92]\} provides a more rapid response to 
load swings, and gives a higher turndown ratio (the lowest load at which a boiler operates efficiently)." [11]

"When the wood fuel being burned in suspension contains wood flour or sander dust, the burner must be equipped with a flame safeguard system because this dry, finely divided wood is highly explosive. In addition, very close control of the combustion air system is essential because the amount and turbulence of excess air can produce disproportionate effects on the completeness of combustion of the fuel in suspension. The optimum amount of excess air will range from 15 to $50 \%$, depending on the moisture content and particle size of the fuel being burned." [11]

"Suspension burning equipment may be of the injection type or the external direct-fired type. The primary disadvantages of suspension burning equipment are the inability to burn wet or green wood, the high cost, and the difficult maintenance characteristics of the burners." [11]

\section{Injection Suspension Burning}

"With this system, impellers and turning vanes ensure violent turbulence and thorough mixing of the air and wood fuel particles. The air-fuel mixture is injected into the furnace combustion chamber where ignition and combustion occur. This type of suspension burning may be accomplished independently or in conjunction with grate burning.

A good example of state-of-the-art injection suspension burning is the HL Power Project in Wendel, CA, a 29 Megawatt electric generating plant burning 6,250 Bone Dry Tons of wood chips daily. The plant personnel are very selective of the sizing, cleanliness and moisture content of the fuel they burn. Below 39\% moisture they experience slagging problems, and above $43 \%$ moisture incomplete combustion and higher emissions become a problem. Because of the high turbulence and induced draft, $90 \%$ of the ash is sent through the boiler, causing continual abrasion of the boiler, leaving mostly rocks and metal as bottom ash. Most of the ash is eventually precipitated out in the multicyclones and electrostatic precipitator. Continual vigilance is required to keep emissions below the state-mandated limit of $0.1 \mathrm{lb} / \mathrm{MBtu}$. $28 \%-30 \%$ of the fly ash is unburned carbon, and Carbon Monoxide emissions average $600 \mathrm{ppm}$. [Information obtained from a personal tour of the facilities, from Ralph Sanders, Plant Manager.] \{Compare these figures with Helen's emissions - $0.007 \mathrm{lb} / \mathrm{MBtu}$ particulate $(14$ times) and 4 ppm (150 times).\}

\section{External Direct-Fired Suspension Burning}

"In this system, complete combustion of the wood fuel takes place in a vortex created in the refractory-lined combustion chamber. The hot combustion gases are injected into the furnace combustion chamber. This type of suspension burning equipment is well suited to modification applications that allow wood fuel to be used with conventional energy systems.

\section{Fluidized Bed Combustion Equipment}

"The fluidized bed is a relatively new development in combustion techniques for wood and other solid fuels. The furnace grate supports a bed of finely divided inert material (sand, limestone, etc.) that is fluidized by air blown through it from the bottom. An auxiliary fuel is first used to heat the bed to approximately $1400^{\circ} \mathrm{F}$. The auxiliary fuel is then shut off, and the wood fuel is dumped onto the bed. The high temperature of the bed causes the volatiles in the wood fuel to flash-evaporate and burn. The remaining char is oxidized in the bed. The fluid motion of the bed serves two purposes--it helps disperse the fuel particles and continually removes char, thereby exposing more carbon for combustion. The fluidized bed furnace is more suitable for use in large industrial energy systems than in small space heating applications. I requires huge, high-powered fans and an elaborate gas-scrubbing system to remove the very high levels of fly-ash.\} 


\section{Hot Air Furnace}

"Many space heating applications do not require steam or hot water. Instead a woodburning hot air furnace may be used. Several different types of woodburning furnaces are available today. Each type of furnace has a firebox, a heat exchanger section, a blower and ductwork system, and a control system. The type of furnace selected for a specific application depends on the same factors that influence the selection of a boiler firebox - primarily fuel quality and particle size."[11]

"Woodburning furnaces can be highly automated or entirely manually controlled and stoked. Smaller systems that are used intermittently are generally manually fired and controlled. Larger system that call for large quantities of fuel are usually highly automated. A primary decision factor is the cost of labor compared to additional equipment costs. In areas where labor costs are high, the furnace will probably be more highly automated than in areas with lower labor costs. "[11]

"Woodburning hot air furnaces are available in sizes up to 60 million Btu per hour output and are fabricated by several different manufacturers. When properly designed, these furnaces are capable of attaining combustion efficiencies as high as 86 percent. Flue gas temperatures may reach $230^{\circ} \mathrm{F}$, depending on the moisture content of the wood fuel and the quantity of excess air. Some furnaces can operate with excess air as low as 15 percent. \{Compare with Helen's 99.9\% combustion efficiency with flue gas temperature of $95^{\circ} \mathrm{F}$, and Vaagner's $0.5 \%$ excess air.\}

\section{Wood Gasifier}

"Gasification is a special case of wood combustion in which a gasifier vessel is filled with wood chips, and a small fire is started on a grate above the ash hopper. Enough air is introduced into the unit to support a glowing bed of coals, but most of the evolved hydrocarbon gases are not ignited. These gases are drawn off and can be stored or piped into a burner for final combustion."[11]

"There are different types of gasifiers, just as there are different methods for burning bio-fuels. The most common types of gasifiers are updraft, downdraft and fluidized bed gasifiers. "[11]

"Wood gasifiers can be as small as 60,000 Btu per hour and as large as 80 million Btu per hour. The maximum thermal output will depend primarily on the gasifier design. The downdraft and crossdraft designs function with a relatively small, high temperature reduction zone. While this reduces the output of problem-causing tars, it also limits the size of the unit since blow holes and cold spots will form in the reduction zone. The maximum output of these designs is limited to about 25 million Btu per hour. Updraft and fluidized bed gasifiers, on the other hand, can be much larger. They do, however, produce a higher percentage of tars which can plug piping and foul burners."[11]

"The overall combustion efficiency of the gasification process may be as high as 90 percent in close-coupled operations that can take advantage of the sensible heat of the wood gas. This type of system, however, does not incorporate tar removal equipment, and this can result in problems. Removal of the tars requires that the gas be cooled sufficiently for them to condense. This decreases the overall combustion efficiency of the system."[11]

"Wood gasifiers are well suited to retrofit applications where an existing gas boiler is modified to burn the wood gas. However, the problems associated with operation of the system and wood tars make wood gasifiers more suited to large industrial systems which operate at or near maximum capacity for extended periods. Wood gasifiers are not recommended for use at commercial sites." [11]

\section{Future Potential of Gasifiers}

The concentric shell ceramic heat exchanger design of the Vaagner system is ideally suited for modification to create a superior stand-alone gasifier for internal-combustion engines and 
other retrofit applications. Several unique features hold great promise for solving some of the fundamental problems with wood gasification:

1. the unlimited potential for preheating the primary pyrolysis air through concentric shelled ceramic heat-exchangers

2. a large, evenly heated, primarily endothermic primary pyrolysis zone to prevent ash slagging with agricultural residues and other problem fuels, and to effect an extremely low ash and organic impurity level in the evolved gases

3. the very large, even and hot secondary reaction zone to allow the complete breakdown of tars and optimizing the water-gas reaction

4. the efficient condensing heat exchanger to cool and remove the steam from the producer gas and recirculate the heat back into the pyrolysis reaction.

\section{Efficiency}

"Typically, the best boiler efficiency achievable with green wood fuels is $65 \%$. Marginal increases above a $40 \%$ moisture content result in significant decreases in efficiency...Predrying (of fuel) can yield flame temperatures of $1800^{\circ} \mathrm{F}$ for green wood and $2300^{\circ} \mathrm{F}$ to $2500^{\circ} \mathrm{F}$ for dry wood, increasing overall boiler efficiency $5 \%$ to $10 \%$. Boiler efficiencies of $76 \%$ are achievable with dry wood." [92]

\begin{tabular}{|c|c|}
\hline \multicolumn{2}{|c|}{$\begin{array}{l}\text { Approximate efficiencies for well } \\
\text { maintained and efficiently operated systems are } \\
{[94 \mathrm{~A}] \text { : }}\end{array}$} \\
\hline oil. & $80 \%$ \\
\hline coal & $80 \%$ \\
\hline natural gas. & $78 \%$ \\
\hline 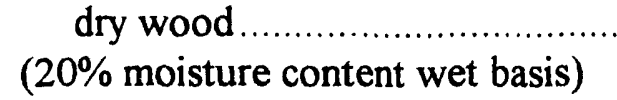 & $77 \%$ \\
\hline $\begin{array}{l}\text { green wood } \ldots \ldots \ldots \ldots \ldots \ldots \ldots \ldots \ldots \ldots \ldots \ldots \\
(50 \% \text { moisture content wet basis })\end{array}$ & $67 \%$ \\
\hline MSW. & $60 \%$ \\
\hline
\end{tabular}

"Biomass combustion efficiency is influenced by various other fuel and air-related parameters. Consequently, wood-fired boilers are generally rated at $67-72 \%$ combustion efficiency." $[14$, 1989]

"The cost of heat from the boiler is also affected by the boiler efficiency. This varies depending on boiler type, size, and wood fuel moisture content. Generally, the efficiency is higher with larger boilers and lower with smaller boilers. Seasonal efficiency is also considerably lower than peak load efficiency. "[11]

All three of these rules are broken with the AGNI boiler. By condensing the moisture back out of the flue gases, overall efficiencies of over $90 \%$ are achieved from wet fuels as well as dry, and the highest efficiencies are obtained at low burn, when the heat-exchanger is operating at optimum efficiency. An efficiency of $90 \%$ compared with $67 \%$ means that one is getting a third more heat for the money. It is like paying \$15/ton for hog fuel, while a competing system has to pay \$20/ton. This factor alone significantly changes the economics of biomass energy.

"Approximately 1500 to 2000 Btus are expended per pound of water removed from the fuel. From $5 \%$ to $10 \%$ of the fuel being processed must be burned to obtain the energy used to dry it. Thermal drying systems are most often used when dry fuel is a necessity, as is the case with suspension burners where particulate matter is burned in an air stream, or where large, existing burners cannot meet rated capacities with wet fuels. Rarely are thermal drying systems capable of producing savings that warrant their use with new combustion systems designed to burn green wood. [92]

Retrofitted coal-designed boilers usually undergo a derating of from $10 \%$ to $50 \%$, because 
of the higher moisture content and lower Btu content of wood.[92]

"Proven technologies (especially combustion technologies) are available for almost all of the subsystems required to use wood as a fuel after it is delivered to the user...Proven systems engineering approaches for designing complete, effective, and trouble-free systems are not widely used, especially for integrating the various pieces of equipment at the wood burning site needed for handling the fuel before it is burned. Also improved design approaches may be needed for matching various types of combustion chambers, e.g. suspension burners, Dutch ovens, moving grates, etc., to the most appropriate means of pollution control, e.g., electrostatic precipitators, bag houses, wet scrubbers, etc.

One possible reason for deficiencies may be that much of the design work for wood burning systems has been done to date by boiler manufacturers who gained most of their experience with coal, natural gas, or oil but not with wood." $[14,1989]$

\section{Turn-Down Ratio}

"Biomass systems perform very inefiriciently when operated at less than $25 \%$ of rated capacity. The size of the energy system selected should be based on the unit rating that can supply the greatest amount of needed energy annually and this may be less than the maximum calculated load. In some cases, it is desirable to design the system so that it handles no more than one-half to two-thirds of the calculated design load, provided a suitable back up system exists."[11]

\section{\{The Agni system is a radical breakthrough on this front, having a turndown ratio of 14 to 1 with green fuels, and even more with dry.\}}

\section{System Features}

The following is a detailed explanation of available burner/boiler types and their strengths \& weaknesses, taken mostly from the Biomass Design Manual - Industrial Size Systems. [11, 1986]

\section{Furnace}

"The furnace (space under or adjacent to burner where the fuel is burned) is a major design concern for successful boiler operation. The methods of fuel feeding and distribution to the furnace as well as the grate type are available in many designs. Sizing, moisture content, age and species of wood affect which type of fuel feed and combustion method are best suited for an application.

Smaller plants using firetube or watertube steam boilers use furnaces such as the Dutch oven, fuel cell, air-cooled stationary and dump grates, water-cooled stationary grates, and fluidized beds. The Dutch oven, which uses stationary grates, is usually only installed when extremely wet (60 percent moisture or more), unsized bark must be burned in an area where stack emissions are a major concern. In some mid to large size applications a forefurnace can be used in front of the boiler. The combustible gases from the forefurnace are then passed into the main furnace. This produces lower emissions as there is greater retention time in the furnace for more complete combustion. (This is the configuration of the AGNI design?

Refractory lined fuel cells with a watercooled cast iron grate or refractory floor, can be used to burn hogged wood wastes containing up to 50 percent moisture. More sophisticated versions of the fuel cell - the cyclone furnace and the wet cell burner - are other alternatives for burning high moisture wood waste.

Inclined grates and stationary grates with different slopes are also used in furnaces for burning fuel with high moisture content. TThe Agni grate system has taken this concept to the limit, with almost vertical slopes on both sides 
of the fuel, a unique approach that maintains a very stable fuel delivery?

Grates with different operating characteristics are used for different sizes of boilers. Stationary, sloped, and intermittent dumping grates are commonly used with boilers that produce up to $100,000 \mathrm{lb} / \mathrm{hr}$ steam.

Spreader-stokers are physically smaller than Dutch ovens but have an equivalent steam generation capacity. They generally have a limited amount of refractory, thereby lowering the cost of maintenance. Required maintenance involves ash removal, which depends on the grate used.

Grates must withstand high temperatures and should expand and contract without buckling, warping, or opening large gaps. They should be designed to remove or permit removal of noncombustible ash on a regular basis with minimum physical labor.

Removal of non-combustible ash should be a major design consideration. The grate system should allow ash removal on a systematic basis with minimum disruption to combustion and minimum entrainments in the exhaust stream. The system should be designed to accommodate the maximum expected rate of ash input. [Agni's water-cooled ceramic grates do not warp, and the fully automated ash removal system can be set to remove ash at any rate, even programmed to automatically detect ash buildup.\}

Ash is removed from grates in a number of ways:

* manually raked grates

* dumping grates

* air or steam swept grates

* reciprocating grates

* traveling grates

* $\quad$ GAGNI uses a unique ash rake to remove ashes from under the stationary grates without disruption to the coal bed or thermal shocking of the ceramic.\}

Traveling, reciprocating grates, and air swept grates offer the advantage of continuous or intermittent ash removal without manual labor and with minimum disruption of the combustion process.

Problems from high grate temperatures can be limited to some extent by not burning fuels with extremely low moisture levels and by using cool (ambient temperature) underfire air. Water cooled grates are a well demonstrated technology that can lower grate temperatures. The disadvantages are costs. \{AGNI's watercooled grates are not expensive because they are non-moving. Their cooling capacity can also be adjusted by changing the insulating properties of the surrounding ceramic shell.\}

Stationary grates maintain a 1 inch to a 2 inch fuel bed and are the least expensive to install. They are usually cooled by water flowing through the pipes that support the individual grate sections. When ashes are removed, the feed to the boiler is halted, causing a loss of steam production capacity. The ashes are then either manually removed by rakes or removed by an automatic dump grate. The cleaning operation can cause refractory damage by thermal shock as cold air rushes through the door.

Refractory grates are limited to fixed grate designs but have the advantage of providing energy to the fuel pile, therefore, assisting in the combustion of high moisture-level fuels. Problems include slagging, limited life, and ash removal.

Intermittent dumping grates perform a selfcleaning process that drops ashes into a pit. The dumping is performed by grate rotation. Traveling grates normally operate on continuous cycle.

Traveling grates are used in larger boilers because of their greater degree of automation and higher cost. Traveling grates provide good air distribution over the grate area. When used in suspension burning, these grates permit high heat release rates.

Wood waste fuel should be distributed in a blanket of uniform thickness over the entire grate surface. If the fuel pile thickness varies over the 
grate, the airflow through the grate cannot provide uniform air/fuel ratios.

Sizing, moisture content, age, and species of wood can influence the type of fuel distributor best suited for a specific situation. Any feeder must provide a constant and equally distributed supply of fuel and must be responsive to changes in boiler load demands.

Uniform distribution includes both vertical and horizontal placement. For uniform left-right distribution, the ideal system, located on the front end of the boiler, should include numerous fuel chutes at the closest practical spacing. The fuel distribution from front to back depends heavily on uniform size and density. Vertical placement should be as close to the grate as possible (to keep particle entrainment in the exhaust low) while still allowing the fuel trajectory to reach the back of the grate.

Both types of fuel distributors, mechanical and pneumatic, have advantages and disadvantages. Pneumatic systems can achieve more uniform fuel distribution from front to back than can mechanical. But pneumatic distributors can upset the distribution of combustion air over the grate by supplying a large amount of overfire air near the front end of the boiler. They can also make it difficult to meet turndown requirements associated with fluctuating heat demand.

On the other hand, mechanical fuel distributors are not hampered by boiler turndown and changes in combustion airflow. However, they might not distribute fuel fines and large particles uniformly over the grate in industrialsize boilers.

Various kinds of pneumatic air swept feeders are available. They have the lowest initial cost, handle the broadest range of fuel size, and are reliable with lower maintenance costs than mechanical feeders. (The Northern Light grate system solves virtually all of the problems mentioned above, and more, with a very simple stationary refractory design.\}

The furnace volume will be a function of the heat required at a given time and the permissible heat release per unit volume. The heat release rate depends on the type a.d construction of the furnace as well as flame length, flame temperature, ash fusion temperature, method of firing, amount of excess air, and turbulence. The ratio of heat release to grate area varies with the furnace design and the fuel's moisture content. A typical design limit for a traveling grate type boiler with a pneumatic spreader is $1,000,000$ $\mathrm{Btu} / \mathrm{hr} \mathrm{ft}^{2}$ of grate area, using fuels with a moisture content of 50 percent.

The 1.5 MBtu AGNI design has a grate area over 3 times this figure, which is a key ingredient in maximizing drying of wet fuels, reducing slagging from heat concentration, increased pyrolysis residence time, and minimizing turbulent particulate entrainment that causes boiler tube fouling and high emission levels.

As mentioned, the type of fuel, particularly the moisture content, has a critical impact on furnace operation. To successfully burn green or wet wood, for example, there must be a refractory lined combustion chamber, which helps in increasing the combustion temperature. The refractory combustion chamber and the flue stack will have a larger volume than is required for burning dry wood only. Likewise, suspension systems usually require dry wood.

"In burning wood a flame collapse phenomenon begins to appear as an instability at approximately $60 \%$ moisture, which will move toward total flame collapse at levels somewhat over $65 \%$. Most of the energy wood will average $50 \%$ on the stump which gives the user little operational room during periods of high precipitation."[10] 
I have not heard of any existing system, including the latest fluidized bed combustor, capable of burning fuel with over $66 \%$ moisture. In contrast, Vaagner has burned $70 \%$ moisture hogged fuel very cleanly, and with modifications to the grate design, Agni should be capable of sustaining clean conbustion with fuels over $70 \%$ moisture.

In addition, the heat release rate requirements for a furnace vary with fuel type. The rates are generally more restrictive for hog fuel than the design parameters are for cleaner burning fuels, such as sander dust. In some cases the heat release rates for cleaner burning fuels approach the rates and the tube bank velocities allowed for oil-fired units.

In the Northern Light systems, because there is minimal ash carryover into the boiler, because excess air is kept to a constant minimum by the microprocessor controls and gas temperatures are optimized by the feedback heat-exchanger design, and due to the unique gravity stratified counterflow condensing heat-exchanger employed in the Agni boiler, heat release rates are optimized for a wide variety of fuel moisture and type.

The most desirable situation is to design the furnace for flexibility in the use of fuels not orly for economic considerations, but also for emergency situations that may require a change from one fuel type to another. For example, situations may arise where a commercial facility may not be able to depend on obtaining dry material and may have to rely on fuel with higher moisture content. In such a case, if the furnace/boiler cannot accommodate this change, efficiency could be greatly impaired.

In summary, in selecting the best alternative, the designer must select a furnace with suitable burners, grates, and heat release rates. It is also desirable to select a furnace that can function with fuels that have undesirable characteristics (flexibility). The flexibility for burning fuels with varying properties in the same furnace is, however, much more difficult to obtain than normally anticipated. The best flexibility is obtained by the fluidized bed furnace, but variations in properties of the planned fuels must be considered during the design of the fluidized bed furnace. [11]

"The important design aspects are:

sizing of stack and flue gas path that is capable of passing wet fuel as well

- cooling of grate to avoid ash melting when dry fuel is used

- adequate under grate and above grate air controls to handle dry as well as wet fuels and to meet emission standards

- good mixing of supply air in the combustion chamber

These furnace alternatives, in turn, must be analyzed with respect to the boiler because the materials, design size, and shape of the boiler firebox will affect the combustion efficiency and the lifetime of the boiler

\section{Boilers}

"Even a brief review of the literature on the boiler furnace is sufficient to show that there does not now exist a complete analysis of this complex system involving large mechanical components and the interaction of thermodynamic, fluid flow and heat transfer considerations." "Much theoretical and experimental work has been done to elucidate the fundamental problems related to the design of boiler furnaces. This work, however, has been hampered by the great difficulty in isolating the individual processes that are related to combustion and heat transfer. To those familiar with the problems of furnace design it is apparent that the prediction of furnace heat absorption has not yet been resolved to a fundamental basis nor to clearly rational methods of calculation." [Combustion Engineering, Edited by Glenn $\mathbf{R}$. Fryling, M.E.] 
The major component of any installation is the boiler. Its prime finction is to provide a means for transferring the heat of combustion to the water (or steam) to be heated. The heat from the steam is then transferred to the facility's distribution system.

The designer must select a boiler with the best heating surface to meet the space limitations and arrangements required by the furnace. The circulation of steam and water within the boiler will control the effectiveness of heat transfer and therefore musi be as trouble-free as possible. Provisions must be made for convenient chemical or mechanical tube cleaning, soot blowing, and washing of air heater surfaces. For example, in cleaning of the boiler, access doors allowing checking and sweeping of fireboxes and firetubes are necessary. Locking mechanisms must be provided for the doors and should be such that, despite changes in the properties of the door sealings, the doors can be shut tightly. Also the design of a good and easy to operate ash removal system is of great importance.

As mentioned in previous sections of this manual, the size of the boiler and its components are based on selected and specified steam pressures and steam generating rates (desired capacity). If operated within design limits, in terms of both steam pressures and steam generating rat-s, the system will work as an integrated and functional unit. If operated outside of the design specifications, it is possible, perhaps probable, that some component of the system will cease to perform as intended. As an example, when boilers are substantially over designed and then operated at steam production levels below 25 Percent of the rated capacity, the following problems are common:

- Frequent "blue haze" emissions due to the low combustion rate and incomplete combustion of volatiles-unburned flue gases leave the boiler and condense to form particles (The Northern Light burner can be turned down below 10\% of rated capacity and maintain optimum combustion conditions with no visible stack emissions\}
- Slow response time of the boiler when steam demand increases because of the low firing rate of the fuel and low furnace temperature \{Totally isolating the combustion zone from the boiler in the Northern Light design prevents cooling of the refractory and combustion gases when the system is turned down. By automatic diversion of the hot gases through the bypass damper to increase the natural draft, very quick response to heat demands can be achieved,

- Corrosion in the exhaust gas handling systems because at low gas flow rates the water vapor in the gases has the opportunity to condense on cool surfaces within the boiler BBecause the Agni boiler is made with stainless steel, is designed for condensing, and produces only mildly acidic condensate due to very thorough combustion, corrosion is not a problem,

- Poor thermal efficiency due to high excess air requirement for complete combustion. BBecause preheated air temperature is kept hot when the Northern Light system is turned down, excess air can be kept very low and thermal efficiency is actually highest at very low burn rates in the gravity-stratified heat-exchanger.\}

Two general configurations are used in heating the water in a boiler. In the firetube design, gases pass through tubes in the pressure vessel and transfer heat to water that circulates around the exterior of the tubes. In watertube boilers, the water (and steam) is inside the tubes, and the hot combustior gases are in contact with the outer tube surface. With this design higher pressure and boilar efficiency can be achieved at a reasonable cost. Firetube boilers are more economical in the small steam production range.

Thire are many applications where the firetube design has advantages over a watertube unit, particularly in light and medium industrial environments. The firetube boiler can be cheaper to purchase initially and cheaper with respect to routine maintenance, particularly water treatment.

Of the firetube boilers, one of the most economical choices below $1000 \mathrm{hn}(34,500 \mathrm{lb} / \mathrm{hr})$ 
is the HRT boiler discussed in previous sections of this manual. These boilers are gererally designed for pressures below 25 psig. The design includes refractory side walls and a large combustion volume - both desirable in burning green wood. The limitations of the firetube boiler are in the 20,000 to $40,000 \mathrm{Jb} / \mathrm{hr}$ range at pressures exceeding $30 \mathrm{psi}$. The firebox tube boiler is also useful for generation of low pressure steam for space heating. Similar to the $\mathrm{HRT}$, but with the addition of waterwalls, the upper limit of the firebox type is $20,000 \mathrm{lbs}$ steam per hour with a maximum of 125 psig.

Larger steam capacities are better handled with a watertube construction pressure above $250 \mathrm{psig}$ or steam output above $50,000 \mathrm{lbs}$, which can produce high pressure and superheated steam. Table 19 shows various heat demand suitability to these boilers.
BOILERS, CAPACITY, \& PRESSURE

Pressure

Size psi

HRT 100-1000 hp Up to 250

Firebox $\quad 1000-20,000 \mathrm{pph} \quad$ Up to 125

Watertube 20,000 pph up 125 and up

Source: TVA, Wood Energy Systems.

"As mentioned, regardless of the boiler type, the necessary design ingredient is to have a relatively large combustion chamber lined with refractory. This is particularly true for green wood. For dry wood, the need for refractory is lessened but not usually eliminated.

"It should be noted that the least expensive boilers are generally the ones with the least flexibility with regard to quality of fuel, i.e., moisture content, size, etc., that may be burned. Thus, costs should be weighed against flexibility when selecting a boiler design.

\section{COMBUSTION PARAMETERS AND THERMAL EFFICIENCY}

\begin{tabular}{|llll|}
\hline Combustion Parameter & Units & $\begin{array}{c}\text { Boiler Efficiency } \\
\text { Range (\%) }\end{array}$ & $\begin{array}{c}\text { Change in Boiler } \\
\text { Efficiency (\%) }\end{array}$ \\
fuel moisture & $\%$ wet basis & $57.6-75.9$ & 18.3 \\
combustion air temp. & $\%$ F & $68.1-81.0$ & 12.9 \\
exhaust gas temp. & $\%$ F & $61.9-71.9$ & 10.0 \\
excess air level & $\%$ & $63.7-70.2$ & 6.5 \\
boiler drum blowdown & $\%$ & $68.0-68.9$ & 0.9 \\
unburned carbon in ash & $\%$ & $67.0-69.0$ & 2.0 \\
Combustibles in flue gas & $\%$ & $68.0-70.0$ & 2.0 \\
\hline
\end{tabular}

Source: Adapted from Junge, D.,1982 and EKONO Envineers, Inc., 1985."[11]

To indicate how combustion variables, including fuel, have an impact on design, Table 20 has been included to show how some of the combustion variables for design consideration influence boiler thermal efficiency. It is important to note the difference in thermal and combustion efficiency. Thermal efficiency is defined as the amount of heat energy that is 
added to the water in the boiler and expressed as a percentage of the total heat energy of the fuel entering the boiler during the same time interval. The amount of energy added to the boiler water is measured in Btu per pound of water (Btu/b) and differs from combustion efficiency. Combustion efficiency refers to the degree to which fuel burns completely.

\section{Draft}

\section{Stacks and Fans}

In order to sustain combustion, it is necessary to supply air and remove the products of combustion. This flow of air in and combustion products out is caused by a difference in pressure between the furnace and boiler exit known as the draft. The draft may be:

* natural chimney draft or supply air fan for small boilers

* induced draft by fan in the stack for small and medium sized boilers

* supply air and induced draft fans for large boilers

(Except for the smallest boilers, positive or balanced draft is provided and supplemented with fans).

Natural draft is not just a phenomenon of exhaust gas temperature and chimney height. It is assisted or retarded at every point in the system where air or gas changes temperature. The Northern Light systems are meticulously designed to optimize internal draft throughout all flow channels, thereby allowing balanced gas flow and quick response time with low stack draft conditions, without the crude and costly addition of an induced draft fan and their consequent problems associated with power outages.

For proper draft, every boiler should have its own stack. The height of the stack depends on the system capacity and layout and should provide enough draft to the boiler. If the boiler is connected to a feeding silo or a chute, the height of the stack has to be measured from the top of the silo. The stack should be tall enough to avoid down wash of flue gases in the wake or other eddy effects of the nearby buildings. The stack has to be so designed and constructed that combustion gases and excess air flow out in all weather and operating conditions. If the boiler is designed for natural draft, the stack has to provide draft through the boiler also. If the boiler is equipped with an induced combustion draft fan, the stack can be smaller. The driving force in the stack is the difference in gas densities due to temperature differences between outdoors and the stack. The pressure difference created by the stack has to overcome pressure losses in the combustion air system, grate, boiler, stack, and outflow from the stack. The velocity of the flue gases at the top of the stack has to be high enough to overcome wind or weather conditions. It should be noted that flue gas volume in wood burning is usually higher than in fossil fuel burning. Also, higher excess air factors (for combustion) are used in wood-fired boilers.

The stack can be constructed from masonry or steel. A steel stack should be insulated so that flue gas temperatures are kept above $175^{\circ} \mathrm{F}$ $\left(180^{\circ} \mathrm{C}\right)$ \{sic!\} at discharge. This helps to maintain the adequate flue gas velocity in the stack and reduces the possibility of creosore formation on the stack surfaces.

Forced draft air fans push combustion air into the furnace. More than one draft fan may be used on a boiler and it is common to have one fan supply under grate air at a moderate pressure, and a second fan to supply high pressure air for overfire use and pneumatic use.

Induced draft fans draw the gaseous combustion products out of the boiler. Most wood-fired boilers are equipped with a single induced draft fan. The operation of the forcedand induced-draft fans affect the air related combustion parameters, including:

* level of excess air

* temperature of the combustion air

* distribution of combustion air 
* turbulence in the furnace

Therefore, the fan systems must be properly designed, installed, and operated. The design criteria are as follows:

* Fans must be coordinated to maintain furnace pressures at a slightly negative level

* Fans must provide combustion air at a rate that keeps the level of excess air in the furnace at a reasonable range, even though the fuel characteristics and steam generation rates may change dramatically

* Pneumatic air supply for fuel distribution should be controlled to supply a uniform distribution of fuel

* Overfire air should be injected with sufficient velocity to bring about turbulent mixing with the volatile, combustible gases

In order to meet these criteria, the fans should be equipped with calibrated, automatic controls. Not all wood-fired boilers are equipped with balanced, automated forced draft and induced draft systems. Others use natural draft from stacks rather than a controlled induced draft system. There is some difference of opinion about whether such stacks can provide good control of the combustion process throughout the full generating range of the boiler. $\{N L$ systems are designed to maintain BETTER control of the combustion process than possible with induced draft.

\section{Boiler and Combustion Controls}

Wood-fired boilers and furnaces require more space than fossil fuel fired ones, and it is generally more feasible to use one central unit than several smaller local units. No matter how well designed a boiler (or series of boilers) is, without the proper ratios of fuel and combustion air for a given load there will $b$, poor combustion efficiency. these, in turn, lead to lower boiler thermal efficiency and high particulate emissions.

For highest efficiency, complete control over combustion processes must be maintained. Such control is based on the quantity of carbon dioxide, carbon monoxide, or oxygen in the flue gas. Proper air distribution (overfire and underfire), proper excess air levels (as low as possible while maintaining stable and complete burning), and elimination of air leaks into the combustion system, can greatly improve efficiency. Underfire air supply is highly important in controlling the combustion process in spreader-stoker boilers. Since about 75 Percent of the fuel supplied to the furnace burns in the gaseous state and only about 25 Percent burns as fixed carbon char, more complete combustion occurs when larger quantities of air are supplied over the fuel bed to burn the rising volatile gases. Only enough air should be provided as underfire air to burn the carbon char on the grate. Besides being introduced at the proper flow rates, the underfire air must also be distributed uniformly across the entire surface of the grate throughout the full steam generating range of the boiler.

Steam boilers must have a steam pressure gauge; hot water boilers must have a pressure gauge and a thermometer. Other instrumentation may include a makeup water meter, steam flow meter, flue gas thermometer, $\mathrm{O}_{2}$-analyzer, and other recording or indicating instruments.

Large installations have a variety of automatic controls (for economizers, feedwater treatment and heater, desuperheater and air heater) as well as steam pressure and temperature controls. They also have flow controls for the forced draft and induced draft fans.

Boiler combustion controls have two main functions: (1) to maintain constant boiler pressure or temperature, and (2) to maintain the proper combustion air to fuel ratio. In general, control systems can be classified as either "open loop" or "closed loop". An example of an "open. loop" system would be to use a calibration curve of the fuel value setting versus steam demand to set the firing rate. Measured output would not be used to adjust this firing rate. While these open loop systems are stable and simple, they are not dependable because wear and fouling cause 
changes in the calibration. Also changes in fuel quality affect the calibration curve strongly.

In contrast, the output of a closed loop system is used to adjust for changes in calibration and for boiler control, and provides a feedback system. In simplest terms, in such a system there is a controller that receives information from set point values for steam pressure, flow, temperature, fuel flow, air flow, etc. The controller also receives feedback indicating the actual instantaneous output values of the setpoint parameters. The controller processes signals and produces activating signal(s) to set fuel flow and air flow. Each activating signal produced by a controller in a closed loop mode is obtained by comparing the set point and feedback signals relative to the desired activation.

"If all conditions were perfect, the activating signals would result in the correct air to fuel ratio and firing rate. However, there, are many disturbances which result in the need for feedback. Disturbances include fuel property changes, air property changes, fouled and dirty burners, etc."

Feedback information can be divided into two categories:

1. information to aid in setting the fuel firing rate

2. information to aid in setting the air/fuel ratio

"All closed loop boiler control systems incorporate feedback of the first type. Only more sophisticated systems include the second type." \{The Northern Light controls go well beyond this level of sophistication.

"Various types of positioning and metering systems are available for control. Performance and cost are the two main criterion for selection."

In terms of performance, the two major considerations are:

1. At a given firing rate, how closely can the system control $\mathrm{O}_{2}$ (excess air)?
2. As the firing rate varies, how much variation is allowed between the actual mean $\mathrm{O}_{2}$ and the desired value?

"Significant savings can be achieved if a sophisticated control system can minimize the variation in $\mathrm{O}_{2}$ (excess air) at a given load. More money can be saved if the control system keeps $\mathrm{O}_{2}$ close to the desired value as the firing rate varies. BBoth of these control features are optimized in the Northern Light control system.\} However, caution should be taken in matching the sophistication of the control system to that of the boiler as a whole. A match should be made between the best that a given control system can achieve and the best that the proposed system can achieve."

"Due to the low levels of $\mathrm{SO}_{2} \& \mathrm{NOx}$ products associated with the whole tree burner, the flue gas condensate can actually become basic. thus, it is prudent to install waste heat recovery equipment to bring the exhaust gas temperatures down to as low as $150^{\circ} \mathrm{F}$, resulting in increased plant efficiency." [Biologue, Dec '88/Jan '89, "The Whole Tree Burner: A New Technology In Power Generation"]

\section{Small-Scale Cogeneration}

Steam turbines are generally used for biomass-fueled cogeneration, but they are generally too expensive for systems under 10 $\mathrm{MBtu} / \mathrm{hr}$. Hot gas turbines are cheaper and less complex, not requiring the high-pressure steam. But particulates in the gas from biomass combustion pose formidable problems with gas turbines. [16A] compares several systems. The smallest one, a $3 \mathrm{MW}$ Allison $501-\mathrm{K}$, is of interest for possible future cogeneration applications. With natural gas it produces 3.3 MW Elec. @ 24\% HHV efficiency and 9,850 lb steam@55.9\% HHV efficiency in a combined cogeneration cycle, or 5.5 MW elect@35\% HHV efficiency for power only. With biomass it was less efficient, because of the lower than optimum gas inlet temperature of $1454^{\circ} \mathrm{F}$, due to solids deposits on turbine blades (the turbine is rated at $\left.1796^{\circ} \mathrm{F}\right)$. The article concludes: 
"Directly-fired systems would be inherently more efficient than other options because the intermediate step of gasification or indirect heating would be eliminated. The particulate clean-up problem is more formidable than with the GSTIG, however, because of larger gas volumes and higher gas temperatures. Furthermore, to achieve viable system efficiencies, much higher turbine inlet temperatures than those achieved to date will probabiy be required.

"Moreover, to exploit state-of-the-art turbine inlet temperatures will require the development of pressurized slagging combustors to accommodate higher combustion temperatures. thus, determination of the long-term commercial viability of directly-fired STIGs appears to be several years away."

Because Northern Light's combustors produce such clean gas, this application deserves more investigation and R\&D work. We can easily achieve the required outlet temperatures from wood waste without slagging up of the ash. This is a major step on the way to solving this cogeneration interface.

A major market for such a system appears to be sugar factories around the world.

Steam engines still have a small niche in marine applications, \& are gaining increased acceptance as prime movers for small (under 1 MW) cogenerating systems using wood waste or other biomass fuels.

They are robust, reliable, simple in operation \& capable of operating under a wide range of steam conditions, but they are massive and inefficient. The ratio of electrical power output to thermal energy for steam engines from 10 15\%. [Biologue, Nov., Dec.'89/Jan.' 90 ] Nevortheless, where most energy requirements are for heat, the low efficiency in power generation does not reduce the overall system efficiencies. We can take a lesson from nature here. (Remember the sun?) The efficiencies of a single operation is irrelevant. What matters is that the whole works together for the desired purpose.
Stirling Engines hold the most exciting potential for small scale application, notably the free-piston linear alternator technology perfected by Sunpower, Inc., of Athens, Ohio, as described in the beginning of this report. They have licensed Cummins Diesel to develop a $10 \mathrm{KW}$ solar-heated model for commercialization.

The engine is a hermetically sealed linear motion machine with a displacer which moves gas between hot and cold heat exchangers, and a piston which expands the working gas in the hot space and compresses the gas when it is in the cold space in order to produce power to drive the alternator. The magnets of the alternator are directly attached to the piston and generate electric power as they move by the stationary wire windings surrounding the magnet ring. All moving parts have non-contact bearings and seals, so there is no intrinsic life-limiting or power degrading wear. The engine contains no oil or other material other than its helium working fluid. The design life is now 40,000 hours, with a target of 100,000 hours. They expect to get costs down to where it will be competitive with diesel operated generators, factoring in fuel costs.

Northern Light R\&D and Sunpower are currently discussing the merits of a joint venture to develop household or small commercial size biomass-fueled cogeneration systems.

\section{Costs Of Complete Systems}

Solid fuels require the most costly handling, storage and burning systems, around nine times as expensive as gas and oil systems.[92, 10/86] "Major factors affecting the economics of wood energy systems include capital costs, installation costs, operation and maintenance costs, fuel costs and financing costs. The 'rule of thumb' payback period is three yes- "[92]

"The cost of a proposed wood energy system increases as the system size increases. While larger systems cost more, unit cost ( per MBtu of heat generating capacity) generally decreases because of the economies of scale. However, a large, highly complex system can have a higher 
unit cost than a smaller system of more simple design. In addition, pollution control requirements become more stringent as the size of the combustion equipment increases, raising the unit cost of larger wood energy systems. Larger systems may also require the use of additional wood fuel sizing equipment, thereby raising costs. Certain design aspects that can increase the unit cost of the proposed system are influenced by the system size."[11]

"In general, systems that have the capacity to generate up to $10 \mathrm{MBtu} / \mathrm{hr}$ will cost $\$ 75,000$ (per million Btu); those with a capacity of $50 \mathrm{MBtu} / \mathrm{hr}$ cost about $\mathbf{\$ 5 0 , 0 0 0}$ (per million Btu). The systems in between increase in cost approximately $\$ 625$ per million Btus produced. These costs may vary considerably, however, depending on whether a company or institution is undertaking a retrofit or must construct a new system, inciusive of a fuel discharge depot, conveyance system, fuel storage structures, unloading equipment, new boilers, ash handling systems and the building that houses the boilers." [92, 1986] [That would put the cost for a 1.5 MBtu/hr system at about \$113,000. Simpler \& better technology can reduce this price substantially.\}

"Fuel quality influences the capital cost of a proposed wood energy system in several ways. Low quality fuels require the use of some type of screening device if the combustion equipment is equipped with a mechanical or pneumatic stoker system. Gravity-fed combustion equipment, on the other hand, is more tolerant of poor-quality fuels. Low quality fuels, however, can increase particulate emissions from the combustion equipment and require the use of more complex, expensive particulate emissions equipment." [11]
A graph in reference [11] gives a rough idea of the extremely wide variations in system costs. The estimated cost of wood fired boilers (uninstalled, 1982 prices) are:

1.5 MBtu/hr boiler:\$7,500 - \$35,500 Manual feed

$\$ 12,500-\$ 80,000$ Automatic feed

$3 \mathrm{MBtu} / \mathrm{hr}$ boiler:\$12,000->\$50,000 Manual feed $\$ 48,000-\$ 170,000 \quad$ Automatic feed 
Recent figures (1990) for the SERBEP region (where labor tends to be lower than elsewhere) are as follows for a "small boiler" (10 MBtu/hr): [35]

No. boiler operators per sm. boiler 0.5

Avg. salary /small boiler operator: 20,575

Avg. no. fuelwood handlers per sm. boiler

Avg. salary boiler fuelwood handlers:

22,000

Avg. salary to operate boiler, annually: ('87) $\$ 15,788$

Avg. expenditure per sm. boiler-engineering design('87): 95,168

Avg. expenditure per sm. boiler-construction('87):

301,146

Avg. expenditure per sm. boiler-heating metal products('87):

321,436

Avg. expenditure per sm. boiler-electrical machinery('87):

187,682

AVG. EXPENDITURE/SM.or LG. BOILER-CONVEYING EQUIPMENT('87): ...... 107,457

Avg. expenditure per sm. boiler-instrumentation: $.5,842$

Avg. total cost for $10 \mathrm{MBtu} / \mathrm{hr}$ boiler installed('87): $\$ 1,018,731$

(Proportional \$ for 1.5MBtu/hr boiler(no scale down penalty):

$\$ 152,810\}$

"Because wood-fired systems require more labor than oil or gas systems maintenance and operation costs are higher. The amount over and above that required for oil- or gas-fired systems is estimated to be $250 \mathrm{hr} /$ year."[11]

The report on wood chips cited earlier [93] finds no correlation between size of an installed chip-burning system and simple payback periods. Residential users cited payback periods from one to nine years, with most in the range of four to six years; commercial users from less than one year to seven years; institutional users three to eight years; and light industrial users from one year to five years. Larger users must invest more in chip storage and handling systems. I have found no local distributors of small commercial chip burners in the Pacific Northwest, outside of Homestead Heating. He has not installed any yet. I have written to the east coast manufacturers, and received only one reply. This leads me to suspect that the need for follow-up servicing and trouble-shooting necessitates keeping business close to home, especially for these relatively small companies. Freight costs could also become prohibitive.

\section{Case Studies}

The following are from "Wood Burning for Energy, Case Studies from the Great Lakes", Sept., 1986 [92]

The Menominee Indian School District is one of the most interesting case studies, both as an example of existing installations and of schools as potential customers.

"The Menominee Indian School District, created by the state of Wisconsin in 1976, shares coterminous boundaries with the Menominee Indian Nation. The tribe's primary source of income is derived from the wood industry. The availability of wood scrap and natural byproducts of logging played a large part in the School Board's decision to install solid fuel movable grate burners in each of its three schools. The Menominee Indian School District is the only district in Wisconsin that relies entirely on wood for its heating needs. The units utilize firetube boilers to supply the schools with hot water heat.

The Keshena High School (113,000 square feet) and Neopit Elementary School $\mathbf{( 3 3 , 0 0 0}$ square feet) are both new facilities designed from the start with woodheating in mind. The Neopit system was installed in 1980 at an initial purchase and installation cost of $\$ 105,000$; the Keshena High School system, installed in 1981, 
cost about $\$ 230,000$. The Menominee Indian Elementary School system at Keshena was installed as a conversion in 1983 at a cost of $\$ 115,000$ and replaced two gas and oil boilers. One of the boilers, which dates back to 1961, remains available for back up heating. The Keshena Elementary School boiler is equipped with a small propane burner located at the end opposite the wood feed system. Should the water temperature drop below $120^{\circ} \mathrm{F}$, the gas burner will automatically start up. Propane burners serve as the backup fuel at both the Keshena High School and the Neopit Elementary School.

The Solid Fuel units are operated with fully automated controls. The Keshena Elementary School unit is installed in conjunction with a three-pass Kewanee type " $\mathrm{C}$ " boiler equipped with 3-inch tubes. If the tubes were any smaller, soot would block the air passageways. Although the boiler, rated at 80 percent efficiency for fuel oil has undergone derating with wood fuel, the 68 percent efficiency it achieves is the highest obtainable and has been cited by the Wisconsin Department of Energy as an exemplary example of a wood boiler for School and hospital use. \{Agni is capable of over $90 \%$ efficiency on low fire.

The High School's 220-Hp boiler has a capacity of 7.4 million Btus per hour. The Neopit unit has a $100-\mathrm{Hp}$ boiler with a 3.4 million Btu per hour capacity. It utilizes a type " $R$ " boiler equipped with 3-inch tubing. The Elementary School, which has a 120-Hp "R" type boiler and 3-inch tubes is the most efficient of the three. Because it is oversized, it is capable of heating up to 15,000 additional square feet should the School Board decide to expand the facility.

The boilers can be operated at low, medium and high fire rate. On low fire, combustion air is provided exclusively by an induced air fan. On medium and high fire, combustion air flow is increased by a two-speed centrifugal fan. The best efficiencies are obtained at high fire.
\{AGNI's best efficiencies are obtained at low fire\}

The boilers are rated at 30 pounds per square inch gauge (psig) water and operate in the 10-15 psig range at all of the buildings. The heated water temperature, determined by an outdoor temperature reset control, range from $215^{\circ} \mathrm{F}$ (at $0^{\circ} \mathrm{F}$ outside temperature) to $160^{\circ} \mathrm{F}$. (This feature is easily incorporated into Agni's controls?

School district superintendent John Tomasich, after reviewing a variety of system options with consulting engineer Tom Posko of Posko Associates, Inc. Waukesha, Wisconsin, opted for a Solid Fuels system. "I like the fact that it's less fuel sensitive and more readily understood and maintained by a nontechnical staff than other units we explored," Tomasich noted.

He said it was important to the district to find a unit capable of burning fuel of varied quality. Some of the fuel is obtained on the reservation from areas where timber has been damaged by a tornado; some is residue left after logging. The amount of fuel obtained Off-site varies from $0-70$ percent.

Green wood chips are the predominant fuel and average 45 percent moisture content. The systems have, on occasion, burned air-dried green wood that has a moisture content as low as 20 percent. The units will burn sawdust and even some stringy bark, as well as the chips, Tomasich said.

The fuel is introduced at the top step of a movable grate system. As the material burns, it tumbles down to the last step, by which time it has been combusted to ash. The grates, powered by a hydraulic ram, are timed to agitate the fuel in a manner that ensures it is adequately distributed on the grates. (SSounds expensive \& susceptible to corrosion, wear, jamming, upkeep\} Primary air entering from beneath the grates penetrates the fuel bed. A fireball above the fuel bed is created when secondary combustion air is it troduced to burn the volatiles. The temperature in the fireball ranges from $2000^{\circ} \mathrm{F}$ to $2200^{\circ} \mathrm{F}$. The fuel bed 
burns at $1200^{\circ} \mathrm{F}$. Below these temperatures, the fuel would not be as completely combusted, lowerine boiler efficiency. Stack exit temperatures range from $248^{\circ} \mathrm{F}$ to $304^{\circ} \mathrm{F}$ at the Keshena elementary school to $375^{\circ} \mathrm{F}$ at Neopit and $350^{\circ} \mathrm{F}$ at the high school. Waagner's stack temperature ranges from $120^{\circ} \mathrm{F}$ to $240^{\circ} \mathrm{F}$ \} A 1985 test of boiler efficiency run at the Keshena elementary school indicated a high stack gas oxygen content (13 percent at high fire and 17 percent at low fire). \{corresponding to $160 \%$ and $430 \%$ excess air, respectively! Vaagner operates typically at $10 \%$ to $50 \%$ excess air, closer to stoichiometric with a more expensive oxygen sensor, and we are expecting to operate eventually below 4\% average.?

The three Solid Fuel combustion units are each equipped with induced draft fans. \{an expense and complexity unnecessary in the Northern Light systems\} These provide negative pressure to balance the positive pressures created by the introduction of primary and secondary air. Another unnecessary fan or two.\} No pollution control devices are 1 . juired, as the units meet Wisconsin air quality standards.

Tom Posko, Engineer, said,

As a rule-of-thumb, potential candidates for wood conversion should determine whether sufficient fuel is available within a 30 -mile radius of the facility. He believes such fuel should not exceed $\mathbf{\$ 2 5}$ a ton if it is to compete with conventional fuels.

Propane costs to the district have ranged from $\$ 0.69$ Per gallon to $\$ 0.74$ per gallon. At the time the systems were installed, fuel oil costs averaged $\$ 1.10$ per gallon.

Estimated payback has been calculated for the Neopit Elementary School at 6.7 years. The district estimates that it saves $\$ 13,430$ a year in propane costs at Neopit. The wood systems in the new schools displace oil, the alternative fuel.

The district received a $\$ 50,000$ federal matching grant through Wisconsin's Institutional
Conservation Program to help finance the installations and conversion at the Keshena Elementary School.

Fuel handling systems for each of the units vary somewhat from school to school. At the high school, a dump truck unloads chips to a below-grade pit where a pair of augers transports the chips to a conveyor. The conveyor leads to a flail type above-ground silo with a storage capacity of 234 tons. Fuel from the $24 \mathrm{ft}$. diameter $\times 50 \mathrm{ft}$. high poured concrete silo is conveyed by a flat, paddle wheel conveyor to a receiving hopper situated directly above the burner's grates. A controlled feed sensor in the hopper signals the conveyor when more fuel is required.

At Neopit, a similar silo, also equipped with a flail system to prevent bridging, is buried below grade. Trucks back up to double-doors and discharge the fuel directly into the top of the silo.

At the Keshena Elementary school fuel is stored in a 32-ton capacity concrete bin equipped with a live-bottom floor. Hydraulically powered scrapes move the chips to an auger as needed. Although the chips were jamming between the scrapes and floor, modifications have corrected this problem.

The School District uses approximately 600 tons of chips per year. The heating season starts in October and lasts through April.

The district paid $\$ 21$ a ton for wood chips in 1985. It purchased $\$ 7,500$ worth of chips for the heating season. Were natural gas used to heat the same facilities, the cost to the district would be $\$ 33,000$.

By negotiating a three-year contract with its local Sawano supplier, Tomasich said the price of fuel would be lowered to $\$ 19.50$ a ton. At present, it takes the supplier one-half hour to unload using a dump truck that carries 7 tons of chips and requires three trips to fill the silo at Neopit. Under a renegotiated contract, the supplier would purchase a live-bottom trailer with a 20-ton hauling capacity, reducing the trips required to just one. 
Superintendent Tomasich noted "The farther north one goes in Wisconsin, the lower the fuel costs, as there are more sawmill operators. A lot of wood is just stockpiled in the field or hauled to the swamp as unwanted waste." Tomasich said he's disappointed that more industries and institutions haven't investigated wood burning. "It's true, there's a relatively high first cost, but the benefits -- cheaper costs over conventional fuels in the long-term and recycling of waste wood -- outweigh this."

For more information contact: John Tomasich, Superintendent, Menominee Indian School District, Box 399, Keshena, WI 54135, 715/799-3824

At Koppers Company, Inc., in Carbondale, II, 750 tons of green sawdust \& chips @ \$8/ton fuel a $20,000 \mathrm{lb}(20 \mathrm{MBtu} / \mathrm{hr})$ watertube boiler purchased from Wellons (Sherwood, OR) at installed cost of $\$ 1.1$ million, with estimated payback of 10-12 years. [That is \$55,000/MBtu of capacity, or $\mathbf{\$ 8 2 , 5 0 0}$ for a Vaagnersize (1.5MBtu/hr capacity) boiler.\} The "cycloblast" furnace is designed to burn $50 \%$ moisture fuel with maximum particle size of 3". Wellons claims a 6:1 turndown ratio. \{Wellon specializes in larger systems\} Natural gas prices in 1985 were 3 to 4 times higher than the purchase price of sawdust.

We can deliver a cleaner-burning, higher efficiency boiler, capable of handling biomass chunks above 6", with a turn down ratio of 14 to 1 , for a lower price, so why not look at the smaller, decentralized cogeneration systems as well?

Jasper, $\mathbb{I N}$, in southwestern Indiana, calls itself the "wood capital of the world." More than 4,300 people are employed in 34 wood working plants in Dubois County. Gas in Jasper is $\mathbf{\$ 5 . 0 0 / m i l l i o n}$ cubic feet (MCF), stoker coal $=\$ \$ \$ 36.50 /$ ton $.(1986) . \quad 12$ of these plants in Jasper burn their own wood waste to provide thermal energy.
Grand View Hospital, on Michigan's upper peninsula, is a 72 -bed facility $(50,000$ sq.ft.) is heated by a $6,700 \mathrm{Pph}(6.5 \mathrm{MBtu} / \mathrm{hr})$ Ange \& Varme "Swedestoker", which is oversized for the facilities. The burner/boiler \& related equipment cost $\$ 230,000$ in 1981 (with an additional $\$ 175,000$ for building \& transmission lines, assisted with state grant of $\$ 205,000$ ), with estimated payback of 4.5 years. They purchase wood chips, $40-48 \%$ moisture, for $\$ 21 /$ ton delivered. "He has encountered some problems related to poor fuel quality and oversizing of the boiler. The hospital uses a top-grade wood chip. Zielinski has experimented with cheaper bark fuels but has found the hospital's suppliers are unable to control the cleaning process to his satisfaction. Dirt delivered along with the stringy bark and sawdust caused "glassification" of the material. This necessitated cleaning of the unit on a daily basis." Because of problems related to lowfiring the oversized system, they are going to have the burner "derated". "Ideally, when sizing a wood system, it should be selected for a plant's base load needs and peak energy should be provided by either gas or oil as this guarantees that the wood system will run at optimum efficiency and will be operated only a minimal amount of time at the low fire, low efficiency position."

\section{- Typical Problems - Case Studies}

Northwest Missouri State University installed a $\$ 2$ million wood-fueled boiler in 1982. A case study written 2 years later, observes the following:[47]

"The staff was extremely disappointed that a satisfactory ash disposal system has not been developed within the industry that is simple, effective, and will eliminate the necessity of an operator handling the ash directly.

There still remains a problem of dust within the plant. caused primarily because of an open conveyor system transporting the wood from point to point. The extremely fine dust is picked 
up and carried by the belt to the returning support roller surfaces...One problem plagued the project for six to eight months following the July start-up. The wet precipitator, or scrubber, used to control flue gas emissions, failed constantly. The primary reason was an overloading of the system with fly ash. The drag chain cleats would fail causing the chains to jam, which resulted in a broken drag chain. This failure resulted in total shutdown of the plant... The auger bed used in unloading the trucks which provided fuel to the plant's conveyor system was another problem. The auger flites were badly damaged due to contaminated fuel. Some of the early deliveries of fuel contained large pieces of wood, bricks and metal scrap. The damage was so extensive that large pillar block bearings were damaged beyond repair... The entire force draft system is operated by a 50 horsepower induction fan in front of the wet scrubber. In the spring of 1983, the University experienced a total electrical failure. Seven hundred degree F. flue gases were suddenly blocked from continuing through the scrubber because of the induction fan shutdown. What resulted bordered on disaster. Smoke and heat filled the power house from the breach end of the boiler and through the metering surge bins. The surge bins acted as a natural flue. Hot gases passed through the raw wood chip fuel resulted in immediate combustion of the stored fuel."[47]

\{The Agni system has several superior features that would prevent this occurrence. The all natural draft system is not impeded by any APC equipment and can continue to operate satisfactorily without electricity. The upper hopper is prevented from becoming a flue by two redundant gravityoperated hopper flaps that seal the hopper above the fuel automatically without the need for electricity. Even the controls can be kept operating on a $12 \mathrm{~V}$ battery backup with auto-switching.?

(At the University of Idaho's $\$ 3.25$ million, $60,000 \mathrm{lb} / \mathrm{hr}$ steam boiler) "Although the system was designed to combust all types of wood residues, it works best with chips... Hogged fuels with a fines content above $25 \%$ have caused operating problems...High Moisture Content fines froze to bucket elevator walls causing bucket damage and shutdowns. This was largely remedied by switching to plastic buckets.

Initially, hogged fuel, pre-dried to $20 \% \mathrm{MC}$ in a rotary drum dryer, was purchased with the expectation that hauling costs and combustion efficiency would favor a low-MC fuel. In actuality, benefits did not materialize for several reasons. First, the grate and burner were designed to have a drying/gasifying zone followed by a combustion zone. With the predried fuel, drying, gasifying, and burning were compressed into the first zone. Incomplete combustion of the rapidly volatized fuel at high loads produced smoke (Particulate emissions). With wet fuel, the particles do not burn as rapidly, and the zones can be effectively separated. Changes in the underfire air through the zones to accommodate dry fuel helped somewhat but was ultimately unsuccessful. Secondly, transportation costs with dry fuel were higher than expected because the fuel had a low density. Thirdly, a large amount of dust in the low-moisture fuel created a safety hazard. Dry bark gave the worst dust problem. In contrast, wood fuel with over $40 \% \mathrm{MC}$ yielded little airborne dust and minimal safety problems."[77]

The following quotes are from the SERBEP region, generally much larger systems than our interest. [44]

"At first they had trouble with haulers trying to unload old and wet, partially rotted fuel. They started to test for moisture content, accepting no more than $50 \%$ moisture wet basis. The fuel cost...is about $1 / 3$ of that fo $r$ natural gas."

(Water got) "in and mixed with some of the particulate matter collected from the exhaust. The mixture turned to something harder than concrete. It was a terrible job to get out. (Jack Daniel had a similar experience)...They believe pine is much less desirable than hardwoods because the resins deposited on tubes and other 
surfaces clog the firetubes in the boiler... They considered a cogeneration system but that required a boiler of about $1000 \mathrm{HP}$ to be feasible. IPC's boiler is only $400 \mathrm{HP}$."

"The seals on top of the gasifier need constant attention and adjustment... They believe they need to replace the present metal-link fuel feed system with a wide rubber conveyor belt...The sawdust may produce operational problems if it becomes wet during transit or handling."

"The Burlington plant at Raybun Gap, GA has the best system they know about. It is a $\$ 5 \mathrm{~m}$ installation that produces 150,000 pounds of steam per hour. They helped design it and they supply wood to it. Of the $\$ 5 \mathrm{~m}$ cost, $\$ 1 \mathrm{~m}$ was for instrumentation...They are not proponents of gasifiers, which have too many problems with wet fuels."

"As long as the load varies from $30 \%$ to $80 \%$ of the system's capacity, no operational problems are encountered. But during the summer when only hot water is needed, the load is below $30 \%$ of capacity and some difficulties are encountered...Occasionally, arches form in the silo preventing the fuel from dropping down. They have had wet wood freeze and block the wood feeder ducts. The unloading ramp for the trucks is not steep enough. It is $45^{\circ}$, but they believe it should be $60^{\circ}$. (They believe live bed trucks are not good.) If the fuel is too wet, they have to clean the boiler tubes by blowing every shift. Once they had the tube that recycles particulate matter stop up...A belt broke once but the motor kept running. This prevented any malfunction signal being given to the operator of the system but stopped the supply of fuel to the boilers. They have too much oxygen in the stack gases indicating the fuel-air ratio is not correct in combustion."

\{Five of these problems are totally solved in the AGNI system; the others can be eliminated by a well-designed feed system\}
"They believe pine causes troubles including heat generated in the storage piles. They pay $\$ 12$ per ton for wood with 8 to $30 \%$ moisture content. They emphasized that if one buys wood with $50 \%$ moisture, half the transportation cost is for water and it takes a lot of heat to get rid of the water...Sawdust entrains a lot more moisture than wood chips because they only accumulate moisture in a thin outer layer. The fuel is stored in the open at Maryville because they believe covered storage is not economical. However, at times they have significant operational problems when wet chips freeze into lumps which the fue' handling system can't sort and transport."

"The application of wood fuel systems outside of the forest products industry is still quite rare if one excludes the use of wood as a fuel in private homes...Hundreds of thousands of tons of wood waste in Missouri and other states are available each year for fuel use. Consequently, there is considerable room for new industry to absorb this abundant fuel...The application of wood as the basic energy system for hospital and uni ersity uses are quite rare. This fact is changing quite rapidly because of (Northwest Missour: State University's) successful demonstration of obvious economical advantages and improved technologies."[47, 1984)]

\section{The Agni Boiler System}

The AGNI boiler is a compact design compared with many wood-fueled systems. It occupies about $570 \mathrm{cu}$. ft., including the ash pit. This compares favorably to the figures given in the "Biomass Design Manual"[11] of 5,300 cu. ft. required for a 1.7 MBtu/hr boiler, and 10,600 $\mathrm{cu}$. ft. requiced for the boiler with automatic feeding system.

The dual-fuel option for cold-start igniting of the fuel and running on gas or oil when necessary is perfectly suited for the Northern Light design of furnaces. Since the entire combustion area is 
of high-temperature ceramic and isolated from the external heat-exchanger, there is no need for a separate gas/oil combustion chamber to insure clean combustion, and the built-in microprocessor can easily handle the required control functions to any degree of sophistication desired.

\section{Agni Fuel Handling}

As discussed earlier, the cost of feed handling equipment can be more than the boiler cost in some installations. The problems associated with poorly designed fuel handling systems have been detailed above. A live bottom storage system usually involves at least $\$ 70,000$ more, and this is the costliest part of the fully-automated system for which we need to find a cheaper solution. One of the major reasons that wood-fired boilers have not been more popular, especially on the 1 $6 \mathrm{MBtu} / \mathrm{hr}$ scale, is that a fully automated fuel feed system of present design is too costly. There are several reasons for this:

* Virtually all automatic fuel-feed systems installed today are custom designed and custom manufactured, one at a time, with very high costs for engineering/design.

* The controls, alarms, and fail-safe provisions for such a system are very expensive, especially when custom designed for each system.

* Most of these systems use a complex combination of live-bottom feed, belt feed, and auger feed requiring very expensive and powerful gearmotors, hydraulic pumps, etc. Because augers jam easily with oversized pieces of wood, metal, and rocks; and because such "contaminants" can cause major problems in most combustion systems, more expensive equipment is often installed to screen and extract this debris.

* The logging industry has traditionally gone for massive heavy equipment with powerful motors to move large volumes of material. We only need to handle small amounts of material, and could significantly improve the economics of bioenergy utilization and open up a vast market that is not presently feasible by designing a more lightweight and universally applicable, "smarter", cheaper feed system.

What does such a new fuel-handling system look like? Before we can address those specifics, let us look at the requirements of the Agni installation.

TYPICAL FUEL-FEED REQUIREMENTS ALL FIGURES FOR FULL CAPACITY BURN RATE

(a) $24 \mathrm{lb} / f^{3}, 46 \%$ moisture, $8700 \mathrm{Btu} / \mathrm{bone} d r y \mathrm{lb}$ Assuming 20 unit storage capacity $:=4,000$ cu.ft.

@ $355 \mathrm{cu}$. ft. $/$ day $=11.2$ days at full capacity

@ $24 \mathrm{lb} / \mathrm{cu}$. ft. $=315 \mathrm{lb} / \mathrm{hr}=7,572 \mathrm{lb} /$ day

$=93,135 \mathrm{lb}$ (46.5 tons) $/ 20$ unit load

Assume $12.5 \mathrm{ft}^{3} /$ hopper load/hour max. $=300 \mathrm{lb}$

Fuel must be transferred at above rate from storage bin to top of feed stack on burner 20 to $25 \mathrm{ft}$ above ground, preferably close to the bin in a horizontal direction.

20 units will fit in a storage area $16^{\prime} \times 7^{\prime} \times 36^{\prime}$ or $12^{\prime} \times 7^{\prime} \times 48^{\prime}$, made with $4 \times 8$ sheets of plywood, suitable for a 12 - 16 unit live-bottom trailer to unload into weekly.

Screw auges $\mathbf{S}$ are used for most boiler feed systems because they must meter the fuel in close to the heat while blocking air passage and combustion travel. Agni does not require this, because the hopper is self-sealing and continuously entering the grate area by gravity, metered by rate of burn. As the upper section of the vertical hopper becomes empty, the uppermost counterweighted hopper flap shuts and signals a batch load to refill the hopper. As this occurs once an hour or so, it is unnecessary to have a continuous feed.

Screw augers will not handle the variety $c f$ fuels Agni is designed for, and have other problems that make them unsuitable for our application. With a belt feed, the central microprocessor turns on and off the various feed 
mechanisms for a timed or weight-metered cycle. A scraper insures that too much cannot be loaded on the belt to overfill the hopper. If too little is delivered, the hopper flap switch will signal for the next batch sooner.

The storage area should be designed so that a live-bottom van or a dump truck (or tree-trimmer truck) can deliver their load directly into storage. Underground concrete bins are sometimes used, but they are costly to build, not appropriate where groundwater is present, and ultimately the fuel must be lifted t.jgher to get it into the boiler, unless the whole boiler room is below ground, an even more costly approach. The simplest delivery is to an open pile, kept confined by walls wide enough apart to allow the trucks to drive in and unload.

"Walking Floor" conveyor systems are available that can be driven on, but they would add another $\$ 100,000$ or so to the equipment costs. It does not make sense to design for the capacity to move the whole 46.5 tons of fuel at once in order to get $300 \mathrm{lbs}$ of it into the hopper every hour. The better approach would seem to be to rake the $300 \mathrm{lb}$ batch off a face of the pile with a slow-moving, low-powered, light weight mechanism that could also handle a variety of fuel types - stringy bark, tree trimmings, chunks, sawdust, etc. It would have the added advantage of raking off the driest top layer first and exposing the damper fuel below to the air, and if it raked from the front opening of the storage bin first, it would create room for the next truck load of fuel to be dumped. A 12' wide, concretefloored bin would allow a standard live-bottomed van or dump truck to drive in easily and dump its load quickly, while containing the pile in a compact area.

In the past, the "intelligence" of a fuel feed system had to be kept elementary to keep costs down and reliability up. A great advantage to the AGNI system is that the powerful central microprocessor has the capacity to perform complex and reliable monitoring and control functions with only the small additional cost of more sensors and switches. We should capitalize on this advantage in designing a new feed system.

Because the proposed pile feeder design is proprietary and the design has not been fieldtested, I will not give further details here. Detailed designs and component costs have been analyzed, and we are confident that we can reduce the current price of a fully automated feed system by two thirds or more.

\section{Agni Fabrication Costs}

Fabrication costs for the complete Agni system should compare favorably with those for a conventional boiler system. Tooling costs are lower, because the large metal components are thin. The boiler tubes can be welded into their plates in about 3 hours with an orbital welder. The bulk of the combustion side of the system is vibration-cast refractory ceramic, which requires a low setup cost. Production molds, however can be a considerable expense, but sizable production runs will bring the unit costs way down.

Where waste disposal is of greater concern than heat output and boiler efficiency, the condensing boiler could be replaced with a much cheaper minimal heat-exchanger, both for hot water and ambient air. This simplification could reduce the component and fabrication cost by over $\$ 2,000$, and shave $\$ 5,000$ off the final sales price.

\section{Total Package Cost}

From the literature collected to make this report, and much of this is 6-8 years old, a typical installation costs for an automated fuelfeed $1.5 \mathrm{MBtu} / \mathrm{hr}$ system seem to range from $\$ 113,000(92,1986)$ to $\$ 153,000(35,1990)$. The latter figure is extrapolated down from a 10 MBtu/hr size system without taking into account any penalty for loss of efficiency of scale nor factoring in the lower wages of the SERBEP region where the study was made.

Additional savings over conventional systems that should be factored in when evaluating a competitive price for the Agni system are: 
- The increased efficiency of the AGNI system could save $\$ 10,000-\$ 15,000$ a year in fuel costs (@ \$20/BDT), plus less ash, fuel handling time, and wear \& tear on the equipment.

- The capacity to handle less desirable, low grade fuels that no other system can accept, could save $\$ 10,000-\$ 20,000$ on fuel costs annually

- The lack of an exhaust fan and high-powered fuel feed motors and hydraulics will afford substantial yearly electricity savings and equipment replacement costs.

- Estimates in the literature of the amount of time involved in fuel handling and tending to the boiler and system range from 250 to 1560 hours per year and must factor in a full-time attendant if the boiler is a high-pressure system. There should be savings in this area as well, with Agni's highly automated combustion, low pressure boiler, fuel feed, and alarm system.

-Where strict emissions regulations apply, as in more and more localities, the savings from not having to install APC equipment will be tremendous (from $\$ 12,000$ for the simplesi cyclone to $\$ 480,000$ for an electrostatic precipitator).

All this adds up to a high potential value for an Agni boiler system. There would appear to be a sizable market for the complete installed system at $\$ 160,000$. We expect to deliver an installed system, complete with fuel storage, omni-fueled burner, condensing boiler, and fully automated fuel feed, ash removal and microprocessor controls for well under $\$ 90,000$.

In all of this analysis, it is important to keep in mind that this small size commercial system has not been economical to install with automated feed for presently available technology, even though it represents the largest potential market. If we can get the installed system price below $\$ 60,000$, simple payback on an installed $1.5 \mathrm{MBtu} / \mathrm{hr}$ system is usually 1 to 2 years. On the other hand, if we target a larger system, the additional costs are a small percentage increase of the total price, since the feed system remains the same, and the economics improve dramatically for just about any installation.

Analyzing a 3 million Btu/hr system, for instance, using the most expensive fuels @ $\$ 25 / B D T$, payback is less than 2 years. This is a high enough fuel price to include the vast fuel markets of agricultural residues and dedicated biomass energy crops, and it can even compete favorably with premium chips for the pulp and paper market.

A larger system could also be cost-effective for applications requiring peak loads of, say 3 $\mathrm{MBtu} / \mathrm{hr}$ and average loads of only one-fourth of that. Thus it is clear that in the range of 1 to 10 MBtu/hr there are economic options for a wide variety of applications.

Another option to consider would be to target the small woodworking plant and other facilities with lesser heating needs with a 150,000 to $300,000 \mathrm{Btu} / \mathrm{hr}$ hand-fed, air-heating model similar to the Vaagner prototype. The elimination of the feed system and the boiler would reduce the manufactured cost considerably, to less than $\$ 2,000$. I have had many inquiries for this size system. There is, however, greater competition on this level, since emissions and efficiency tend to be less of an issue on this scale and there are many basic systems now on the market. This would appear to be a better model line down the road, when the controls and all components are optimized and economies of scale can be capitalized on. 


\section{APPENDIX}

UNITS AND CONVERSION

DEFINITIONS AND CONVERSION FACTORS FOR MEASURES OF WOODY

\section{PRODUCTS}

\section{Measure}

Unit

Green Unit (GU) - Chips

Bone Dry Unit (BDU)

- Chips

Green Ton (GT)

Bone Dry Ton (BDT)

Wood density

Cord

Board foot (BF)

Lumber scale

Board foot (BF)

Log scale

One Log Truck Load

Log Weight

\section{Definition}

200 cubic of uncompacted volume

Weighs approximately 3,430 Lbs@30\% MCWB

Used as a basis for payment for pulp

chips. A measure of weight, not volume, defined as 2,400 Lbs@0\% MC.

$2,000 \mathrm{lbs}$ of woody material, as received and includes the weight of water in the material. 2,000 Lbs of woody material @ 0\% MC.

The most accurate measure for energy purposes. Range for Western softwoods, 23 to $28 \mathrm{lbs} / \mathrm{ft}^{3}$ (a) $0 \% \mathrm{MC}$. Varies with species and location. Stack of wood, 4'x 4'x 8' or 128 gross cubic feet (usually about 80-90 net cubic feet but varies widely with $\log$ diameter)

A measure of the volume of wood fiber in lumber form nominally equal to $1 / 12$ th cubic foot.

There are many varieties of $\log$ scale measuring systems. Converting BF log scale to BF lumber scale depends upon the log scale system.

Approximately $5,500 \mathrm{BF}, \log$ scale.

$1,000 \mathrm{BF}, \operatorname{logs}, \log$ scale, has a weight range of from $6,463 \mathrm{lbs}$ to $10,262 \mathrm{lbs}$ depending upon species. When converted to residue, 1,000 BF yields 2 units of a combination of chips, sawdust, and hog fuel. 


\section{MOISTURE CONTENT CONVERSION:}

Moisture content can be measured on a wet or a dry basis. In engineering calculations moisture content (MC) is usually expressed as a percent of the total weight. This is the wet basis method. In forest product calculations, the dry basis method is used; the moisture content is expressed as a percent of the dry weight of the woor Thus:

MC $(\%$ Wet Basis $)=($ Water Weight $) /($ Total Weight $) \times 100$

MC $(\%$ Dry Basis $)=($ Water Weight $) /\{($ Total Weight $)-($ Weight of Water $)\} \times 100$

If $M \& D$ represent the moisture contents on the moist-wood and dry-wood bases respectively, then:

$M=D /(1+D) \quad$ and $\quad D=M /(1-M)$

UNIT of HEAT VALUE

$1 \mathrm{KWhr}$

1 Cubic Foot Gas

1 Therm Gas

$1 \mathrm{lb}$ Bituminous Coal

$1 \mathrm{lb}$ Charcoal

1 Gallon \#2 Diesel Oil

1 Gallon Propane

1 Ton Whole Tree Chips

(50\% moisture)

1 quad

1 Boiler Horsepower

1 Btu (British Thermal Unit)

1 million Btu (1MBtu)

- $1 \mathrm{lb}$ of steam $/ \mathrm{hr}$

$1 \mathrm{lb}$ of steam

\section{Btus}

3,413

1,000

100,000

12,500

13,000

140,000

92,000

8.3 to $8.8 \mathrm{MBtu}$

1015

$33,475(33,472)$

$=9.8095 \mathrm{~kW}$

$=0.29307 \mathrm{watt}$

$=293.07 \mathrm{~kW}$

$=0.2843 \mathrm{~kW}$

$=1000 \mathrm{Btu}$ 


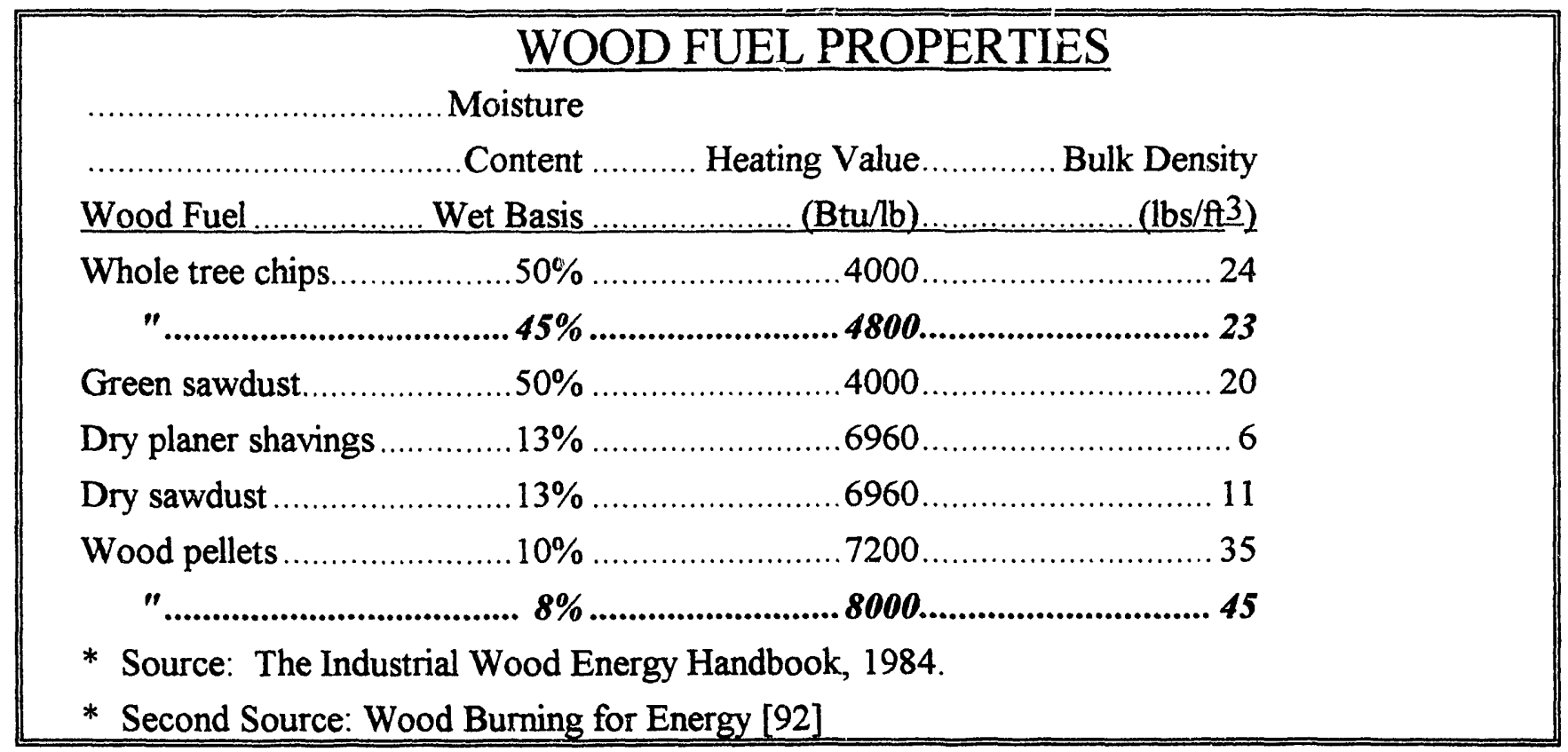

Throughout this report many figures will be given on volumes, weights and energy equivalents of biomass fuels. To give some feel for the size of these numbers, I will sometimes give an "AGNI" equivalent. This means roughly the amount of biomass fuel that the AGNI boiler would consume over a year operating at $50 \%$ capacity day $\&$ night, or the amount of fuel that will heat a typical 100,000 sq. ft. uninsulated industrial facility or a 200,000 sq. ft. insulated building using an AGNI Boiler in the Pacific Northwest.

\section{GRANTS AND OTHER ASSISTANCE TO RESEARCH \& DEVELOPMENT}

*Alternative Sources of Energy Magazine Minigrant, 1977

* Washington State Energy Office, grant, 1987-88

* Vaagen Timber Products Company, assistance in prototype development, 1988

* U.S. DEPARTMENT OF ENERGY, Energy-Related Inventions Grant, 1989-1993

\section{PUBLISHED RESEARCH:}

* Proceedings of the Weltkongress Alternativen und Umwelt, Vienna, 1980, A High Efficiency Home Energy System Burning Biomass

* Alternative Sources of Energy Magazine, 1980, The G'rendle Report

* The Mother Earth News Guide to Home Energy, 1980, An Amazingly Efficient Sawdust Stove

* International Bio-Energy Directory and Handbook, 1.984

* Proceedings of the 1986 International Conference on Residential Wood Energy, High-Tecis Von-catalytic Woodstove Design Considerations

* Proceedings of the 1988 Washington Wood Utilization Conference, A State of the Art Woodchip Boiler 


\section{BIBLIOGRAPHY \\ for Footnotes and Further Information \\ \{Footnote Numbers Correspond to Source Numbers\} \\ \{Key Categories in Italics\}}

1. 1990 Wood Residue Survey and Directory of Secondary Wood Processing Facilities in Washington State, Washington State Energy Office, 9/90.

1A. 1991 Northwest Conservation and Electric Power Plan, Volume 1, Northwest Power Planning Council

2. A Model Resource Recovery \& Conservation Plan for Northwest Missouri State University, Northwest Missouri State University, 10/89, On integrated recycling, resource recovery, and conservation efforts at Northwest Missouri State University, Environment, Fuel Source

3. Alaska Energy Authority Bioenergy News, a monthly newsletter, Good case-studies and up-todate regional information

4. An Overview of Wood Energy in the Southeastern United States, P.C. Badger \& C.D. Stephenson, Southeastern Regional Biomass Energy Program, 6/89, Good detailed overview, Wood Energy

5. Analyzing Market Constraints in Woody Biomass Energy Production, Timothy M. Young \& David M. Ostermeier, Southeastern Regional Biomass Energy Program, 9/86, Final Report, Customer, Fuel Source, Competition, Regulation

5A. Ash Deposition During Coal and Biomass Combustion, Larry L. Baxter, Combustion Research Facility, Sandia National Laboratories, Livermore, CA, Presented at the Biomass Combustion Conference, Reno, 1/92

5B. Atlas of the Environment, Geoffrey Lean, et.al., Prentice Hall, 1990

6. Assessment of Biomass Resources for Electric Generation in the Pacific Northwest, James D. Kerstetter, Ph.D. Washington State Energy Office for Northwest Power Planning Council, 1990, Wood Energy, Electricity, Fuel Source

7. Assessment of Biomass Resources for Florida, Final Report, Southeastern Regional Biomass Energy Program, 1985?, Fuel Source, Survey

8. Auger Combustor for Chicken Litter, Dennis R. Jaasma, Southeastern Regional Biomass Energy Program, 12/87, Fuel Feed, Fuel Source, Combustion, Competition

8A. BIO Conversion--Fuels from Biomass, E.E. Robertson, executive director of the Biomass Institute, Winnipeg, Manitoba, Canada, 1977

9. Bioenergy Brief, a monthly newsletter, Pacific Northwest \& Alaska Regional Bioenergy Program

9A. Bioenergy Projects Degest; Materials Handling 1984-1989, A review of Bioenergy Materials Handling R\&D projects funded by Energy, Mines and Resources, Ottawa, Ontario, Canada, 1990

9B. Biofuels, Air Pollution, and Health, a Global Review, by Kirk R. Smith, 1987, Plenum Press, NY. 
10. Biologue, and the Regional Energy Program Reports, Official Publication of the National Wood Energy Association, published quarterly --- very informative and up-to-date, Regulation, Fuel Source, Conference, Customer

10A. Biologue Article, May/June,'91: "Renewable Energy Boosted by Iowa Utilities Board"; Electricity

11. Biomass Design Manual, Industrial Size Systems, Southeastern Regional Biomass Energy Program, 9/86, Covers wood-fired boiler, emphasis on larger than $8.5 \mathrm{MBtu} / \mathrm{hr}$, bibliography, glossary and list of fuel brokers, suppliers, and equipment manufacturers, Boiler/Heat-exchange, Competition, Fuel Feed, Emissions

11A. Biomass Energy: A Monograph, Edited by Edward A. Hiler \& Bill A. Stout, 1985, Texas Engineering Experiment Station, Texas A \& M University Press.

12. Biomass Energy Facilities, 1988 Directory of the Great Lakes Region, Great Lakes Regional Biomass Energy Program, 1988, Survey, Wood Energy, Customer, Fuel Source

12A "Biomass Energy: The Forgotten Fuel", Biologue, May/June' 91, Panel of experts discuss present \& future trends. 1989; Dr. Ralph Overend-manager SERI Biomass Power program; Robert P. Kennel-constructs \& operates large scale biomass facilities; Dr. Mark C. Trexler-energy \& environmental consultant, World Resource Institute; Leonard Theran-pres. G\&S mill.

13. Biomass Energy Project Development Guidebook, John M. Vranizan, et.al., Pacific Northwest \& Alaska Regional Bioenergy Program, 7/87, "..written for managers, engineers, and financial officers in business, industry, and government so that they might investigate the feasibility of using biomass fuels," Fuel Source, Case Study, Customer

14. Biomass Energy Systems: A Preliminary Investment Decision-Making Guide for the Small Business, Southeastern Regional Biomass Energy Program, 1/88, Includes 'BIOVEST', 1989 economic assessment software for Lotus $1,2,3$. The sample calculations seem to be faulty on p.7 - Using a 4,000 BTU/lb heat value for $50 \%$ moisture wood along with a $67 \%$ boiler efficiency results in a system efficiency of $31 \%$ - this seems too low, creating an unfairly high steam cost. Economics

15. Biomass Energy, A Resource Assessment, Western Regional Biomass Energy Program, 10/87, Survey, Wood Energy

16. Biomass Estimates for Five Western States, James O. Howard, Pacific Northwest \& Alaska Regional Bioenergy Program, 10/90, Fuel Source, Environment

16A. Biomass-Fired Steam-Injected Gas Turbine Cogeneration, by Eric D. Larson \& Robert $H$. Williams, Princeton University

17. Biomass Fuel Characterization: Testing \& Evaluating the Combustion Characteristics of Selected Biomass Fuels, Final Report, Dwight J. Bushnell, C. Haluzok, Abbas Dadkhah-Nikoo, Oregon State University, for Bonneville Power Administration, 9/89, Combustion, Fuel Source, MSW, Emissions

18. Biomass Fueled Stirling Engine Combustor Research, W.H. Percival, et.al., United Stirling Inc., Alexandria, VA, 1982?, Electricity

19. Biomass News, a monthly newsletter, Western Regional Biomass Energy Program

20. Biomass, International Directory of Companies, Products, Processes \& Equipment, J. Coombs, Macmillan, Stockton Press, 1986, A British Publication - expensive, but good source of broad spectrum of 
21. Boilers Fired with Wood and Bark Residues, David C. Junge, Ph.D., Oregon State University School of Forestry \& Plywood Research Foundation, 11/75, Combustion, Boiler/Heat-exchange, Emissions

22. Burning Wood for Energy, Negative Perceptions \& State of the Art Facts, Nancy $R$. Holmes, NRH Associates, Inc., Swanton, VT, 11/91, She is very interested in our work, Fuel Source, Environment, Emissions, Boiler/Heat-exchange

23. California Biomass Facilities Directory Survey, Final Report, NEOS Corporation, Calif. Energy Commission \& Western Regional Biomass Energy Program, 3/91, All large electricitygenerating plants, Electricity

24. Case Studies of Biomass Energy Facilities in the Southeastern U.S., Meridian Corporation, Southeastern Regional Biomass Energy Program, 8/86, Good crossection of installations, Customer, Boiler/Heat-exchange, Competition, Fuel Feed

25. Catalytic Gasifier/Combustor for biomass Fuels, D.R. Jaasma, et.al., Southeastern Regional Biomass Energy Program, 9/86, Combustion

26. Central Biomass Combustion Facility Feasibility Study, Charles, Crane, MERDI, Inc., for, Montana Department of Natural Resources \& Conservation, 7/82, Fuel Source, Customer

27. Clean Air Washington, Washington State Department of Ecology, A set of publications explaining the Clean Air Washington Act of 1991, the problems and regulations to assist solutions.

28. Cogeneration Feasibility Study, Comparison of Rankine Vs Stirling Engines Adapted to a Solid Fuel Combustor, Robert J. Boucher, Montana Department of Natural Resources \& Conservation, 11/83, Electricity, Wood Energy

29. Cogeneration from Biofuels: A Technical Guidebook, James L. Easterly, P.E., \& Dr. Michael Z. Lowenstein, Meridian Corp. for Southeastern Regional Biomass Energy Program, 9/86, Electricity, Fuel Source, Regulation, Wood Energy

30. Combined Cycle Biomass Energy Research Project, Final Report, Task 4: Resource Assessment; Part 1, Executive Summary, James W. Funck, et.al., Department of Forest Products, Oregon State University, 9/86, Very detailed, county-by-county assessment in full report, would be useful for sales staff., Fuel Source, Wood Energy

31. Demand for Wood Residue by Kiln Drying Enterprises in the Central Appalachians, Final Report, James P. Armstrong \& Samuel M. Brock, Southeastern Regional Biomass Energy Program, 10/87, Customer, Fuel Source, Survey

31A. Design and Performance of Wood-Chip-Fired Stokers and Pre-Heaters (output range 25 - 75 kW), Prepared for Technology Branch, Energy Mines and Resources, Canada, 1988

32. Design Manual for Small Steam Turbines, Gerald R. Guinn, Ph.D., Southeastern Regional Biomass Energy Program, 3/90, Electricity

33. Directory of Biomass Installations in 13 Southeastern States, Southeastern Regional Biomass Energy Program, 12/86, All-inclusive, but not much detail or analysis of results, Survey, Customer, Wood Energy

33A. Economic Impact of Harvesting Wood for Energy, James E. Johnson, et.al., Great Lakes Regional Biomass Energy Program, 3/87 
34. Economic Impact of Industrial Wood Energy Use in the Southeast Region of the U.S., Volume I: Summary Report, Meridian Corporation, Southeastern Regional Biomass Energy Program, 11/90, Wood Energy, Survey

35. Economic Impact of Industrial Wood Energy Use in the Southeast Region of the U.S., Volume II: Data Collection Methodology \& Databases, Meridian Corporation, Southeastern Regional Biomass Energy Program, 11/90, Comes with Lotus spreadsheet program, Fuel Source, Customer, Environment, Regulation

36. Economic Impact of Industrial Wood Energy Use in the Southeast Region of the U.S., Volume III: Model Description, Meridian Corporation, Southeastern Regional Biomass Energy Program, 11/90, A description of the computer-based model used in study, Wood Energy, Survey

37. Electronic Control of Wood Combustion, David W. Guernsey, U.S.D.O.E., 11/82, Combustion

37A. Energy for Planet Earth; Special Issue of Scientific American, Vol. 263, No.3; 9/90

38. Energy From Crops and Agricultural Residues in Montana, Howard E. Haines, Montana Department of Natural Ressurces and Conservation, 8/87, Fuel Source, Biomass Farming

39. Enhancement of Output of a Wood Burning Gas Turbine with Water/Steam Injection, Joseph T. Hamrick, Southeastern Regional Biomass Energy Program, 11/87, Work done at Aerospace Research Corporation, Combustion, Electricity

40. Environmental Impacts of Advanced Biomass Combustion Systems, Final Report, OMNI Environmental Services, Inc., for, U.S.D.O.E., 1/88, Report of emissions from 'Helen' prototype built by Mr. Dobson, Emissions, Combustion, Case Study, Wood Energy

41. Environmental Impacts of Harvesting Wood for Energy, James E. Johnson, et.al., Great Lakes Regional Biomass Energy Program, 3/87, Biomass Farming, Environment

41A. Evaluating Effects of Wood Smoke Control Legislation in Washington State on Electrical Customers, prepared for Bonneville Power Administration by Mile Nelson, et.al., WSEO, 6/90

42. Evaluating Recently Developed Two-Stage Combustion Technology for Small-Scale Application, Frederick A. Payne, Southeastern Regional Biomass Energy Program, 8/85, Combustion, Case Study

43. Evaluation of Potential for Electrical Generation Using Solid Waste as Fuel in the Pacific Northwest, Gershman, Brickner \& Bratton, Inc., with, Systems Architects Engineers for, Bonneville Power Administration, 6/83, Electricity, MSW

44. Final Report on Biomass Technology Transfer Studies, Robert W. House \& Robert T. Nash, Southeastern Regional Biomass Energy Program \& TVA, 5/85, Addressing potential for using more wood for energy, what potential customers, fuel harvesting, handling, storage, combustion, How to promote \& encourage this energy use., Fuel Source, Customer, Regulation

45. Garbage, The Practical Journal for the Environment, see article in Nov/Dec/91 issue, "Great Green Hopes"

45A. The Gaia Atlas of Future Worlds, by Norman Myers, Gaia Books Ltd, London 1990

46. Hogged Wood Fuel Supply and Price Analysis, Final Report, Richard T. Biederman \& Christopher F. Blazek, Institute of Gas Technology, for Bonneville Power Administration, 5/91, For Pacific Northwest Region, comes with a Lotus spreadsheet forecast model for the PC, Fuel Source 
47. Implementation and Management of an Alternative Fuel System Through Private Funding in a Public Assisted Institution, Dwight, Branson \& Robert E. Bush, The Missouri Department of Natural Resources, 5/84, Case Study, Boiler/Heat-exchange, Biomass Farming

47A. Industrial/Commercial Wood Energy Conversion, a Guide to Wood Burning, Fuel Storage \& Handling Systems, Great Lakes Regional Biomass Energy Program, 1992?

48. Industrial Wood Energy Information Survey, Final Report, Harold, King, Great Lakes Regional Biomass Energy Program, 5/86, "The purpose of this survey was to obtain a better understanding of the information needs of businesses and public institutions in the Great Lakes region that may convert to wood fuel as their primary energy source." Customer

48A. Industrial Wood Fuel Market Assessment in Washington State, James D. Kerstetter, Ph.D., Washington State Energy Office, in Proceedings of energy from Biomass and Wastes X Conference, April, 1986

49. Industrial/Commercial wood Energy Conversion, A guide to Wood Burning, Fuel Storage \& Handling Systems, Great Lakes Regional Biomass Energy Program, 1987?, good glossary, Boiler/Heat-exchange, Fuel Source, Fuel Feed, Emissions

50. Mill Residue Availability in Montana, Montana Department of Natural Resources and Conservation, 1986, Fuel Source, Wood Energy

51. Montana Bioenergy Publications, Montana Department of Natural Resources and Conservation, 6/89, Good bibliography of regional studies \& statistics

52. Montana Biomass Cogeneration Manual: A Workshop Handbook, Dilip R. Limaye \& Shahzad Qasim, Montana Department of Natural Resources and Conservation, 5/83, Electricity, Wood Energy

53. Montana Bionotes, Summaries of Biomass Energy Projects funded by the, Montana Department of Natural Resources \& Conservation, 1986?

54. Montana's Bioenergy Project Permitting Guidebook, Montana Department of Natural Resources \& Conservation, 7/86, Regulation

55. Municipal Solid Waste to Energy Analysis of a National Survey, For Washington Communities Interested in Energy Recovery as an Alternative to landfilling MSW, James D. Kerstetter, Washington State Energy Office, 6/87, MSW

56. Municipal Waste Combustion Study, Costs of Flue Gas Cleaning Technologies, U.S.E.P.A., MSW

57. Municipal Waste Combustion Study: Characterization of the Municipal Waste Combustion Industry, Radian Corporation, U.S.E.P.A., 6/87, MSW, Survey

58. Municipal Waste Combustion Study: Flue Gas Cleaning Technology, Charles B. Sedman \& Theodore G. Brna, U.S.E.P.A., Office of Solid Waste, 6/87, MSW, Emissions, Survey

59. Municipal Waste Combustion Study: Report to Congress, U.S.E.P.A., 6/87, MSW, Regulation

60. Municipal Waste Combustion Systems Operation and Maintenance Study, U.S.E.P.A., 6/87, MSW, Combustion

61. National Wood Energy Survey, Final Results, Timothy M. Young \& David M. Ostermeier, Department of Forestry, Wildlife \& Fisheries, U. of Tennessee, Study done for SERBEP, Survey

62. Northwest Energy News, a bimonthly publication by the, Northwest Power Planning Council 
62A. OMNI magazine, $1 / 92$

62B. "Opportunities for Biomass Power", by Dr. Robert San Martin, Deputy Assistant Secretary, Office of Utility Technologies, Office of Conservation \& Renewable Energy, Department of Energy, presented to First National Fuelwood Conference, 11/91

63. Pacific Northwest and Alaska regional Bioenergy Program Yearbook, 1984 to present, Excellent summary of regional activities and future emphasis of DOE bioregion programs

64. Pacific Northwest and Alaska Regional Bioenergy Program, Five Year Report: 1985-1990, Pacific Northwest \& Alaska Regional Bioenergy Program, 2/91, Wood Energy, Regulation

64A. Paper Recycling: The View to 1995, Franklin Associates \& the American Paper Institute, $2 / 90, M S W$

65. Permits-Regulations-For Biomass Energy Facilities in the Southeast, Richard E. DeZeeuw, et.al., Southeastern Regional Biomass Energy Program, 8/86, Includes detailed maps showing non-attainment areas, class I PSD areas, and detailed state requirements \& contacts; glossary, Regulation

66. "Plan Ahead to Avoid Feeding Problems", David H. Wilson \& Donald L. Dunnington, Chemical Engineering, 8/91, Good overview of materials-feed technology, Fuel Feed

67. Planting \& Growing Trees for Energy: the Historical Perspective, J.W. Ranney, Environmental Sciences Division, Jak Ridge Nat. Lab., U.S.DOE, 11/91, Biomass Farming

67A. Power, the Magazine of Power-Generation Technology, Dec./91

68. Proceedings of the 1985 Biomass Thermochemical Conversion contractors' Meeting, Pacific Northwest Laboratory, U.S.D.O.E., 10/85, Conference in Minneapolis attended by Mr. Dobson

69. Proceedings: Pacific Northwest Bioenergy Systems: Policies and Applications, Pacific Northwest \& Alaska Regional Bioenergy Program, 5/10/84, A seminar attended by Mr. Dobson, Regulation, Wood Energy

70. Proceedings: Washington Wood Utilization Conference, Sponsored by, Washington State University, 3/88, A conference in Fife, WA, attended by Mr. Dobson, Conference

71. Productivity of Forests of the United States and Its Relation to Soil and Site Factors and Management Practices: A Review, Charles C. Grier, et.al., U.S. Department of Agriculture, Pacific Northwest Research Station, 3/89, Biomass Farming, Survey, Environment

72. Regional Assessment of Nonforestry-Related Biomass Resources, Summary Volume, JAYCOR, Southeastern Regional Biomass Energy Program, 3/90, Includes Appendix D: Significance of Food Processing By-Products as Contributors to Animal Feeds, Phase I, Food Processing Survey. Fuel Source, Survey, Biomass Farming

73. Regional Logging Residue Supply Curve Project, Volume 1 - Final Report, Envirosphere Company, Pacific Northwest \& Alaska Regional Bioenergy Program, 8/86, Table of Contents \& Summary only, Fuel Feed

74. Resource Assessment of Waste Feedstocks for Energy Use in the Western Regional Biomass Energy Area, K. Shaine, Tyson, Western Regional Biomass Energy Prograr., 2/91, WAPA Project BF983232 Evaluates the near term potential of waste feedstock supplies, specifically agricultural residue and waste paper for ethanol production, for each county in WRBEP area.

74A. Secrets of the Soil, "Biomass Can Do It" 
75. Science \& Technology In Review, Quarterly news magazine of, Solar Energy Research Institute, (SERI), Summer/91

76. Short-Rotation Intensive Culture of Woody Crops for Energy, Principles \& Practices for the Great Lakes Region, Meridian Corporation, Great Lakes Regional Biomass Energy Program, 1986?, 12/10

77. Small-Scale Bioenergy Alternatives for Industry, Farm, and Institutions: A User's Perspective, Proceedings of the National Bioenergy Conference, U.S.D.O.E., University of Idaho, \& Idaho Dept. of Water Resources, 3/18/91, Conference

78. Solid Waste Management Alternatives, Buncombe County, North Carolina, Final Report, HDR Techserv, Inc., Southeastern Regional Biomass Energy Program, 1/88, $M S W$

79. Southeastern Regional Biomass Energy Program, Six Year Report: 1983-1989, Southeastern Regional Biomass Energy Program, 11/90, Good state-by-state survey \& annotated bibliography of SERBEP publications, Wond Energy, Regulation, Survey

80. Stack Emission Standards for Industrial Wood-Fired Boilers, Final Report, Roy F. Weston, Northeastern Regional Biomass Energy Program, 1984, Detailed description of APC equipment on p.6-3 through p.6-36, extensive bibliography, a Regulation, Customer, Survey

81. Status of Industrial Wood-Fueled Systems, P.C. Badger, et.al., American Socisty of Agricultural Engineers, 6/87, general overview, Wood Energy, Boiler/Heat-exchange, Fuel Source, Fuel Feed

82. The Development of a $1 \mathrm{~kW}$ Electrical Output Free Piston Stirling Engine Alternator Unit, David M. Berchowitz, Sunpower Inc., Athens, Ohio, 8/83, Electricity

83. The Expected Influence of Biomass in the British Columbia Energy Sector to $2010 \mathrm{AD}$, Forestry Canada, Pacific \& Yukon Region, Pacific Forestry Center., 1991, Fuel Source, Environment, Regulation. Information collected 1988.

83A. Trees for Fuelwood: A Step Toward Energy Diversity, Edited by James R. Fazio, 1993, The Arbor Day Institute, 100 Arbor Avenue, Nebraska City, NE 68410

84. Trees for Energy: First National Fuelwood Conference, Arbor Day Institute, 11/11/91, Notes from talks, handouts at conference, Conference, Biomass Farming, Environment, Fuel Source

85. Turndown Ratio of Two-Stage Combustors, P.K. Chandra \& F.A. Payne, Southeastern Regional Biomass Energy Program, 1985?, Combustion, Case Study

86. Two-Stage Biomass Combustion for Direct Drying Applications, P.K. Chandra, Southeastern Regional Biomass Energy Program, 1986?, Combustion

86A. Use of Biomass Energy by Non-Forest Product Facilities - Case Studies, Prepared by Gerald Fleischman, P.E., Idaho Department of Water Resources, Energy Division, Boise, Idaho, $3 / 91$

87. User's Manual, Economic Feasibility Assessment for an Agricultural Biomass Furnace System, Agricultural Engineering Department, Montana State University, 2/86, describes a userinteractive computer program that helps an agricultural producer decide if a biomass-fueled system (straw, etc.)for drying grain or heating a structure may be economically feasible for a particular operation, compared with conventionally-fueled system. Includes appendix G: Research, Design, \& Construction of controller to mix drying air.

87A. U.S. Industrial Outlook '92, U.S. Department of Commerce, 1/92 
88. Utilization of Biomass to Dry Whole Corn, Mark A. Little et.al., Montana Department of Natural Resources \& Conservation, 10/84, Case Study, Customer, Fuel Source

89. Vortex Gasifier Burner and the EZY FLOW Dryer/Metering Bin, Summary Final Report, ALA-TENN Industries, Inc., for, Southeastern Regional Biomass Energy Program, 1985, Wood Energy, Case Study

90. Washington Directory of Biomass Energy Facilities, James D. Kerstetter, Ph.D., Washington State Energy Office, 8/87, Fuel Source, Customer, $M S W$

90A. Washington State Biomass Data Book, Joyce A. Deshaye \& James D. Kerstetter, Ph.D., Washington State Energy Office, 7/91, WAOENG 91-10,, the most up-to date information on biomass resources, energy use \& future potential, (Along with the 1990 Wood Residue Survey and Directory of Secondary Wood Processing Facilities in Washington State [0A]), bibliography, glossary, and sample of detailed county profile (All the detailed county reports have been obtained as well. from WSEO), Fuel Source, Customer, $M S W$

90B. Waste-To-Energy Systems, A Great Lakes Casebook, prepared by J.K. Cliburn \& Assisciates for the Great Lakes Regional Biomass Energy Program, Council of Great Lakes Governors, 1/92

91. Weight, Volume, and Physical Properties of Major Hardwood Species in the UplandSouth, Alexander, Clark II, et.al., Southeastern Forest Experiment Station, 11/86, Fuel Source, Biomass Farming

91A. Whole Earth Review, Winter 1992, "Kiil More Trees; As Fast As Possible" by Philip A. Rutter Badgersett Research Farm RR 1/Box 141 Canton MN 55922 (Hazelnuts \& chestnuts)

91B. Wood Ash Compesition as a Function of Furnace Temperature, Mahendra Misra \& Keneth Ragland, Dept. of Mechanical Engineering, University of Wisconsin-Madison.

92. Wood Burning for Energy, Case Studies from the Great Lakes, Abby, Feely, Great Lakes Regional Biomass Energy Program, 9/86, good glossary, Customer, Boiler/Heat-exchange, Fuel Feed, Fuel Source

93. Wood Chips: An Exploration of Problems \& Opportunities, E.C. Jordan Co. \& Maine Audubon Society, Northeastern Regional Biomass Energy Program, 1984, Good list of fuel dealers \& furnace manufacturers, Fuel Source, Competition, Customer, Fuel Feed

94. Wood Energy Guide for Agricultural and Small Commercial Applications, Larry G. Jahn, Southeastern Regional Biomass Energy Program, 10/85, Good cost figures \& equipment vendors, Customer, Boiler/Heat-exchange, Fuel Feed, Fuel Source

94A. Wood Energy Information Guide, R. N. Elliott, North Carolina Agricultural Extension Service, North Carolina State University, 1984

95. Wood for Fiber Products and Fuel, a Diminishing Supply?, Charles E. Keegan \& Mary L. Lenihan, Montana Department of Natural Resources and Conservation, ?, Fuel Source, Wood Energy

96. Wood Waste Energy Incentive Program, Summary Report, Wisconsin Energy Bureau, 9/90, Customer, Fuel Source

97. Wood Waste Review, a newsletter by the, Iowa Department of Natural Resources, 6/90

98. Wood-Fueled Processes \& Equipment, Georgia Institute of Technology, Georgia Office of Energy Resources, 5/80, Concentrates on gasifiers, Combustion, Boiler/Heat-exchange, Biomass Farming 
98A. World Congress - Alternatives \& Environment - Proceedings, Vienna, United Nations World, 1980

\section{SUPPLEMENTAL BIBLIOGRAPHY \\ PUBLICATIONS NOT REFERENCED IN REPORT:}

* Energy from Biomass and Municipal Waste, U.S.D.O.E., 1/88, Current abstracts: Prepared by Office of Scientific and Technical Information.

* Five Year Research Plan 1988-1992 Biofuels: Renewable Fuels for the future, EPA/600/D91/053, U.S.E.P.A., 1988, OCLC\# 19804606, Report \#DOE/CH10093-25 The paper discusses a portion of EPA's global climate change program, a program plan for methane climate change program, especially research efforts on global landfill methane.

* "Fuel Handling and Storage," W.S. Bulpitt \& J.L. Walsh, Jr., The Sixth International Forest Products Research Society Industrial Wood Energy Forum, Proceedings 7334, 1982.

* Guide to Oregon's Environmental Permits for Biomass Energy Projects, sponsored by the Oregon dept. of Energy

* Handbook for Conversions to Wood Energy Systems, "a technical publication that may be of interest to administrators and plant managers of facilities considering conversion to wood fuel systems." Council of Great Lakes Governors, Great Lakes Regional Biomass Energy Program, 122 W. Washington Avenue, Suite 801A, Madison, WI 53703

* Incineration of Solid Waste, C.C. Lee, et. al., U.S.E.F.A., Cincinnati, OH, Risk Reduction Engineering Lab., 1989, The objective of the paper is to review the fundamentals of incineration (combustion) and to provide an incinerator design example to show how combustion fundamentals are applied to an incineration system.

* State Biomass Statistical Directory - \$12.50 from NWEA

* The Industrial Wood Energy Handbook, 1984 (or more recent if available), prepared by the Georgia Institute of Technology, write to Council of Great Lakes Governors, Great Lakes Regional Biomass Energy Program, 122 W. Washington Avenue, Suite 801A, Madison, WI 53703

* "Municipal Solid Waste: a Resource Assessment for energy Recovery in Alaska", \& Annual Report, highlighting activities of Alaska Bioenergy Program 7/90-6/91, free from Rick Rogers, Alaska Energy Authority, PO Box 190869, Anchorage, AK 99519-0869, (907)561-7877

* MICHIGAN Wood \& Waste Fuel User Survey \& Waste Exchange Services. To receive copy of final survey report, (including all users of wood, municipal, \& ag. wastes) contact Michigan Biomass Energy Program 517/334-6264 or write care of tom Stanton, MBEP, Michigan PSC, P.O. Box 30221, Lansing, MI 48909 - ORDERED Nov 1, 1991

* Three scheduled research projects: "Emissions Data for Wood Waste Fuel Containing NonWood Material", to be conducted jointly with the other 4 regional programs. \& the NY. Energy Off. "Wood Manufacturing Directory" "Ash Testing" of ash from 50 - 100\% wood \& wood waste fuels. Reported in Biomass Energy Program Report, Great Lakes Region; Biologue, MR/AP'91 
* DATABASE; WRBEP (Western Regional Biomass Energy Project) is developing a database of companies offering biomass-related services \& products for the 13 state area ...to be completed...summer '92? Contact Pat McCann, 303-980-1969

* "Wood Waste Energy Incentive Program a Success"; governmental summary: 19 new wood systems were installed in Wisconsin with grants. From Biologue article, May/June ,'91.

* "SERBEP Irodustrial Wood Fuel Economic Impact study Revised"; Economics Of Biomass Energy In Southeast Region. Summary From article in Biologue, May/June, '91.

* KSU to Develop Agribusiness Database that will characterize and catalog sources, types, and volumes of agribusiness processing residues generated within the state of Kansas. contact Dr. Richard Nelson, Energy and Waste Specialist, Engineering Extension, or Dr. Rolando Flores, Food Engineering Specialist, Agricultural Engineering, KSU, (913) 532-6026 

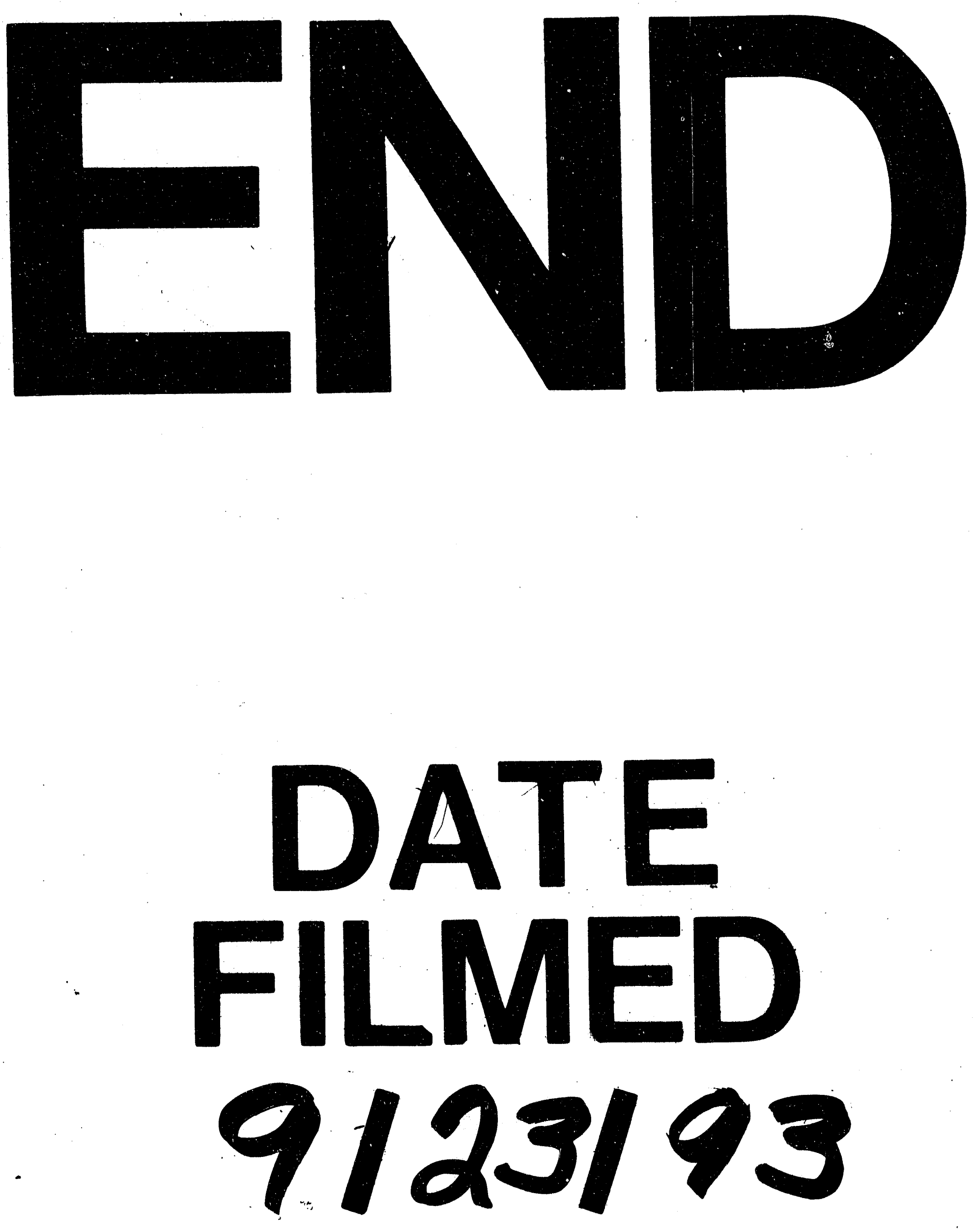

1 
